\title{
Uncertainty and Sensitivity Analysis of Food Pathway Results with the MACCS Reactor Accident Consequence Model
}

Manuscript Completed: November 1994

Date Published: January 1995

Prepared by

J. C. Helton, ${ }^{1}$ J. D. Johnson, ${ }^{2}$ J. A. Rollstin, ${ }^{2}$ A. W. Shiver, J. L. Sprung

Sandia National Laboratories

Albuquerque, NM 87185

\section{Prepared for}

Division of Systems Technology

Office of Nuclear Regulatory Research

U.S. Nuclear Regulatory Commission

Washington, DC 20555-0001

NRC Job Code L2294

${ }_{1}$ Arizona State University, Tempe, AZ 85287

${ }^{2}$ GRAM, Inc., Albuquerque, NM 87112 


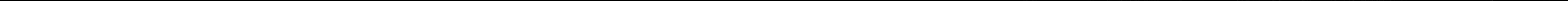




\section{DISCLAIMER}

This report was prepared as an account of work sponsored by an agency of the United States Government. Neither the United States Government nor any agency thereof, nor any of their employees, make any warranty, express or implied, or assumes any legal liability or responsibility for the accuracy, completeness, or usefulness of any information, apparatus, product, or process disclosed, or represents that its use would not infringe privately owned rights. Reference herein to any specific commercial product, process, or service by trade name, trademark, manufacturer, or otherwise does not necessarily constitute or imply its endorsement, recommendation, or favoring by the United States Government or any agency thereof. The views and opinions of authors expressed herein do not necessarily state or reflect those of the United States Government or any agency thereof. 


\section{DISCLAIMER}

Portions of this document may be illegible in electronic image products. Images are produced from the best available original document. 


\begin{abstract}
Uncertainty and sensitivity analysis techniques based on Latin hypercube sampling, partial correlation analysis and stepwise regression analysis are used in an investigation with the MACCS model of the food pathways associated with a severe accident at a nuclear power station. The primary purpose of this study is to provide guidance on the variables to be considered in future review work to reduce the uncertainty in the important variables used in the calculation of reactor accident consequences. The effects of 87 imprecisely-known input variables on the following reactor accident consequences are studied: crop growing season dose, crop long-term dose, milk growing season dose, total food pathways dose, total ingestion pathways dose, total long-term pathways dose, area dependent cost, crop disposal cost, milk disposal cost, condemnation area, crop disposal area and milk disposal area. When the predicted variables are considered collectively, the following input variables were found to be the dominant contributors to uncertainty: fraction of cesium deposition on grain fields that is retained on plant surfaces and transferred directly to grain, maximum allowable ground concentrations of Cs- 137 and Sr-90 for production of crops, ground concentrations of Cs-134, Cs-137 and I-131 at which the disposal of milk will be initiated due to accidents that occur during the growing season, ground concentrations of Cs-134, I-131 and Sr-90 at which the disposal of crops will be initiated due to accidents that occur during the growing season, rate of depletion of $\mathrm{Cs}-137$ and $\mathrm{Sr}-90$ from the root zone, transfer of Sr-90 from soil to legumes, tranfer of Cs-137 from soil to pasture, transfer of cesium from animal feed to meat, and the transfer of cesium, iodine and strontium from animal feed to milk.
\end{abstract}





\section{Contents}

Abstract $\ldots \ldots \ldots \ldots \ldots \ldots \ldots \ldots \ldots \ldots \ldots \ldots \ldots \ldots \ldots \ldots \ldots \ldots$

Acknowledgments $\ldots \ldots \ldots \ldots \ldots \ldots \ldots \ldots \ldots \ldots \ldots \ldots \ldots \ldots \ldots$

1. INTRODUCTION $\ldots \ldots \ldots \ldots \ldots \ldots \ldots \ldots \ldots \ldots \ldots \ldots \ldots \ldots \ldots$

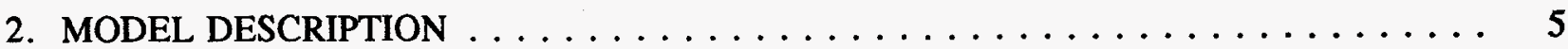

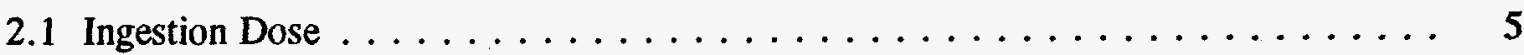

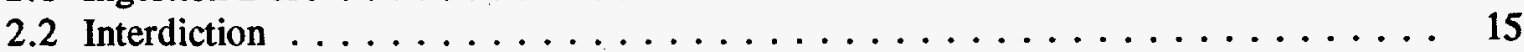

2.3 Groundshine, Inhalation and Water Ingestion Doses . . . . . . . . . . 18

2.4 Interdiction Cost . . . . . . . . . . . . . . . . . . 21

3 PROBLEM FOR ANALYSIS $\ldots \ldots \ldots \ldots \ldots \ldots \ldots \ldots \ldots \ldots$

4. DETERMINATION OF DOMINANT VARIABLES . . . . . . . . . . . . 39

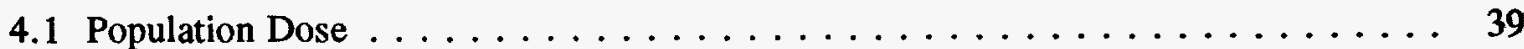

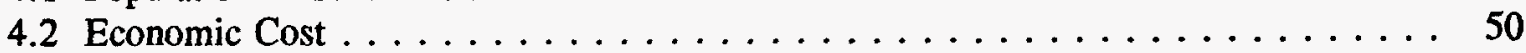

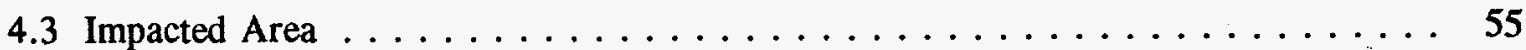

5. EFFECT OF DOMINANT VARIABLES $\ldots \ldots \ldots \ldots \ldots \ldots \ldots$

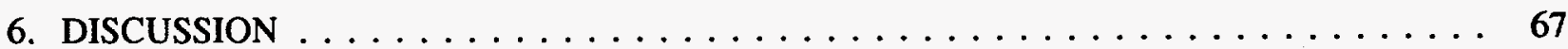

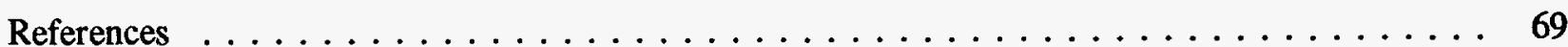




\section{Figures}

\section{Figure}

1.

Mean and Percentile Curves for Population Dose. . . . . . . . . . . . . . . 40

2. Distribution of CCDFs for Milk Growing Season Dose.

3. Partial Rank Correlation Coefficients for Exceedance Probabilities Associated with Individuai Dose Values . . . . . . . . . . . . . . . . . . . . . 43

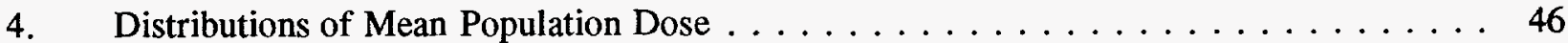

5. Mean and Percentile Curves for Economic Costs . . . . . . . . . . . . . . . 52

6. Partial Rank Correlation Coefficients for Exceedance Probabilities Associated with

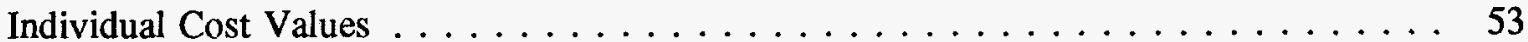

7. Distributions of Mean Economic Costs $\ldots \ldots \ldots \ldots \ldots \ldots \ldots \ldots \ldots$

8. Mean and Percentile Curves for Impacted Area . . . . . . . . . . . . . . . 57

9. Partial Rank Correlation Coefficients for Exceedance Probabilities Associated with Individual Impacted Areas $\ldots \ldots \ldots \ldots \ldots \ldots \ldots \ldots \ldots \ldots$

10. Distributions of Mean Impacted Area . . . . . . . . . . . . . . . . . . . . . 59

11. Mean and Percentile Curves for Crop Long-Term Dose with the Variables in Table 14 Set to Their Best-Estimate Values. . . . . . . . . . . . . . . . . . . . . . 62

12. Distribution of Mean Crop Long-Term Dose With the Variables In Table 14 Set to Their Best-Estimate Values . . . . . . . . . . . . . . . . . . . . . . . 64 


\section{Tables}

Table

1. Crop Categories and Associated Variables Used in MACCS Food Pathways Model in Analysis for Surry (Ref. 32, Table 4.1)

2. Dose Factors For Effective Whole Body Dose Equivalent ${ }^{36}$ and Halflives for Radionuclides Used in MACCS Food Pathways Model (Ref. 32, Appendix A.4;

Refs. 37, 38). As indicated in Ref. 32, Appendix A.4, a full MACCS calculation uses 60 radionuclides and dose factors for a variety of organs . . . . . . . . .

3. Transfer Factors $\left(T F_{i j}\right)$ from Deposition to Crop Category $j$ for Radionuclide $i$ (adapted from Table 3.2 of Ref. 3) $\ldots \ldots \ldots \ldots \ldots \ldots \ldots \ldots \ldots$

4. Values for Retention/Transfer Factors Appearing in Table 3 Used in Analysis for Surry ................................. 11

5. Values Used in Definition of Transfer Factor CTD Appearing in Table 3 for Accidents Occurring During the Crop Growing Season in the Analysis for Surry . . . . . . . . 14

6. Permissible Ground Concentrations $\left(\mathrm{Bq} / \mathrm{m}^{2}\right)$ and Soil Depletion Rates $\left(\mathrm{yr}^{-1}\right)$ Used in Surry Analysis to Evaluate Crop Disposal and Interdiction of Farmland . . . . . . . . . 16

7. Variables Used in Conjunction with the Decontamination Model in MACCS in the Surry Analysis (Ref. 32, Appendix A.3; Ref. 39) . . . . . . . . . . . . . . . . 17

8. Regional Economic Data Used as Input to MACCS in Surry Analysis (Ref. 32, Appendix A.3) . . . . . . . . . . . . . . . . . . . . . . 24

9. Imprecisely Known Variables Selected for Inclusion in an Uncertainty/Sensitivity Study of the MACCS Food Pathways Model . . . . . . . . . . . . . . . . .

10. Predicted Variables Associated with the Food Pathways Model in MACCS Selected

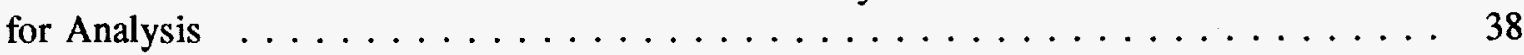

11. Stepwise Regression Analyses with Logarithmically Transformed Data for Mean

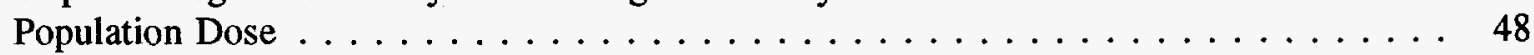

12. Stepwise Regression Analyses with Logarithmically Transformed Data for Mean Economic Cost . . . . . . . . . . . . . . . . . . . . . . . . 55

13. Stepwise Regression Analyses with Logarithmically Transformed Data for Mean Impacted Area . . . . . . . . . . . . . . . . . . . . . . 60

14. Dominant Variables Identified in Uncertainty and Sensitivity Analyses Presented in

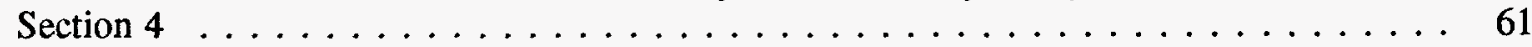

15. Standard Deviations (SDs), Means, Medians and 95th Percentiles for Predicted Variables Obtained With and Without the Variables in Table 14 Set to Their BestEstimate Values . . . . . . . . . . . . . . . . . . . . . . . . . . . . 63

16. Stepwise Regression Analyses with Logarithmically Transformed Data for Mean Population Dose With the Variables in Table 14 Set to Their Best-Estimate Values . . . . . . . . . . 65 


\section{Acknowledgments}

Recognition is extended to David Chanin of Technadyne, Inc. for his role in the development of the MACCS program and for many useful discussions involving MACCS and reactor accident consequence analysis. Review of the report was provided by Sarah Higgins and Leann Miller of Sandia National Laboratories. The support and encouragement of Jim Glynn and Christiana Lui of the US Nuclear Regulatory Commission is greatly appreciated. Finally, thanks are extended to Fred Harper of Sandia National Laboratories for providing a productive environment in which to perform this analysis and to Judy Jones and Darla Tyree, also of Sandia National Laboratories, for editorial support in the production of documentation for the analysis. 


\section{INTRODUCTION}

In preparation for a joint study ${ }^{1}$ with the Commission of European Communities (CEC) on the uncertainties associated with the input variables used in reactor accident consequence models, the U.S. Nuclear Regulatory Commission (NRC) is sponsoring a sequence of uncertainty and sensitivity analyses with the MACCS ${ }^{2-4}$ reactor accident consequence model. The primary purpose of these analyses is to identify the MACCS input variables that have the greatest effect on the uncertainty in MACCS predictions. The uncertainty in these variables will then be assessed as part of an expert-review process in the joint CEC/NRC study. Due to the large investments of resources (i.e., time, people, money) associated with an expert-review process, the number of variables that can be considered is limited. Thus, it is important to select variables for the review process that contribute substantially to the uncertainty in MACCS predictions.

A prior uncertainty and sensitivity analysis considered early exposure results calculated with MACCS. ${ }^{5}$ The present analysis considers the effects of uncertainty in the MACCS food pathway model. An additional analysis considers the effects of uncertainty in the MACCS chronic exposure model. ${ }^{6}$ All three analyses use the same source term (Ref. 5, Section 4.1) from the NUREG-1150 analysis ${ }^{7}$ for the Surry Nuclear Power Station.,

In performing uncertainty and sensitivity studies, it is important to maintain a clear distinction between the different types of uncertainty involved. ${ }^{10-17}$ When viewed at a high level, there are two basic types of uncertainty associated with the calculation of reactor accident consequences: stochastic uncertainty, which results because the system under study can behave in many different ways (e.g., many different types of weather are possible at the time of a reactor accident), and subjective uncertainty, which results from the existing state of knowledge with respect to the correctness of the assumptions used in an analysis (e.g., what is the appropriate dry deposition velocity to use for a particular combination of release characteristics and weather). Thus, stochastic uncertainty is a property of the system under study, and subjective uncertainty is a property of the analysts performing the study (Ref. 5, Section 2). The primary focus of this study is subjective uncertainty.

The ordered triple representation for risk proposed by Kaplan and Garrick ${ }^{17}$ provides a useful framework with which to both describe the conceptual structure of a consequence calculation and distinguish between stochastic and subjective uncertainty. In this representation, risk is expressed as a set $\mathbf{R}$ of ordered triples of the form

$$
R=\left\{\left(S_{i}, p S_{i}, c S_{i}\right), i=1,2, \cdots, n S\right\},
$$

where $\mathbf{S}_{i}$ is a set of similar occurrences (i.e., a scenario), $p S_{i}$ is the probability (or frequency, as appropriate) for $S_{i}, c S_{i}$ is a vector of consequences associated with $S_{i}, n S$ is the number of sets selected for consideration, and the sets $S_{i}$ have no occurrences in common (i.e., the $S_{i}$ are disjoint). This representation formally decomposes risk into what can happen (the $\mathbf{S}_{i}$ ), how likely things are to happen (the $p S_{i}$ ), and the consequences of what can happen (the $c S_{i}$ ). In the context of a typical reactor accident consequence model such as MACCS, the $S_{i}$ are sets of similar weather conditions (Ref. 5, Section 3.1), the $p S_{i}$ are probabilities for these sets of weather conditions (Ref. 5, Section 3.1), and the $c S_{i}$ contain consequence values calculated for these sets of weather conditions (Ref.5, Section 3.2). An overview of how $c S_{i}$ is determined for the MACCS food pathways model is provided in Section 2. To facilitate 


\section{Introduction}

visual examination, the information in $p S_{i}$ and $\mathbf{c S}_{i}$ is usually summarized with complementary cumulative distribution functions (CCDFs) (Ref. 5, Figure 1).

The probabilities $p S_{i}$ in Eq. (1) characterize stochastic uncertainty. Subjective uncertainty enters when the computational reality of evaluating the risk representation in Eq. (1) must be addressed. In practice, evaluation of the expression in Eq. (1) requires extensive computation and, in turn, this computation requires many inputs. If these inputs are represented by a vector

$$
x=\left[x_{1}, x_{2}, \cdots, x_{n v}\right],
$$

where $n V$ is number of such inputs, the representation in Eq. (1) becomes

$$
R(x)=\left\{\left(S_{i}(x), p S_{i}(x), c S_{i}(x)\right), i=1,2, \cdots, n S(x)\right\} .
$$

If the vector $x$ was known with complete certainty, then the expression in Eq. (3) could be evaluated and presented as the unambiguous outcome of the analysis. However, $\boldsymbol{x}$ is not known with certainty in most analyses, with the result that there is not a single CCDF for a particular consequence value that can be identified as the unambiguous outcome of evaluating the expression in Eq. (3). In particular, subjective uncertainty in $x$ leads to a distribution of CCDFs, with the individual CCDFs displaying the effect of stochastic uncertainty conditional on a specific value of $x$ and the distribution of CCDFs displaying the effect of subjective uncertainty in $\boldsymbol{x}$ (Ref. 5, Figure 2).

As previously indicated, the primary focus of this study is on the effect of subjective uncertainty in the MACCS food pathway model. Thus, the analysis objective is to determine the relationship between the uncertainty in a vector $x$ of the form defined in Eq. (2) and the uncertainty in a risk representative $\mathbf{R}(\boldsymbol{x})$ of the form defined in Eq. (3). This relationship will be determined by characterizing the uncertainty in $\boldsymbol{x}$ with a sequence of distributions

$$
D_{1}, D_{2}, \ldots, D_{n V}
$$

where $D_{j}$ describes a degree of belief as where the appropriate value to use for $x_{j}$ is located given that the analysis has been structured so that only a single value of each variable $x_{j}$ is required in the determination of the set $\mathbf{R}(\boldsymbol{x})$. Correlations and other restrictions between the $x_{j}$ are also possible, which is equivalent to the specification of a joint probability distribution for the variables contained in $x$. The distributions developed for the $x_{j}$ are characterizing subjective uncertainty as they indicate the possible cations of fixed, but unknown, quantities. The variables selected for consideration in this study and their assigned distributions are discussed in Section 3.

In practice, Monte Carlo techniques must be used to determine the distribution of CCDFs that results from the subjective uncertainty characterized by the distributions in Eq. (4). Specifically, a sample of the form 


$$
x_{k}=\left[x_{1 k}, x_{2 k}, \ldots, x_{n V, k}\right], k=1,2, \ldots, n L H S,
$$

is generated by Latin hypercube sampling ${ }^{18}$ or some other appropriate sampling procedure according to the distributions characterizing the subjective uncertainty in the individual elements $x_{j}$ of $x$, where $n L H S$ is the sample size. Evaluation of the MACCS model for each sample element $x_{k}$ produces a sequence of results of the form

$$
R\left(x_{k}\right)=\left\{\left(S_{i}, p S_{i}, c S_{i}\left(x_{k}\right)\right), i=1,2, \ldots, n S\right\}
$$

for $k=1,2, \ldots, n L H S$. Although the general representation for $\mathbf{R}(x)$ in Eq. (3) shows $\mathbf{S}_{i}, p S_{i}, c S_{i}$ and $n S$ as functions of $\boldsymbol{x}$, only $c S_{i}$ is a function of $\boldsymbol{x}$ in the present study. As each set $\mathbf{R}\left(x_{k}\right)$ yields a CCDF for each consequence result under consideration, distributions of CCDFs are produced that characterize subjective uncertainty. Further, the sets $\mathbf{R}\left(\boldsymbol{x}_{k}\right)$ provide a mapping from analysis inputs to analysis results that can be explored with sensitivity analysis techniques based on regression analysis, partial correlation analysis and possibly other procedures. ${ }^{1924}$ The uncertainty analysis results obtained in this study and their subsequent exploration with regression-based sensitivity analysis techniques are presented in Sections 4 and 5.

Additional background on the uncertainties in reactor accident consequence calculations can be obtained from a number of studies..$^{5,25-35}$ 
Introduction

THIS PAGE INTENTIONALLY LEFT BLANK 
Introduction

\section{MODEL DESCRIPTION}

Detailed descriptions of the models implemented in MACCS are available elsewhere. ${ }^{2-4,32}$ Further, an overview of the models in MACCS is provided in a preceding report (Ref. 5, Section 3). As the present report considers the effect of imprecisely-known variables in the MACCS food pathways model, this section provides a brief description of the MACCS food pathways model and associated models used in the calculation of the results under study.

\subsection{Ingestion Dose}

The basic relationship used in MACCS to determine the population dose $D_{i j k l}(\mathrm{~Sv})$ to organ $k$ for radionuclide $i$ and crop category $j$ in spatial element $l$ is

$$
D_{i j k l}=D F_{i k} F C_{j} T F_{i j} F A C_{j l} F A_{l} G C_{i l},
$$

where $D F_{i k}$ is the ingestion dose conversion factor $(\mathrm{Sv} / \mathrm{Bq})$ for radionuclide $i$ and organ $k, F C_{j}$ is the fraction (dimensionless) of crop category $j$ consumed by man, $T F_{i j}$ is the transfer factor (dimensionless) from deposition to crop category $j$ for radionuclide $i$ (i.e., $T F_{i j}=A C_{i j} / A D_{i j}$, where $A C_{i j}$ is the amount $\left(\mathrm{Bq} / \mathrm{m}^{2}\right)$ of radionuclide $i$ transferred to crop category $j$ over the time period under consideration and $A D_{i j}$ is the initial deposition of radionuclide $i\left(\mathrm{~Bq} / \mathrm{m}^{2}\right)$ onto land on which crop category $j$ is being grown), $F A C_{j l}$ is the fraction (dimensionless) of farmland in spatial element $l$ devoted to crop category $j, F A_{l}$ is the area $\left(\mathrm{m}^{2}\right)$ in spatial element $l$ devoted to farming, and $G C_{i l}$ is the initial ground concentration $\left(\mathrm{Bq} / \mathrm{m}^{2}\right)$ of radionuclide $i$ in spatial element $l$.

The ground concentrations $G C_{i l}$ are calculated by MACCS with a Gaussian plume model as discussed in Refs. 2-3. The spatial elements and their associated areas $F A_{l}$ used in this analysis for the Surry reactor site are given in Appendix A.3 of Ref. 32. In particular, spatial elements are defined on a polar coordinate grid centered at Surry with 16 angular $22.5^{\circ}$ sectors and 26 radial intervals with outer radii of $0.1,0.32,0.75,1,1.5,2,2.5,3,3.5,5,7,10,13,16,20,25,30,40,50,70,100,150,200$, 350,500 and $1000 \mathrm{mi}$. The crop categories used in the Surry analysis are listed in Table 1, together with values for the consumption fractions $F C_{j}$ and area fractions $F A C_{j l}$. The transfer factors $T F_{i j}$ have a complex form and will be discussed in subsequent paragraphs. The ingestion dose factors $D F_{i k}$ for the radionuclides included in the food pathways in this analysis are listed in Table 2. 


\section{Model Description}

Table 1. Crop Categories and Associated Variables Used in MACCS Food Pathways Model in Analysis for Surry (Ref. 32, Table 4.1)

\begin{tabular}{|c|c|c|c|c|c|c|c|}
\hline & Pasture & $\begin{array}{l}\text { Stored } \\
\text { Forage }\end{array}$ & Grain & $\begin{array}{r}\text { Leafy } \\
\text { Green } \\
\text { Vegetables } \\
\end{array}$ & $\begin{array}{l}\text { Other } \\
\text { Food }\end{array}$ & $\begin{array}{l}\text { Legumes } \\
\& \text { Nuts }\end{array}$ & $\begin{array}{c}\text { Roots } \\
\& \\
\text { Tubers }\end{array}$ \\
\hline & $\begin{array}{c}\text { Various } \\
\text { grasses }\end{array}$ & $\begin{array}{l}\text { Alfalfa } \\
\text { Clover } \\
\text { Sorghum }\end{array}$ & $\begin{array}{l}\text { Wheat } \\
\text { Oats } \\
\text { Barley } \\
\text { Corn(incl. } \\
\text { sweetcorn) } \\
\text { Sorghum }\end{array}$ & $\begin{array}{l}\text { Lettuce } \\
\text { Cabbage } \\
\text { Broccoli } \\
\text { Spinach } \\
\text { Celery } \\
\text { Cauliflower } \\
\text { Greens }\end{array}$ & $\begin{array}{l}\text { Fruits: } \\
\text { Apples } \\
\text { Grapes } \\
\text { Citrus: } \\
\text { Oranges } \\
\text { Grapefruit } \\
\text { Lemons } \\
\text { Vegetables: } \\
\text { Tomatoes } \\
\text { Cucumbers } \\
\text { Peppers }\end{array}$ & $\begin{array}{l}\text { Soybeans } \\
\text { Peanuts } \\
\text { Snap } \\
\text { beans } \\
\text { Dried } \\
\text { beans } \\
\text { Peas } \\
\text { Nuts }\end{array}$ & $\begin{array}{l}\text { Potatoes } \\
\text { Carrots } \\
\text { Beets } \\
\text { Sugar } \\
\text { Onion }\end{array}$ \\
\hline FRCTCH $^{a}$ & 0.0 & 0.0 & 0.35 & 1.0 & 1.0 & 0.24 & 1.0 \\
\hline FRCTCM $^{\mathrm{b}}$ & 0.1 & 0.13 & 0.04 & 0.0 & 0.0 & 0.046 & 0.0 \\
\hline FRCTCB $^{c}$ & 0.9 & 0.87 & 0.61 & 0.0 & 0.0 & 0.714 & 0.0 \\
\hline FRCTTFL & 0.41 & 0.13 & 0.21 & 0.002 & 0.004 & 0.15 & 0.003 \\
\hline TGSBEG $^{e}$ & 90 & 150 & 150 & 150 & 150 & 150 & 150 \\
\hline TGSEND $^{i}$ & 270 & 240 & 240 & 240 & 240 & 240 & 240 \\
\hline
\end{tabular}

${ }^{a}$ Fraction consumed by man $\left(F C_{j}\right.$ in Eq. 7); Ref. 32, Table 4.22.

braction consumed by milk producing animals; Ref. 32, Table 4.22 .

'Fraction consumed by meat producing animals; Ref. 32, Table 4.22 .

${ }^{\mathrm{d}}$ Fraction of crop land $\left(F A C_{j l}\right.$ in Eq. 7); Ref. 32, Table 4.22.

'Beginning of growing season in days measured from beginning of year; Ref. 32, Table 4.2.

${ }^{f}$ End of growing season in days measured from beginning of year; Ref. 32, Table 4.2. 
Model Description

Table 2. Dose Factors For Effective Whole Body Dose Equivalent ${ }^{36}$ and Halflives for Radionuclides Used in MACCS Food Pathways Model (Ref. 32, Appendix A.4; Refs. 37, 38). As indicated in Ref. 32, Appendix A.4, a full MACCS calculation uses 60 radionuclides and dose factors for a variety of organs

\begin{tabular}{||l|c|c|c|c|c|c||}
\hline \multicolumn{1}{|c|}{ Dose Factor } & Sr-89 & Sr-90 & Cs-134 & Cs-137 & I-131 & I-133 \\
\hline Cloudshine $\left[(\mathrm{Sv} / \mathrm{s}) /\left(\mathrm{Bq} / \mathrm{m}^{2}\right)\right]$ & $3.796 \times 10^{-16}$ & $9.537 \times 10^{-17}$ & $6.968 \times 10^{-14}$ & $2.526 \times 10^{-14}$ & $1.667 \times 10^{-14}$ & $2.685 \times 10^{-14}$ \\
Groundshine $\left[(\mathrm{Sv} / \mathrm{s}) /\left(\mathrm{Bq} / \mathrm{m}^{2}\right)\right]$ & $5.069 \times 10^{-17}$ & $5.000 \times 10^{-18}$ & $1.377 \times 10^{-15}$ & $5.104 \times 10^{-16}$ & $3.553 \times 10^{-16}$ & $5.637 \times 10^{-16}$ \\
Chronic Inhalation $(\mathrm{Sv} / \mathrm{Bq})$ & $1.787 \times 10^{-9}$ & $5.919 \times 10^{-8}$ & $1.253 \times 10^{-8}$ & $8.628 \times 10^{-9}$ & $8.872 \times 10^{-9}$ & $1.583 \times 10^{-9}$ \\
Ingestion $(\mathrm{Sv} / \mathrm{Bq})$ & $2.503 \times 10^{-9}$ & $3.518 \times 10^{-8}$ & $1.975 \times 10^{-8}$ & $1.355 \times 10^{-8}$ & $1.434 \times 10^{-8}$ & $2.800 \times 10^{-9}$ \\
\hline Halflife & $52.0 \mathrm{~d}$ & $28.1 \mathrm{yr}$ & $2.06 \mathrm{yr}$ & $30.0 \mathrm{yr}$ & $8.04 \mathrm{~d}$ & $0.87 \mathrm{~d}$ \\
\hline
\end{tabular}

When radioactive material is deposited onto farmland, an ingestion dose to the exposed population can result from two pathways: (1) a growing season pathway resulting from the direct deposition of radionuclides onto the growing crops, and (2) a long-term pathway resulting from root uptake, and possibly soil ingestion by animals, from contaminated soil. The growing season pathway can contaminate only those crops being grown at the time of the accident. The resulting dose to the population will depend on the day in the year when the accident occurs. The growing seasons for the individual crop categories are indicated in Table 1. If the accident occurs outside the growing season, there will be no dose from the growing season pathway. In contrast, the long-term root uptake of radioactive material into food products may span many successive growing seasons. The dose resulting from the long-term pathway is independent of the time of the year when the accident occurs. The manner in which the transfer factors $T F_{i j}$ appearing in Eq. (7) are defined in the MACCS food pathways model for growingseason dose and soil-uptake dose are summarized in Table 3. 
Model Description

Table 3. Transfer Factors $\left(T F_{i j}\right)$ from Deposition to Crop Category $j$ for Radionuclide $i$ (adapted from Table 3.2 of Ref. 3)

Growing-Season Doses

Crop-to-Man:

$T F_{i j}=F P L S C H_{i j} D C Y P C H_{i j} C T D_{i j}$

Crop-to-Milk-to-Man:

$T F_{i j}=D_{C Y P M H_{i}} T_{F M L K_{i}} D_{C Y P C M_{i j}} C T D_{i j}$

Crop-to-Meat-to-Man:

$T F_{i j}=D_{C Y P B H_{i}} T F B F_{i} D_{C Y P C B_{i j}} C T D_{i j}$

Soil-Uptake Doses

Crop-to-Man:

$$
T F_{i j}=F_{P L S C H} \text { DCYPCH }_{i j} \text { TCROOT }_{i j}
$$

Crop-to-Milk-to-Man:

$T F_{i j}=D_{C C Y M H_{i}}$ TFMLK $_{i}$ DCYPCM $_{i j}$ TCROOT $_{i j}$

Crop-to-Meat-to-Man:

$T F_{i j}=D_{C Y P B H_{i}} \operatorname{TFBF}_{i}$ DCYPCB $_{i j}$ TCROOT $_{i j}$ 
Table 3 (concluded)

\begin{tabular}{|c|c|c|c|}
\hline \multicolumn{4}{|c|}{ Definition of Terms } \\
\hline & & Tim & Delay \\
\hline $\begin{array}{l}\text { Retention/ } \\
\text { Transfer } \\
\text { Factors* }\end{array}$ & $\begin{array}{l}\text { Relevant } \\
\text { Phenomena }\end{array}$ & From & To \\
\hline$C T D$ & $\begin{array}{l}\text { weathering } \\
\text { radioactive decay }\end{array}$ & $\begin{array}{l}\text { deposition onto } \\
\text { plants }\end{array}$ & harvest \\
\hline$D C Y P B H$ & $\begin{array}{l}\text { meat trimming } \\
\text { radioactive decay }\end{array}$ & slaughter & consumption \\
\hline$D C Y P C B$ & radioactive decay & harvest & consumption \\
\hline$D C Y P C M$ & radioactive decay & harvest & consumption \\
\hline DCYPCH & radioactive decay & harvest & consumption \\
\hline$D C Y P M H$ & radioactive decay & $\begin{array}{l}\text { production of } \\
\text { milk }\end{array}$ & consumption \\
\hline FPLSCH & $\begin{array}{l}\text { food processing } \\
\text { food preparation }\end{array}$ & harvest & consumption \\
\hline TCROOT & $\begin{array}{l}\text { radioactive decay } \\
\text { percolation } \\
\text { binding with soil }\end{array}$ & $\begin{array}{l}\text { deposition onto } \\
\text { soil }\end{array}$ & harvest \\
\hline$T F B F$ & $\begin{array}{l}\text { biological } \\
\text { filtration } \\
\text { radioactive decay }\end{array}$ & $\begin{array}{l}\text { feed } \\
\text { consumption }\end{array}$ & slaughter \\
\hline TFMLK & $\begin{array}{l}\text { biological } \\
\text { filtration } \\
\text { radioactive decay }\end{array}$ & $\begin{array}{l}\text { feed } \\
\text { consumption }\end{array}$ & milk production \\
\hline
\end{tabular}

All of the variables used in Table 3 in the definition of the transfer factor $T F_{i j}$ are input variables to MACCS except for CTD; a summary of the values used for these variables in the Surry analysis is given in Table 4. The variable CTD is defined on the basis of the time of year at which an accident occurs and additional MACCS input variables that define interception fractions, weathering halflifes and growing seasons for different crop categories (Ref. 3, pp. 3-26 to 3-28; Ref. 32, Section 4.3.1). The 


\section{Model Description}

values used for interception fractions and weathering halflifes are given in Table 5, and crop growing seasons are defined in Table 1. 
Table 4. Values for Retention/Transfer Factors Appearing in Table 3 Used in Analysis for Surry

\begin{tabular}{|c|c|c|c|c|c|c|c|}
\hline \multicolumn{8}{|c|}{ Retention and transfer factors involving milk and meat (Ref. 32, Tables $4.10,4.17,4.37,4.42$ ). } \\
\hline \multirow{2}{*}{\multicolumn{2}{|c|}{ Nuclide }} & \multicolumn{3}{|c|}{$\begin{array}{c}\text { Retention Factors } \\
\text { Processing and Decay }\end{array}$} & \multicolumn{3}{|c|}{$\begin{array}{c}\text { Transfer Factors } \\
\text { (Bq Transferred)/(Bq Ingested) }\end{array}$} \\
\hline & & $\begin{array}{l}\text { Milk/Man } \\
\text { DCYPMH }\end{array}$ & \multicolumn{2}{|c|}{$\begin{array}{l}\text { Meat/Man } \\
D C Y P B H\end{array}$} & $\begin{array}{l}\text { Milk } \\
\text { TFMLK }\end{array}$ & \multicolumn{2}{|c|}{$\begin{array}{l}\text { Meat } \\
\text { TFBF }\end{array}$} \\
\hline \multicolumn{2}{|c|}{ Sr-89 } & 0.66 & \multicolumn{2}{|c|}{0.77} & 0.022 & \multicolumn{2}{|c|}{0.00022} \\
\hline \multicolumn{2}{|c|}{$\mathrm{Sr}-90$} & 1.0 & \multicolumn{2}{|c|}{1.0} & 0.022 & \multicolumn{2}{|c|}{0.00022} \\
\hline \multicolumn{2}{|c|}{ Cs-134 } & 1.0 & \multicolumn{2}{|c|}{1.0} & 0.11 & \multicolumn{2}{|c|}{0.023} \\
\hline \multicolumn{2}{|c|}{ Cs-137 } & 1.0 & \multicolumn{2}{|c|}{1.0} & 0.11 & \multicolumn{2}{|c|}{0.024} \\
\hline \multicolumn{2}{|c|}{$\mathrm{I}-131$} & 0.28 & \multicolumn{2}{|c|}{0.18} & 0.13 & \multicolumn{2}{|c|}{0.0024} \\
\hline \multicolumn{2}{|c|}{$1-133$} & 0.002 & \multicolumn{2}{|c|}{0.0} & 0.062 & \multicolumn{2}{|c|}{0.0011} \\
\hline \multicolumn{8}{|c|}{$\begin{array}{l}\text { Transfer factor from soil to plant by root-uptake (and by soil ingestion for grazing on pasture) integrated } \\
\text { over all time [(Bq transferred)/(Bq deposited)] (Ref. 32, Tables } 4.29,4.30) \text {. }\end{array}$} \\
\hline Nuclide & $\begin{array}{l}\text { Pasture } \\
\text { TCROOT }\end{array}$ & $\begin{array}{c}\text { Stored } \\
\text { Forage } \\
\text { TCROOT }\end{array}$ & $\begin{array}{l}\text { Grains } \\
\text { TCROOT }\end{array}$ & $\begin{array}{l}\text { Green } \\
\text { Leafy } \\
\text { Vegetables } \\
\text { TCROOT }\end{array}$ & $\begin{array}{l}\text { Other } \\
\text { Food } \\
\text { Crops } \\
\text { TCROOT }\end{array}$ & $\begin{array}{c}\text { Legumes } \\
\text { and } \\
\text { Seeds } \\
\text { TCROOT }\end{array}$ & $\begin{array}{c}\begin{array}{c}\text { Roots } \\
\text { and } \\
\text { Tubers }\end{array} \\
\text { TCROOT }\end{array}$ \\
\hline Sr-89 & $4.1 \times 10^{-4}$ & $1.3 \times 10^{-3}$ & $4.3 \times 10^{5}$ & $1.7 \times 10^{-4}$ & $8.6 \times 10^{-6}$ & $3.7 \times 10^{-4}$ & $1.1 \times 10^{4}$ \\
\hline Sr-90 & $2.6 \times 10^{-2}$ & $9.0 \times 10^{-2}$ & $3.3 \times 10^{-3}$ & $1.3 \times 10^{-2}$ & $6.6 \times 10^{-4}$ & $2.8 \times 10^{-2}$ & $8.4 \times 10^{-3}$ \\
\hline Cs-134 & $1.3 \times 10^{-3}$ & $7.1 \times 10^{-4}$ & $3.5 \times 10^{-5}$ & $1.4 \times 10^{-5}$ & $1.1 \times 10^{-4}$ & $9.3 \times 10^{-5}$ & $5.6 \times 10^{-5}$ \\
\hline Cs-137 & $6.9 \times 10^{-3}$ & $1.5 \times 10^{-3}$ & $7.6 \times 10^{5}$ & $3.0 \times 10^{-5}$ & $2.3 \times 10^{-4}$ & $2.0 \times 10^{-4}$ & $1.2 \times 10^{-4}$ \\
\hline$I-131$ & $1.6 \times 10^{-4}$ & 0.0 & 0.0 & 0.0 & 0.0 & 0.0 & 0.0 \\
\hline I-133 & $1.7 \times 10^{-6}$ & 0.0 & 0.0 & 0.0 & 0.0 & 0.0 & 0.0 \\
\hline
\end{tabular}


Model Description

Table 4 (continued)

\begin{tabular}{|c|c|c|c|c|c|c|c|}
\hline \multicolumn{8}{|c|}{$\begin{array}{l}\text { Radioactive decay retention factors (i.e., } 1-F \text {, where } F=\text { fraction of radioactivity lost by decay) for radionuclides in } \\
\text { crops from time of harvest to time of consumption by humans (Ref. 32, Table } 4.13 \text { ). }\end{array}$} \\
\hline Nuclide & $\begin{array}{c}\text { Pasture } \\
\text { DCYPCH }\end{array}$ & $\begin{array}{l}\text { Stored } \\
\text { Forage } \\
\text { DCYPCH }\end{array}$ & $\begin{array}{c}\text { Grains } \\
D C Y P C H\end{array}$ & $\begin{array}{c}\text { Green } \\
\text { Leafy } \\
\text { Vegetables } \\
D C Y P C H\end{array}$ & $\begin{array}{c}\text { Other } \\
\text { Food } \\
\text { Crops } \\
\text { DCYPCH }\end{array}$ & $\begin{array}{c}\text { Legumes } \\
\text { and } \\
\text { Seeds } \\
D C Y P C H\end{array}$ & $\begin{array}{c}\text { Roots } \\
\text { and } \\
\text { Tubers } \\
D C Y P C H\end{array}$ \\
\hline Sr-89 & $N A^{a}$ & NA & 0.18 & 0.67 & 0.21 & 0.18 & 0.18 \\
\hline Sr-90 & NA & NA & 0.99 & 1.0 & 0.99 & 0.99 & 0.99 \\
\hline Cs-134 & NA & NA & 0.84 & 0.96 & 0.85 & 0.84 & 0.84 \\
\hline Cs-137 & NA & NA & 0.99 & 1.0 & 0.99 & 0.99 & 0.99 \\
\hline $\mathrm{I}-131$ & NA & NA & 0.0099 & 0.21 & 0.024 & 0.0099 & 0.0099 \\
\hline I-133 & NA & NA & 0.0 & 0.0 & 0.0 & 0.0 & 0.0 \\
\hline \multicolumn{8}{|c|}{$\begin{array}{l}\text { Crop processing and preparation retention factors for radionuclides in food crops consumed by humans (Ref. } 32 \text {, Table } \\
4.20 \text { ). Factors account for loss of radionuclides from foods due to processing (e.g., washing of fruit, peeling of } \\
\text { potatoes, losses during canning) and food preparation (cooking) from the time of processing of the harvested crop to the } \\
\text { time of consumption by humans. Factors do not reflect losses due to radioactive decay. }\end{array}$} \\
\hline Nuclide & $\begin{array}{l}\text { Pasture } \\
\text { FPLSCH }\end{array}$ & $\begin{array}{l}\text { Stored } \\
\text { Forage } \\
\text { FPLSCH }\end{array}$ & $\begin{array}{l}\text { Grains } \\
\text { FPLSCH }\end{array}$ & $\begin{array}{l}\text { Green } \\
\text { Leafy } \\
\text { Vegetables } \\
\text { FPLSCH }\end{array}$ & $\begin{array}{l}\text { Other } \\
\text { Food } \\
\text { Crops } \\
\text { FPLSCH }\end{array}$ & $\begin{array}{c}\text { Legumes } \\
\text { and } \\
\text { Seeds } \\
\text { FPLSCH }\end{array}$ & $\begin{array}{c}\text { Roots } \\
\text { and } \\
\text { Tubers } \\
\text { FPLSCH }\end{array}$ \\
\hline $\mathrm{Sr}-89$ & NA & NA & 0.25 & 0.5 & 0.71 & 0.8 & 0.8 \\
\hline Sr-90 & NA & NA & 0.25 & 0.5 & 0.71 & 0.8 & 0.8 \\
\hline Cs-134 & NA & NA & 0.25 & 0.5 & 0.71 & 0.8 & 0.8 \\
\hline Cs-137 & NA & NA & 0.25 & 0.5 & 0.71 & 0.8 & 0.8 \\
\hline $\mathrm{I}-131$ & NA & NA & 0.33 & 0.5 & 0.71 & 0.8 & 0.8 \\
\hline I-133 & NA & NA & 0.33 & 0.5 & 0.71 & 0.8 & 0.8 \\
\hline
\end{tabular}


Model Description

Table 4 (concluded)

\begin{tabular}{|c|c|c|c|c|c|c|c|}
\hline \multicolumn{8}{|c|}{$\begin{array}{l}\text { Retention factors for radionuclides in crops from time of harvest to time of consumption by milk-producing and meat- } \\
\text { producing animals (Ref. 32, Table 4.11). Factors account for losses due to radioactive decay. }\end{array}$} \\
\hline Nuclide & $\begin{array}{c}\text { Pasture } \\
D C Y P C B \\
D C Y P C M\end{array}$ & $\begin{array}{l}\text { Stored } \\
\text { Forage } \\
D C Y P C B \\
D C Y P C M\end{array}$ & $\begin{array}{c}\text { Grains } \\
D C Y P C B \\
D C Y P C M\end{array}$ & $\begin{array}{c}\text { Green } \\
\text { Leafy } \\
\text { Vegetables } \\
D C Y P C B \\
D C Y P C M\end{array}$ & $\begin{array}{c}\text { Other } \\
\text { Food } \\
\text { Crops } \\
D C Y P C B \\
D C Y P C M\end{array}$ & $\begin{array}{c}\text { Legumes } \\
\text { and } \\
\text { Seeds } \\
D C Y P C B \\
D C Y P C M\end{array}$ & $\begin{array}{c}\begin{array}{c}\text { Roots } \\
\text { and }\end{array} \\
\text { Tubers } \\
D C Y P C B \\
D C Y P C M\end{array}$ \\
\hline Sr-89 & 1.0 & 0.37 & 0.20 & NA & NA & 0.20 & NA \\
\hline Sr-90 & 1.0 & 0.99 & 0.99 & NA & NA & 0.99 & NA \\
\hline $\mathrm{Cs}-134$ & 1.0 & 0.92 & 0.85 & NA & NA & 0.85 & NA \\
\hline Cs-137 & 1.0 & 0.99 & 0.99 & NA & NA & 0.99 & NA \\
\hline I-131 & 1.0 & 0.063 & 0.032 & NA & NA & 0.032 & NA \\
\hline I-133 & 1.0 & 0.0068 & 0.0034 & NA & NA & 0.0034 & NA \\
\hline
\end{tabular}

Not applicable 


\section{Model Description}

Table 5. Values Used in Definition of Transfer Factor CTD Appearing in Table 3 for Accidents Occurring During the Crop Growing Season in the Analysis for Surry

Losses due to weathering from plant surfaces and during translocation from plant surfaces to interior edible portions of plants are modelled by

Fraction Retained $=C T C O E F 1 \exp (-\ln 2 \Delta t / C T H A L F 1)+C T C O E F 2 \exp (-\ln 2 \Delta t / C T H A L F 2)$,

where $\Delta t$ is the time from the accident to the end of the growing season. Growing seasons are defined in Table 1. For pasture, stored forage, green leafy vegetables, and other food crops, this equation is used as a two term weathering equation. Time periods of 14 days $\left(1.21 \times 10^{6} \mathrm{~s}\right)$ and 50 days $\left(4.32 \times 10^{6} \mathrm{~s}\right)$ are used for weathering. For grains, legumes and seeds, and roots and tubers, where radionuclides are consumed only if translocated to edible portions of the plant, this equation is reduced to a translocation transfer factor by setting CTCOEF2 to zero, CTHALF2 to one second and $C T H A L F 1$ to one million years $\left(1 \times 10^{13} \mathrm{~s}\right)$ and using CTCOEF1 as a translocation factor.

\begin{tabular}{|c|c|c|c|c|c|c|c|c|}
\hline \multicolumn{9}{|c|}{ Direct deposition transfer coefficients $[(\mathrm{Bq}$ intercepted $) /(\mathrm{Bq}$ deposited $)]($ Ref. 32, Tables 4.8, 4.9) } \\
\hline & Nuclide & Pasture & $\begin{array}{l}\text { Stored } \\
\text { Forage }\end{array}$ & Grains & $\begin{array}{c}\text { Green } \\
\text { Leafy } \\
\text { Vegetables }\end{array}$ & $\begin{array}{l}\text { Other } \\
\text { Food } \\
\text { Crops }\end{array}$ & $\begin{array}{c}\text { Legumes } \\
\text { and } \\
\text { Seeds }\end{array}$ & $\begin{array}{l}\text { Roots } \\
\text { and } \\
\text { Tubers }\end{array}$ \\
\hline CTCOEF1 & Sr-89 & 0.3 & 0.2 & 0.01 & 0.24 & 0.2 & 0.005 & 0.0006 \\
\hline CTCOEF1 & Sr-90 & 0.3 & 0.2 & 0.01 & 0.24 & 0.2 & 0.005 & 0.0006 \\
\hline CTCOEFI & Cs-134 & 0.3 & 0.2 & 0.05 & 0.24 & 0.2 & 0.01 & 0.025 \\
\hline CTCOEF1 & Cs-137 & 0.3 & 0.2 & 0.05 & 0.24 & 0.2 & 0.01 & 0.025 \\
\hline CTCOEF1 & I-131 & 0.3 & 0.2 & 0.0 & 0.24 & 0.2 & 0.0 & 0.0 \\
\hline CTCOEF1 & I-133 & 0.3 & 0.2 & 0.0 & 0.24 & 0.2 & 0.0 & 0.0 \\
\hline CTCOEF2 & Sr-89 & 0.076 & 0.05 & 0.0 & 0.06 & 0.05 & 0.0 & 0.0 \\
\hline CTCOEF2 & Sr-90 & 0.076 & 0.05 & 0.0 & 0.06 & 0.05 & 0.0 & 0.0 \\
\hline CTCOEF2 & Cs-134 & 0.076 & 0.05 & 0.0 & 0.06 & 0.05 & 0.0 & 0.0 \\
\hline CTCOEF2 & Cs -137 & 0.076 & 0.05 & 0.0 & 0.06 & 0.05 & 0.0 & 0.0 \\
\hline CTCOEF2 & $1-131$ & 0.076 & 0.05 & 0.0 & 0.06 & 0.05 & 0.0 & 0.0 \\
\hline CTCOEF2 & $1-133$ & 0.076 & 0.05 & 0.0 & 0.06 & 0.05 & 0.0 & 0.0 \\
\hline
\end{tabular}


Table 5 (concluded)

\begin{tabular}{||l|c|c|c|c|c|c|c|c||}
\hline & \multicolumn{8}{|c|}{ Crop transfer half-lives (s) (Ref. 32, Table 4.8) } \\
\hline & Nuclide & Pasture & $\begin{array}{c}\text { Stored } \\
\text { Forage }\end{array}$ & Grains & $\begin{array}{c}\text { Green } \\
\text { Leafy } \\
\text { Vegetables }\end{array}$ & $\begin{array}{c}\text { Other } \\
\text { Food } \\
\text { Crops }\end{array}$ & $\begin{array}{c}\text { Legumes } \\
\text { and } \\
\text { Seeds }\end{array}$ & $\begin{array}{c}\text { Roots } \\
\text { and } \\
\text { Tubers }\end{array}$ \\
\hline CTHALF1 & Sr-89 & $1.21 \times 10^{6}$ & $1.21 \times 10^{6}$ & $1 \times 10^{13}$ & $1.21 \times 10^{6}$ & $1.21 \times 10^{6}$ & $1 \times 10^{13}$ & $1 \times 10^{13}$ \\
CTHALF1 & Sr-90 & $1.21 \times 10^{6}$ & $1.21 \times 10^{6}$ & $1 \times 10^{13}$ & $1.21 \times 10^{6}$ & $1.21 \times 10^{6}$ & $1 \times 10^{13}$ & $1 \times 10^{13}$ \\
CTHALF1 & Cs-134 & $1.21 \times 10^{6}$ & $1.21 \times 10^{6}$ & $1 \times 10^{13}$ & $1.21 \times 10^{6}$ & $1.21 \times 10^{6}$ & $1 \times 10^{13}$ & $1 \times 10^{13}$ \\
CTHALF1 & $\mathrm{Cs}-137$ & $1.21 \times 10^{6}$ & $1.21 \times 10^{6}$ & $1 \times 10^{13}$ & $1.21 \times 10^{6}$ & $1.21 \times 10^{6}$ & $1 \times 10^{13}$ & $1 \times 10^{13}$ \\
CTHALF1 & $\mathrm{I}-131$ & $1.21 \times 10^{6}$ & $1.21 \times 10^{6}$ & 1.0 & $1.21 \times 10^{6}$ & $1.21 \times 10^{6}$ & 1.0 & 1.0 \\
CTHALF1 & $\mathrm{I}-132$ & $1.21 \times 10^{6}$ & $1.21 \times 10^{6}$ & 1.0 & $1.21 \times 10^{6}$ & $1.21 \times 10^{6}$ & 1.0 & 1.0 \\
CTHALF2 & $\mathrm{Sr}-89$ & $4.32 \times 10^{6}$ & $4.32 \times 10^{6}$ & 1.0 & $4.32 \times 10^{6}$ & $4.32 \times 10^{6}$ & 1.0 & 1.0 \\
CTHALF2 & $\mathrm{Sr}-90$ & $4.32 \times 10^{6}$ & $4.32 \times 10^{6}$ & 1.0 & $4.32 \times 10^{6}$ & $4.32 \times 10^{6}$ & 1.0 & 1.0 \\
CTHALF2 & $\mathrm{Cs}-134$ & $4.32 \times 10^{6}$ & $4.32 \times 10^{6}$ & 1.0 & $4.32 \times 10^{6}$ & $4.32 \times 10^{6}$ & 1.0 & 1.0 \\
CTHALF2 & $\mathrm{Cs}-137$ & $4.32 \times 10^{6}$ & $4.32 \times 10^{6}$ & 1.0 & $4.32 \times 10^{6}$ & $4.32 \times 10^{6}$ & 1.0 & 1.0 \\
CTHALF2 & $\mathrm{I}-131$ & $4.32 \times 10^{6}$ & $4.32 \times 10^{6}$ & 1.0 & $4.32 \times 10^{6}$ & $4.32 \times 10^{6}$ & 1.0 & 1.0 \\
CTHALF2 & $\mathrm{I}-133$ & $4.32 \times 10^{6}$ & $4.32 \times 10^{6}$ & 1.0 & $4.32 \times 10^{6}$ & $4.32 \times 10^{6}$ & 1.0 & 1.0 \\
\hline \hline
\end{tabular}

\subsection{Interdiction}

In addition to the transport of released radionuclides with a Gaussian plume model and the calculation of population exposure with the model indicated in Eq. (7), the MACCS food pathways model also implements interdiction criteria to mitigate population dose from both the growing season and long-term pathways. When an accident occurs within the growing season, the necessity for the disposal of milk within spatial element $l$ is determined on the basis of a milk dose ratio $M D R_{l}$ defined by

$$
M D R_{l}=\sum_{i}\left(G C_{i l} / P C S M L K_{i}\right),
$$

where $P C S M L K_{i}$ is a user-specified maximum permissible ground concentration $\left(\mathrm{Bq} / \mathrm{m}^{2}\right)$ of radionuclide $i$ for milk production. Milk disposal occurs for three months in spatial element $l$ when $M D R_{t}>1$ (Ref. 3, p. 5-16). Similarly, the necessity for the disposal of crops within spatial element $l$ is determined on the basis of a non-milk dose ratio $N M D R_{l}$ defined by

$$
N M D R_{l}=\sum_{i}\left(G C_{i l} / P S C O T H_{i}\right)
$$

where $P S C O T H_{i}$ is a user-specified maximum permissible ground concentration $\left(\mathrm{Bq} / \mathrm{m}^{2}\right)$ of radionuclide $i$ for crop production. Crop disposal occurs for one growing season in spatial element $l$ if $N M D R_{l}>1$ (Ref. 3, p. 5-16).

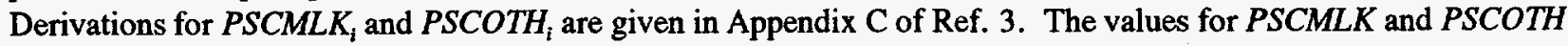
used in the Surry analysis are summarized in Table 6. 
Model Description

Table 6. Permissible Ground Concentrations $\left(\mathrm{Bq} / \mathrm{m}^{2}\right)$ and Soil Depletion Rates ( $\left.\mathrm{yr}^{-1}\right)$ Used in Surry Analysis to Evaluate Crop Disposal and Interdiction of Farmland

Permissible ground concentrations (PSCMLK, PSCOTH, GCMAXR) were derived by inverting the food pathway model, thereby making the dose to an organ the independent variable and ground concentration the dependent variable (Ref. 32, Table 4.47). Permissible ground concentrations were calculated assuming (1) allowable first year (i.e., direct deposition) organ doses of $15 \mathrm{rem}$ to thyroid and $5 \mathrm{rem}$ to any other organ, and (2) allowable doses in subsequent years (i.e., root uptake) of 1.5 rem to thyroid and 0.5 rem to any other organ. Depletion rates (QROOT) were derived from processes involving radioactive decay, percolation and irreversible binding to soil (Ref. 32, Table 4.48).

\begin{tabular}{||c|c|c|c|c||}
\hline Nuclide & $\begin{array}{c}\text { Growing Season } \\
\text { Milk } \\
\text { PSCMLK }\left(\mathrm{Bq} / \mathrm{m}^{2}\right)\end{array}$ & $\begin{array}{c}\text { Growing Season } \\
\text { Other Crops } \\
\text { PSCOTH }\left(\mathrm{Bq} / \mathrm{m}^{2}\right)\end{array}$ & $\begin{array}{c}\text { Long Term } \\
\text { All Crops } \\
\text { GCMAXR }\left(\mathrm{Bq} / \mathrm{m}^{2}\right)\end{array}$ & $\begin{array}{c}\text { Annual Depletion } \\
\text { Rate } \\
\text { QROOT }\left(\mathrm{yr}^{-1}\right)\end{array}$ \\
\hline Sr-89 & $2.1 \times 10^{6}$ & $2.2 \times 10^{6}$ & $8.3 \times 10^{5}$ & 4.9 \\
Sr-90 & $4.6 \times 10^{4}$ & $5.1 \times 10^{4}$ & $4.0 \times 10^{3}$ & 0.065 \\
Cs-134 & $1.4 \times 10^{5}$ & $9.6 \times 10^{4}$ & $1.1 \times 10^{5}$ & 0.59 \\
Cs-137 & $1.9 \times 10^{5}$ & $1.3 \times 10^{5}$ & $1.2 \times 10^{5}$ & 0.28 \\
I-131 & $1.0 \times 10^{5}$ & $9.2 \times 10^{6}$ & $2.1 \times 10^{7}$ & 32.0 \\
I-133 & $1.2 \times 10^{9}$ & $1.0 \times 10^{20}$ & $1.6 \times 10^{12}$ & 290.0 \\
\hline
\end{tabular}

The interdiction of long-term food pathways is based on three criteria: habitability, maximum allowable ground concentrations for crop production, and cost effectiveness. Specifically, land is (1) temporarily removed from crop production if the projected long-term groundshine and inhalation doses to an individual living on the land would exceed a specified dose level ( $2 \mathrm{rem}$ in first year and $0.5 \mathrm{rem} / \mathrm{yr}$ for years 2 through 5 for effective whole body dose equivalent in this analysis), (2) temporarily removed from crop production if maximum allowable ground concentrations $\left(\mathrm{Bq} / \mathrm{m}^{2}\right)$ for crop production are exceeded (MACCS variable GCMAXR defined in Table 6), and (3) permanently interdicted (i.e., condemned) if the cost of returning the land to agricultural production within eight years of the accident exceeds the value of the land and its associated investments. Each of these interdiction criteria are now discussed in more detail.

The decision on whether the people residing in a given spatial element are allowed to return after temporary relocation or evacuation depends on the habitability criterion indicated in the preceding paragraph and the cost effectiveness of protective actions such as decontamination and temporary interdiction. Two protective measures are considered to restore habitability: decontamination only and a combination of decontamination and temporary interdiction. The MACCS decontamination model assumes that several decontamination methods will be available for both farm and non-farm property. For each decontamination method, the model requires a cost per hectare for farm property (MACCS variable CDFRM) and per person for non-farm property (MACCS variable CDNFRM) and a decontamination factor $F_{D}$ (MACCS variable DSRFCT), where 
Model Description

$$
F_{D}=C_{i} / C_{f}
$$

and $C_{i}$ and $C_{f}$ are the surface contamination levels before and after decontamination. These variables and other variables used in conjunction with the MACCS decontamination model in the Surry analysis are summarized in Table 7.

Based on a projection of exposures resulting from groundshine and inhalation of resuspended radionuclides (see Section 2.3) over a user-specified projection period (5 yr in the Surry analysis), MACCS determines if a given spatial element is immediately habitable. A spatial element is considered to be habitable if the projected dose commitment to the critical organ (effective whole body dose equivalent in the Surry analysis) does not exceed a user specified dose limit (2 rem in first year and 0.5 $\mathrm{rem} / \mathrm{yr}$ for next four years in Surry analysis). If a spatial element is immediately habitable, the resident population is assumed to be present for the entire long-term period and no mitigative actions are taken to limit their exposure. If the evaluation of the long-term phase criterion indicates that the spatial element is not immediately habitable, mitigative actions are taken to assure that the criterion is not exceeded. The mitigative actions are evaluated in a predetermined sequence to select the least stringent action that will allow the dose criterion to be satisfied. The order of these actions is: (1) decontamination alone, (2) maximum level of decontamination followed by an interdiction period, and (3) permanent interdiction (condemnation) of the property. A given level of decontamination is considered to restore habitability if the projected dose over the projection period does not exceed the dose limit, with the projection period starting at the time of the prospective return of the resident population.

Table 7. Variables Used in Conjunction with the Decontamination Model in MACCS in the Surry Analysis (Ref. 32, Appendix A.3; Ref. 39)

\begin{tabular}{||l|c|c|c||}
\hline \multicolumn{1}{|c|}{ Description } & $\begin{array}{c}\text { MACCS } \\
\text { Variable }\end{array}$ & $\begin{array}{c}\text { Decontamination } \\
\text { Level 1 }\end{array}$ & $\begin{array}{c}\text { Decontamination } \\
\text { Level 2 }\end{array}$ \\
\hline Dose Reduction Factor & DSRFCT & 3 & 15 \\
Cost Farm Decontamination (\$/Ha) & $C D F R M$ & 562.5 & 1250. \\
Cost Nonfarm Decontamination (\$/Person) & $C D N F R M$ & 3000. & 8000. \\
Decontamination Time (Days) & $T I M D E C$ & 60. & 120. \\
Fraction Farm Cost Due to Labor & $F R F D L$ & 0.3 & 0.35 \\
Fraction Nonfarm Cost Due to Labor & $F R N F D L$ & 0.7 & 0.5 \\
Fraction Farm Labor Time in Decontamination Work & $T F W K F$ & 0.1 & 0.33 \\
Fraction Nonfarm Labor Time in Decontamination Work & $T F W K N F$ & 0.33 & 0.33 \\
Average Cost of Decontamination Labor (\$/man-yr) & DLBCST & 35000 & 35000 \\
\hline
\end{tabular}

To evaluate the cost effectiveness of decontamination or decontamination followed by temporary interdiction of nonfarm areas, the following criteria are used in MACCS: (1) If a spatial element cannot be 


\section{Model Description}

restored to habitability by decontamination followed by temporary interdiction, then the spatial element is condemned permanently. (2) If a spatial element is not permanently condemned by the preceding criterion and the cost of decontamination and temporary interdiction of the property is less than the cost of condemning the property, then people residing in the spatial element are allowed to return after the interdiction period. (3) If a spatial element is not permanently condemned by the first criterion and the cost of decontamination and temporary interdiction of the property is greater than or equal to the value of the property, then the property is condemned permanently. The determination of costs in the MACCS economic model is discussed in Section 2.4.

When farmland is habitable, a need may still exist to restrict long-term crop production if radionuclide concentrations are too high (Ref. 3, Section 5.3.3.1). The allowable ground concentrations for long-term crop production are defined by the MACCS variable GCMAXR as indicated in Table 6 . A discussion on the derivation of GCMAXR is given in Appendix C of Ref. 3. The determination of when the radionuclide concentrations in spatial element $l$ are sufficiently low to permit crop production are made on the basis of the ratio

$$
R S_{l}=\sum_{i}\left[G C_{i l} \exp \left(-Y R S_{l} Q R O O T_{i}\right)\right] / G C M A X R_{i},
$$

where $Y R S_{l}$ is the time period (yr) over which crop production in spatial element $l$ will be prohibited, $G C M A X R_{i}$ is the maximum allowable ground concentration $\left(\mathrm{Bq} / \mathrm{m}^{2}\right)$ of radionuclide $i$ for long-term crop production (see Table 6), QROOT is the annual depletion rate $\left(\mathrm{yr}^{-1}\right)$ for loss of radionuclide $i$ due to radioactive decay, percolation and irreversible binding to soil (see Table 6), and $G C_{i l}$ has been defined previously. Crop production is assumed to resume in spatial element $l$ for the smallest integer value of $Y R S_{l}$ for which $R S_{l}<1$.

To evaluate the cost effectiveness of decontamination of farmland or decontamination followed by temporary interdiction of crop production, the following steps are used in MACCS (Ref. 3, Section 5.3.2.2): (1) If a spatial element is condemned permanently according to the habitability criterion or the restriction on crop production exceeds eight years, farmland is assumed to be permanently condemned. Cost effectiveness is not evaluated. (2) If the farmland in a spatial element is not permanently condemned and the cost of farmland decontamination and temporary interdiction is less than the value of the farmland and associated investments, then the farmland of that spatial element is allowed to return to production after a period of interdiction. The interdiction period ends at the larger of the two following times: (i) the time at which farmland meets the habitability criterion, and (ii) the time at which farmland can return to crop production. (3) If a spatial element is not permanently condemned but the cost of farmland decontamination and temporary interdiction is greater than or equal to the value of the farmland and associated investments, then the farmland is permanently condemned. The determination of costs in the MACCS economic model is described in Section 2.4.

\subsection{Groundshine, Inhalation and Water Ingestion Doses}

The groundshine dose $D G_{k l}\left(t_{1}, t_{2}\right)$ (Sv) to organ $k$ of an individual in spatial element $l$ between times $t_{1}$ and $t_{2}$ is given by (Ref.3, Section 3.2.2) 
Model Description

$$
D G_{k l}\left(t_{1}, t_{2}\right)=\left[\sum_{i} G C_{i l} D F G_{i k}\left(t_{1}, t_{2}\right)\right] S F G
$$

where $D F G_{i k}\left(t_{1}, t_{2}\right)$ is the groundshine dose factor $\left(S v-\mathrm{m}^{2} / \mathrm{Bq}\right)$ for organ $\mathbf{k}$ and radionuclide $\mathrm{i}$ for exposures incurred between time $t_{1}$ and $t_{2}$, SFG is a groundshine shielding factor (dimensionless), and $G C_{i l}$ has been defined previously. In the Surry analysis, the groundshine shielding factor for normal activity (MACCS variable GSHFAC) is 0.33 (Ref. 32, Appendix A.2; also see Ref. 32, Section 3.2). The dose factor $D F G_{i k}\left(t_{1}, t_{2}\right)$ is given by

$$
D F G_{i k}\left(t_{1}, t_{2}\right)=D R F G_{i k} \int_{t_{1}}^{t_{2}} G W(t) \exp \left(-\lambda_{i} t\right) d t,
$$

where $D R F G_{i k}$ is the groundshine dose rate conversion factor $\left(\mathrm{Sv}-\mathrm{m}^{2} / \mathrm{Bq}-\mathrm{s}\right)$ for organ $k$ and radionuclide $i$ (see Table 2), $G W(t)$ is Gale's weathering function as defined in Eq. (14), and $\lambda_{i}$ is the decay constant for radionuclide $i$ as previously defined. Gale's equation ${ }^{40}$ for the attenuation of groundshine due to weathering is given by

$$
G W(t)=\sum_{m=1}^{2} G W C O E F_{m} \exp \left(-t \ln 2 / T G W H L F_{m}\right)
$$

where $G W C O E F_{m}$ is a weathering coefficient (dimensionless), $T G W H L F_{m}$ is a weathering halflife(s) and $t$ is the time (s) since the initial deposition. In the Surry analyses, $G W C O E F_{m}=0.5$ for $m=1$ and 2, $T G W H L F_{1}=1.6 \times 10^{7}$ s (i.e., a weathering halflife of $0.5 \mathrm{yr}$ ) and $T F W H L F_{2}=2.8 \times 10^{9} \mathrm{~s}$ (i.e., a weathering halflife of $90 \mathrm{yr}$ ) (Ref. 32, Section 2.7).

The resuspension inhalation dose $D R_{k l}\left(t_{1}, t_{2}\right)(\mathrm{Sv})$ to organ $k$ of an individual in spatial element $l$ between times $t_{1}$ and $t_{2}$ is given by (Ref. 3, Section 3.2.3)

$$
D R_{k l}\left(t_{1}, t_{2}\right)=\left[\sum_{i} G C_{i l} D F R_{i k}\left(t_{1}, t_{2}\right)\right] S F I,
$$

where $D F R_{i k}\left(t_{1}, t_{2}\right)$ is the resuspension inhalation dose factor $\left(\mathrm{Sv}-\mathrm{m}^{2} / \mathrm{Bq}\right)$ for organ $k$ and radionuclide $i$ for exposures incurred between times $t_{1}$ and $t_{2}, S F I$ is an inhalation shielding factor (dimensionless), and $G C_{i l}$ has been defined previously. In the Surry analysis, the inhalation shielding factor for normal activity (MACCS variable PROTIN) is 0.41 (Ref. 32, Appendix A.2; also see Ref. 32, Section 3.2). The resuspension dose factor $D F R_{i k}\left(t_{1}, t_{2}\right)$ is given by

$$
D F R_{i k}\left(t_{1}, t_{2}\right)=D F I_{i k} B R \int_{t_{1}}^{t_{2}} R W(t) \exp \left(-\lambda_{i} t\right) d t,
$$

where $D F I_{i k}$ is the inhalation dose conversion factor $(\mathrm{Sv} / \mathrm{Bq})$ for organ $k$ and radionuclide $i$ (see Table $2.2), B R$ is the breathing rate $\left(\mathrm{m}^{3} / \mathrm{s}\right), R W(t)$ is the resuspension weathering function defined in $\mathrm{Eq}$. (17), 


\section{Model Description}

and $\lambda_{i}$ is the decay constant for radionuclide $i$. The resuspension weathering function is similar to Gale's equation in Eq. (14) and is given by

$$
R W(t)=\sum_{m=1}^{3} R W C O E F_{m} \exp \left(-t \ln 2 / T R W H L F_{m}\right),
$$

where $R W C O E F_{m}$ is the resuspension coefficient $\left(\mathrm{m}^{-1}\right)$ for the $m$-th term, $T R W H L F_{m}$ is the resuspension halflife $\left(\mathrm{s}^{-1}\right)$ for the $m$-th term, and $t$ is the time (s) since the initial deposition. The values used for $R W C O E F_{m}$ and $T R W H L F_{m}$ in the Surry analysis are given by $R W C O E F_{1}=1 \times 10^{-5} \mathrm{~m}^{-1}, R W C O E F_{2}=$ $1 \times 10^{-7} \mathrm{~m}^{-1}, R W C O E F_{3}=1 \times 10^{-9} \mathrm{~m}^{-1}, T R W H L F_{1}=1.6 \times 10^{7} \mathrm{~s}(6 \mathrm{mn}), T R W H L F_{2}=1.6 \times 10^{8} \mathrm{~s}(5 \mathrm{yr})$ and $T R W H L F_{3}=1.6 \times 10^{9} \mathrm{~s}(50 \mathrm{yr})$ (Ref. 32, Section 2.9).

Unlike the population dose given in Eq. (7), the groundshine and resuspension doses given in Eqs. (12) and (15) are individual doses. The actual population doses are determined in the following manner (Ref. 3, Section 5.3.1.3). If decontamination at level $m$ (e.g., with a dose reduction factor of $3(m=1)$ or $15(m=2)$ in the Surry analysis as indicated in Table 7) is sufficient to meet the habitability criterion, people originally residing in a given spatial element are assumed to move back at the end of the decontamination period. Individual dose is obtained by adding the groundshine dose in Eq. (12) and the inhalation dose in Eq. (15), with the initial ground concentration $G C_{i l}$ in these equations reduced in accordance with the decontamination level used. The integration times in Eqs. (13) and (16) are defined with $t_{1}$ equaling the time at which people return after decontamination and $t_{2}$ equaling $t_{1}$ plus one million years. As all radionuclides typically considered in reactor accident consequence calculations with MACCS have halflives that are short compared to one million years, the integration is effectively from $t_{1}$ to infinity. If the maximum decontamination effort fails to meet the dose criterion for immediate habitation and some temporary interdiction is cost effective to meet the habitability criterion, $t_{1}$ is the time at which the interdiction period ends. Population dose for a spatial element is then obtained by summing the individual doses.

The dose $D W N F_{k l}\left(t_{1}, t_{2}\right)(\mathrm{Sv})$ to organ $k$ for decontamination workers engaged in the clean-up effort for nonfarm properties in spatial element $l$ between times $t_{1}$ and $t_{2}$ is given by (Ref. 3, Section 5.3.2)

$$
D W N F_{k l}\left(t_{1}, t_{2}\right)=F T I M N U M W_{l} S F G \sum_{i} G C_{i l} D F G_{i k}\left(t_{1}, t_{2}\right)
$$

where FTIM is the fraction of the decontamination period that workers actually spend in the area being decontaminated, $N U M W_{1}$ is the number of workers required to perform decontamination in spatial element $l$, and the variables $S F G, G C_{i l}$ and $D F G_{i k}\left(t_{1}, t_{2}\right)$ have been defined previously. The time interval $\left[t_{1}, t_{2}\right]$ used in the definition of the groundshine dose factor $D F G_{i k}\left(t_{1}, t_{2}\right)$ in Eq. (13) is the time interval within which decontamination takes place and is defined by the MACCS variable TIMDEC (see Table 7). The fraction FTIM of the time inteval $\left[t_{1} t_{2}\right]$ that workers spend in the area being decontaminated is defined by the MACCS variable TFWKNF (see Table 7). The number of workers $N U M W_{l}$ is given by 


$$
N U M W_{l}=\operatorname{CSTDNF} P O P N_{l} \text { FLBNF }[\text { LBCST TIMD }]^{-1}
$$

where CSTDNF is the decontamination cost (\$/person) for nonfarm property (MACCS variable CDNFRM in Table 7), $P O P N_{l}$ is the number of persons living in spatial element $l$ (a MACCS input; see Ref. 32, Appendix A.3), FLBNF is the fraction of nonfarm decontamination cost due to labor (MACCS variable FRNFDL in Table 7), LBCST labor cost (\$/worker-s)(MACCS variable DLBCST in Table 7), and TIMD is the time (s) required to perform decontamination (MACCS variable TIMDEC in Table 7). The dose to workers engaged in the clean-up effort for farmland is determined in a similar manner (Ref.3, Section 5.3.4).

The population dose $D_{i k l}(\mathrm{~Sv})$ to organ $k$ due to water ingestion resulting from radionuclide $i$ initially deposited in spatial element $l$ is given by

$$
D_{i k l}=D F_{i k} W I N G F_{l i}\left[\frac{\lambda_{i} W S H F R I_{i}+W S H R T A_{i}}{\lambda_{i}+W S H R T A_{i}}\right] T A_{l} G C_{i l},
$$

where $W I N G F_{i i}$ is the fraction of radionuclide $i$ entering surface water from spatial element $l$ that will be consumed by man, WSHFRI is the fraction of deposition of radionuclide $i$ onto land surfaces that moves to surface-water bodies in a short period of time after deposition, WSHRTA $A_{i}$ is the rate constant $\left(\mathrm{s}^{-1}\right)$ for the long-term movement of radionuclide $i$ from land surfaces to surface-water bodies, $T A_{l}$ is the area $\left(\mathrm{m}^{2}\right)$ of spatial element $l, \lambda_{i}$ is the decay constant $\left(\mathrm{s}^{-1}\right)$ for radionuclide $i$, and the variables $D F_{i k}$ and $G C_{i l}$ have been defined previously (Ref.3, Section 3.2.5; Ref. 32, Section 2.8; Ref. 41). The preceding expression results from using the following differential equation to represent radionuclide movement from land surfaces to surface water bodies:

$$
\frac{d x_{i l}}{d t}=-\left(\lambda_{i}+\text { WSHRTA }_{i}\right) x_{i l}, x_{i l}(0)=\left(1-\text { WSHFRI }_{i}\right) T A_{l} G C_{i l},
$$

where $x_{i l}(\mathrm{t})$ is the amount of radionuclide $i$ on land surfaces in spatial element $l$ at time $t$. In the present analysis, WINGF $F_{i i}$ equals $5 \times 10^{-6}$ or 0 depending on whether spatial element $l$ is predominantly land or ocean; WSHRTA $A_{i}$ equals $0.004 \mathrm{~s}^{-1}$ and $0.001 \mathrm{~s}^{-1}$ for strontium and cesium, respectively; and WSHFRI equals 0.01 and 0.005 for strontium and cesium, respectively (Ref. 32, Section 2.8).

\subsection{Interdiction Cost}

The costs resulting from long-term protective actions have five sources (Ref. 3, Section 4.3): decontamination, decontamination followed by temporary interdiction of farm and urban areas, disposal of crops or products produced on farms, temporary prohibition of farm production, and condemnation of property. Long-term protective action costs are divided into two groups: farm costs and nonfarm costs. Specifically, the cost $C L_{l}(\$)$ of long-term protective action in spatial element $l$ is given by 
Model Description

$$
C L_{l}=C N F_{l} P_{l}+C F_{l} A F_{l} \text {, }
$$

where $C N F_{l}$ is the cost of long-term protective action for nonfarm property in spatial element $l$ (\$/person), $P_{l}$ is the population within spatial element $l$ (persons), $C F_{l}$ is the cost of long-term protective action for farm property in spatial element $l(\$ / \mathrm{Ha})$, and $A F_{l}$ area of farmland within spatial element $l(\mathrm{Ha})$. The population $P_{l}$ is user-specified (Ref.32, Appendix A.3), and the farmland area $A F_{l}$ is calculated by MACCS using site data (Ref. 32, Appendix A.3). The cost $C N F_{l}$ of long-term protective action for nonfarm property is either the cost of restoring habitability or the cost of condemning the nonfarm property if it is not possible or cost effective to restore habitability. The cost $C F_{l}$ of long-term protective action for farm property is the sum of (1) the cost of restoring habitability and farm production of the farm property or the cost of condemning the farm property and (2) the cost of crop disposal if the accident occurs during the growing season. The models used in MACCS in the estimation of these costs are now summarized.

A dose criterion for groundshine and inhalation exposure is used to determine if a spatial element is habitable. Decontamination without interdiction, decontamination with interdiction, or condemnation may be required for nonfarm property within any spatial element. The cost $C N F_{l}$ (\$/person) of restoring habitability for nonfarm property in spatial element $l$ is the sum of the costs for decontamination, relocation, and loss of usage of property. Specifically,

$$
C N F_{l}=C D N F_{l}+C R+C C N F_{l},
$$

where $C D N F_{l}$ is the cost of decontamination (\$/person) for nonfarm property (MACCS variable CDNFRM in Table 7), $C R$ is the relocation cost (\$/person) (MACCS variable POPCST, which equals $\$ 5000 /$ person in Surry analysis), and $C C N F_{l}$ is the cost for loss of usage of property (depreciation, deterioration, and losses) in spatial element $l$ (\$/person) for nonfarm property. The cost $C C N F_{l}$ for loss of usage of nonfarm property is given by

$$
C C N F_{l}=P I_{l}+P V D_{l}
$$

where $P V I_{I}$ is the present value (\$/person) of lost income due to interdiction of property in spatial element 1 and $P V D_{l}$, is the present value (\$/person) of depreciation occurring due to interdiction of property in spatial element $l$. In turn, $P V I_{l}$ and $P V D_{l}$ are defined by

$$
P V_{l}=\left[V A L W_{l} \exp \left(T H_{l} R I R\right)-V A L W_{l}\right] \exp \left(-T H_{l} R I R\right)
$$

and

$$
P V D_{l}=\left[V A L W_{l} F I M-V A L W_{l} F I M \exp \left(-T H_{l} R D P\right)\right] \exp \left(-T H_{l} R I R\right),
$$

where $V A L W_{l}$ is the value of nonfarm wealth (\$/person) in spatial element $l$ at the time of the accident, $F I M$ is the fraction of nonfarm wealth resulting from improvements (i.e., $(1-F I M) V A L W_{l}$ is value of unimproved land in spatial element $l$ ), $T H_{l}$ is the interdiction period (yr) in spatial element $l, R I R$ is the inflation adjusted rate of investment return $\left(\mathrm{yr}^{-1}\right)$, and $R D P$ is the depreciation rate during interdiction (yr 
1). Values for $V A L W_{l}$ are supplied through the MACCS input variable VNFRM as indicated in Table 8. The variables FIM, RIR and RDP correspond to the MACCS input variables FRNFIM, DSRATE and $D P R A T E$ and are assigned values of $0.8,0.12 \mathrm{yr}^{-1}$ and $0.2 \mathrm{yr}^{-1}$, respectively, in the Surry analysis (Ref. 32, Sections 5.1, 5.2). 
Model Description

Table 8. Regional Economic Data Used as Input to MACCS in Surry Analysis (Ref. 32, Appendix A.3)

\begin{tabular}{|c|c|c|c|c|c|c|}
\hline Index ${ }^{a}$ & Region $^{b}$ & $F R M F R C^{\mathrm{c}}$ & $D P F^{\mathrm{d}}$ & $\begin{array}{l}A S F P^{c} \\
(\$ / \mathrm{Ha})\end{array}$ & $\begin{array}{l}V F R M^{\mathrm{f}} \\
(\$ / \mathrm{Ha})\end{array}$ & $\begin{array}{c}V N F R M^{\mathrm{B}} \\
\text { (\$/person) }\end{array}$ \\
\hline 1 & ALA & .354 & 0.40 & 459. & 1824 & 62000 . \\
\hline 2 & ARIZ & .516 & .104 & 110. & 682. & 74000 . \\
\hline 3 & ARK & .483 & .041 & 466. & 2049 & 61000. \\
\hline 4 & CALIF & .330 & .144 & 1022 & 4394. & 93000 . \\
\hline 5 & COLO & .522 & .048 & 211. & 971. & 83000 . \\
\hline 6 & CONN & .160 & .294 & 1605. & 4980. & 107000. \\
\hline 7 & DEL & .534 & .042 & 1723. & 3428. & 82000 . \\
\hline 8 & FLA & .375 & .080 & 832. & 3341. & 80000 . \\
\hline 9 & GA & .363 & .060 & 613. & 1885. & 73000 . \\
\hline 10 & IDAHO & .270 & .144 & 343. & 1562. & 61000. \\
\hline 11 & ILL & .806 & .044 & 709. & 3900. & 86000 . \\
\hline 12 & IND & .713 & .079 & 611. & 3283. & 72000 \\
\hline 13 & IOWA & .938 & .060 & 695. & 3133. & 73000 . \\
\hline 14 & KANS & .917 & .035 & 281. & 1204. & 81000 . \\
\hline 15 & $\mathrm{KY}$ & .571 & .112 & 482. & 1838 & 61000. \\
\hline 16 & LA & .354 & .074 & 459. & 3284. & 61000 \\
\hline 17 & MAINE & .079 & .260 & 662. & 1133. & 70000 \\
\hline 18 & MD & .429 & .216 & 956. & 4489. & 93000 . \\
\hline 19 & MASS & .136 & .249 & 1349. & 2563 & 97000. \\
\hline 20 & MICH & .313 & .247 & 658. & 2187. & 81000. \\
\hline 21 & MINN & .597 & .223 & 516. & 2111. & 82000 . \\
\hline 22 & MISS & .470 & .054 & 403. & 2084 & 53000 . \\
\hline 23 & MO & .703 & .102 & 322. & 1647. & 76000 . \\
\hline 24 & MONT & .657 & .030 & 61. & 563. & 65000 . \\
\hline 25 & NEBR & .962 & .031 & 318. & 1148. & 75000 . \\
\hline 26 & NEV & .127 & .139 & 63. & 601. & 84000 . \\
\hline
\end{tabular}


Model Description

Table 8 (continued)

\begin{tabular}{|c|c|c|c|c|c|c|}
\hline Index ${ }^{a}$ & Region $^{b}$ & $F R M F R C^{\mathrm{c}}$ & $D P F^{\mathrm{d}}$ & $\begin{array}{l}A S F P^{\star} \\
(\$ / \mathrm{Ha})\end{array}$ & $\begin{array}{l}\text { VFRM } \\
(\$ / \mathrm{Ha}) \\
\end{array}$ & $\begin{array}{c}V N F R M^{\mathbf{B}} \\
\text { (\$/person) }\end{array}$ \\
\hline 27 & N.H. & .096 & .482 & 518. & 2018 . & 87000 . \\
\hline 28 & N.J. & .203 & .129 & 1399. & 6477 & 102000 \\
\hline 29 & N.MEX & .590 & .144 & 53. & 473. & 63000 \\
\hline 30 & N.Y. & .310 & .589 & 711. & 1378 & 94000. \\
\hline 31 & N.C. & .352 & .065 & 860. & 2658 & 68000. \\
\hline 32 & N.DAK & .924 & .048 & 164. & 948. & 69000. \\
\hline 33 & OHIO & .602 & .175 & 581. & 2686 & 76000 \\
\hline 34 & OKLA & .751 & .060 & 204. & 1508. & 67000 \\
\hline 35 & OREG & .292 & .111 & 236. & 1203 & 73000 \\
\hline 36 & PA & .303 & .447 & 855. & 2534 & 78000 \\
\hline 37 & R.I. & .108 & .213 & 1062. & 6438 & 80000 . \\
\hline 38 & S.C. & .290 & .084 & 472. & 1843. & 62000. \\
\hline 39 & S.DAK & .915 & .091 & 145. & 587. & 65000 \\
\hline 40 & TENN & .509 & .153 & 360. & 1850. & 66000 \\
\hline 41 & TEX & .816 & .064 & 164. & 1492. & 74000 . \\
\hline 42 & UTAH & .225 & .259 & 123. & 1286. & 60000 \\
\hline 43 & VT & .286 & .789 & 628. & 1472. & 73000 \\
\hline 44 & VA & .382 & .198 & 371. & 2075 & 84000 . \\
\hline 45 & WASH & .377 & .154 & 476. & 1948. & 82000. \\
\hline 46 & W.VA & .246 & .224 & 150. & 1728. & 58000 \\
\hline 47 & WIS & .517 & .591 & 723. & 1751. & 76000 \\
\hline 48 & WYO & .561 & .028 & 43. & 380. & 70000 \\
\hline 49 & BRIT COL & .377 & .154 & 476. & 1948. & 60000 \\
\hline 50 & OCEAN & .000 & .000 & 0. & 0. & 0. \\
\hline 51 & SASKAT & .657 & .030 & 61. & 563. & 60000. \\
\hline 52 & MANITOBA & .924 & .048 & 164. & 948. & 60000 . \\
\hline
\end{tabular}


Table 8 (concluded)

\begin{tabular}{|c|c|c|c|c|c|c||}
\hline Index $^{\mathrm{a}}$ & Region $^{\mathrm{b}}$ & $F R M F R C^{\mathrm{c}}$ & $D P F^{\mathrm{d}}$ & $\begin{array}{c}A S F P^{\mathrm{c}} \\
(\$ / \mathrm{Ha})\end{array}$ & $\begin{array}{c}\text { VFRM } \\
(\$ / \mathrm{Ha})\end{array}$ & $\begin{array}{c}\text { VNFRM } \\
(\$ / \text { person })\end{array}$ \\
\hline 53 & ONTARIO & .597 & .223 & 516. & 2111. & 60000. \\
54 & QUEBEC & .310 & .589 & 711. & 1378. & 60000. \\
55 & NOVA SCOT & .079 & .260 & 662. & 1133. & 6000. \\
56 & BAJA CAL & .330 & .144 & 1022. & 4394. & 10000. \\
57 & SONORA & .516 & .104 & 110. & 682. & 10000. \\
58 & CHIHUAHUA & .590 & .144 & 53. & 473. & 10000. \\
59 & COAHUILA & .816 & .064 & 164. & 1492. & 10000. \\
\hline
\end{tabular}

"Index used to identify region in MACCS input.

bName of Region.

${ }^{\mathrm{C}} \mathrm{Fraction}$ of land devoted to farming in region.

${ }^{\mathrm{d}}$ Fraction of farm income in region resulting from dairy products.

${ }^{\circ}$ Annual farm income in region $(\$ / \mathrm{Ha})$.

Value of farm wealth in region $(\$ / \mathrm{Ha})$.

sValue of non-farm wealth in region (\$/person).

The cost $C F_{l}(\$)$ of restoring habitability and farm production for farm properties in spatial element $l$ is determined in a manner similar to that used for non-farm properties. Specifically,

$$
C F_{l}=C D F_{l}+C C F_{l} \text {, }
$$

where $C D F_{l}$ is the cost of decontamination for farm property in spatial element $l(\$ / \mathrm{Ha})$ and $C C F_{l}$ is the cost for loss of usage of farm property (depreciation, deterioration, loss of income) $(\$ / \mathrm{Ha})$. The variable $C D F_{l}$ is determined on the basis of the decontamination level used and the MACCS input variable CDFRM (see Table 7). The variable $C C F_{l}$ is determined in the same manner as $C C N F_{l}$ in Eqs. (24), (25) and (26) except that $V A L W_{l}$ is value of farm wealth $(\$ / \mathrm{Ha}$ ) in spatial element $l$ (MACCS variable VFRM in Table 8) and FIM is the fraction of farm wealth resulting from improvements (MACCS variable FRFIM, which equals 0.25 in the Surry analysis). The variable $T H_{l}$ is determined by MACCS and corresponds to the time at which farmland satisfies both the habitability criterion and the maximum allowable ground concentration criteria for farm production (Section 2.2). The value of $T H_{l}$ used in the determination of $C F_{l}$ may be different from the value of $T H_{l}$ used in the determination $C N F_{l}$.

The model for growing season crop disposal estimates the costs of milk and other crop disposal for a reactor accident that occurs during the growing season. The cost of milk disposal $C M D_{l}(\$)$ in spatial element $l$ is given by 


$$
C M D_{l}=F P_{l} F D P_{l} F M D
$$

where $F P_{l}$ is the value of annual farm production (\$/hectar) in spatial element $l, F D P_{l}$ is the fraction of annual farm production value that comes from dairy products in spatial element $l$, and $F M D$ is the fraction of the year over which milk disposal occurs (dimensionless). The variables $F P_{l}$ and $F D P_{l}$ are defined by the MACCS input variables $A S F P$ and DPF (see Table 8). The value of $F M D$ is hard-wired in MACCS and equal to 0.25 , which is equivalent to the assumption that milk disposal occurs for three months. Similarly, the expression

$$
C N M D_{l}=F P_{l}\left(1-F D P_{l}\right)
$$

gives the cost $C N M D_{l}(\$ / \mathrm{Ha})$ of the disposal of nondairy products in spatial element $l$.

by

The per person cost $C C N F_{l}(\$ /$ person) to condemn nonfarm property in spatial element $l$ is given

$$
C C N F_{l}=C R+V A L W_{l}
$$

where $C R$ is the cost of relocating an individual (\$/person) and $V A L W_{l}$ is the value of wealth for nonfarm property (\$/person) in spatial element $l$. The variables $C R$ and $V A L W_{l}$ have been discussed previously in conjunction with Eqs. (23), (25) and (26). The cost $C C F_{l}(\$ / \mathrm{Ha})$ to condemn farmland in spatial element $l$ is the value of farm wealth in the spatial element, which is determined by the MACCS input variable VFRM as indicated in Table 8. 
THIS PAGE INTENTIONALLY LEFT BLANK 


\section{PROBLEM FOR ANALYSIS}

To facilitate comparisons across analyses, this study and its two companion uncertainty/sensitivity studies $^{5,6}$ use the same source term. In particular, the source term SUR-11-3 from the NUREG-1150 probabilistic risk assessment ${ }^{7}$ for the Surry Nuclear Power Station ${ }^{8,9}$ is used. This source term results from a steam generator tube rupture and is listed in Table 2 of Ref. 5. The following chemical group release fractions are associated with this source term: Noble gases $\sim 1.0$, Iodine $\sim 0.47$, Cesium $\sim$ 0.45 , Tellurium $\sim 0.25$, Strontium $\sim 0.07$, Ruthenium $\sim 0.002$, Lanthanum $\sim 0.006$, Cerium $\sim 0.008$, and Barium $\sim 0.06$.

The performance of a MACCS calculation requires a large amount of input. The development of this input for use in the NUREG-1150 analyses is documented in Sprung et al., ${ }^{32}$ with the actual MACCS input files used in the NUREG-1150 analyses for Surry appearing in Appendix A of the indicated report. The MACCS input for Surry described in Sprung et al ${ }^{32}$ and summarized in Section 2 of this report is taken as the base-line description for the analysis problem considered in this study. Taken collectively, this input corresponds to the vector $x$ shown in Eqs. (2) and (3). An overview of the analysis assumptions used in MACCS for the analyses contained in this presentation is given in Table 3 of Ref. 5.

After a review of the results in Sprung et al. ${ }^{32}$ and descriptions of the food pathways models in MACCS, ${ }^{2,3}$ the 87 variables listed in Table 9 were selected for consideration in this study. The distributions associated with the individual variables characterize subjective uncertainty and thus correspond to the distributions shown in Eq. (4). When done carefully, the development of such distributions is a very demanding task and requires detailed knowledge of the operation of the model under consideration, extensive literature review, and interaction with many individual investigators who are knowledgeable about the individual variables. The ranges in Table 9 were developed by the investigators in this study and are not the result of a comprehensive review process. In particular, ranges were obtained for each variable by applying a multiplicative scale factor to a central or "best-estimate" value. For example, the best-estimate value for AF (fraction of intercepted radionuclides undergoing rapid weathering from crop surfaces for pasture, forage, green leafy vegetables and "other" food) was assigned a best-estimate value of 0.2 , with an uncertainty scale factor of 1.25 . In turn, this produced an uncertainty range for $\mathrm{AF}$ from $0.2 / 1.25=0.16$ to $0.2(1.25)=0.25$. All variables listed in Table 9 were assigned log uniform distributions, which assured both the full coverage of the range of each uncertain variable and an equal probability for values of a variable above and below the best-estimate value. The intent is for this preliminary assessment of subjective uncertainty to help identify the most important contributors to the (subjective) uncertainty in MACCS results. Then, efforts can be focused on characterizing the uncertainty in the inputs that have significant impacts on the uncertainty in predictions made by MACCS.

The correlations indicated in Table 9 are rank correlations, which provide a measure of the extent to which variables tend to move up and down together. ${ }^{42,43}$ Rank correlations also have the desirable property that they are independent of the distributions assigned to the individual variables. The assigned correlations result from the belief that many MACCS input variables are not independent but are rather influenced by common underlying variables: The reactor accident consequences selected in this study are listed in Table 10. The predicted values for these consequences constitute the elements of the vector $c S_{i}$ appearing in Eq. (1). 
Problem for Analysis

Table 9. Imprecisely Known Variables Selected for Inclusion in an Uncertainty/Sensitivity Study of the MACCS Food Pathways Model

\begin{tabular}{|c|c|}
\hline Variable & Description \\
\hline $\mathrm{AF}$ & $\begin{array}{l}\text { Fraction of intercepted radionuclides undergoing rapid weathering from crop surfaces for } \\
\text { pasture, forage, green leafy vegetables and "other" food. Used in definition of MACCS } \\
\text { variable CTCOEF1 for weathering of radionuclides from pasture, forage, green leafy } \\
\text { vegetables and "other" food; see IF1, IF2, IF5, IF7. Range: } 0.16-0.25 \text { (i.e., } 0.2 \times 1.25 \text { ). } \\
\text { Additional information: Sec. } 4.3 \text {, Ref. } 32 \text {; Sec. } 3.2 .4 \text {, Ref.2. }\end{array}$ \\
\hline C1GCS & $\begin{array}{l}\text { Fraction of cesium deposition onto grain fields that is retained on plant surfaces and } \\
\text { transferred directly to grain. Defines MACCS variable CTCOEF } 1 \text { for weathering of } \\
\text { cesium from grain, which in conjunction with an infinite (i.e., } 1 \times 10^{6} \text { yr) weathering } \\
\text { halflife produces a transfer factor rather than a weathering term. Range: } 0.025-0.1 \text { (i.e., } \\
0.05 \times 2 \text { ). Additional information: p. A-25, Appendix A, Ref. } 32 \text {. }\end{array}$ \\
\hline C1GSR & Same as C1GCS but for strontium. Range: $0.005-0.02$ (i.e., $0.01 \times 2$ ). \\
\hline C1LCS & Same as C1GCS but for legumes. Range: $0.005-0.02$ (i.e., $0.01 \times 2$ ). \\
\hline CILSR & Same as C1GSR but for legumes. Range: $0.0025-0.01$ (i.e., $0.005 \times 2$ ). \\
\hline C1RCS & Same as C1GCS but for roots and tubers. Range: $0.0125-0.05$ (i.e., $0.025 \times 2$ ). \\
\hline CIRSR & Same as C1GSR but for roots and tubers: Range: $0.0003-0.0012$ (i.e., $0.006 \times 2$ ). \\
\hline CDELAY & $\begin{array}{l}\text { Time (days) from slaughter of animal to consumption of meat. Used in definition of } \\
\text { MACCS variable DCYPBH. Range: } 16-25 \text { days (i.e., } 20 \text { days } \times 1.25 \text { ). Additional } \\
\text { information: Sec. } 4.3 .2 \text {, Ref. } 32 \text {; Sec. } 3.2 .4 \text {, Ref. } 2 \text {. }\end{array}$ \\
\hline CTHALF 1 & $\begin{array}{l}\text { Halflife (days) for rapid weathering of deposited radionuclides from plant surfaces. Defines } \\
\text { MACCS variable CTHALF for pasture, forage, grain, green leafy vegetables and "other" } \\
\text { foods. Range: } 11.2-17.5 \text { days (i.e., } 14 \text { days } \times 1.25) \text {. Additional information: Same as } \\
\text { AF. }\end{array}$ \\
\hline CTHALF2 & $\begin{array}{l}\text { Same as CTHALF1 but for slow weathering. Range: } 40-62.5 \text { days (i.e., } 50 \text { days } \times \\
1.25 \text { ). }\end{array}$ \\
\hline FDELAY & $\begin{array}{l}\text { Time (days) from harvest of forage to consumption by cattle. Used in definition of } \\
\text { MACCS variables DCYPCB, DCYPCM. Range: } 73.6-115 \text { days (i.e., } 92 \text { days } \times 1.25 \text { ). } \\
\text { Additional information: Sec. } 4.3 .3 \text {, Ref. } 32 \text {; Sec. } 3.2 .4 \text {, Ref. } 2 \text {. }\end{array}$ \\
\hline FPLSCHG & $\begin{array}{l}\text { Fraction of radionuclides present in grain at harvest that is retained until consumption by } \\
\text { man. Does not account for losses due to radioactive decay. Defines MACCS variable } \\
\text { FPLSCH for grains. Range: } 0.2-0.31 \text { (i.e., } 0.25 \times 1.25 \text { ). Additional information: Sec. } \\
\text { 4.3.6, Ref. } 32 \text {; Sec. } 3.2 .4 \text {, Ref. } 2 \text {. }\end{array}$ \\
\hline FPLSCHL & Same as FPLSCHG but for legumes. Range: $0.64-1.0$ (i.e., $0.8 \times 1.25$ ). \\
\hline FPLSCHO & Same as FPLSCHG but for "other" foods. Range: $0.568-0.888$ (i.e., $0.75 \times 1.25$ ). \\
\hline
\end{tabular}


Table 9 (continued)

\begin{tabular}{|c|c|}
\hline Variable & Description \\
\hline FPLSCHR & Same as FPLSCHG but for roots and tubers. Range: $0.64-1.0$ (i.e., $0.8 \times 1.25$ ). \\
\hline FPLSCHV & Same FPLSCHG but for green leafy vegetables. Range: $0.4-0.625$ (i.e., $0.5 \times 1.25$ ). \\
\hline FRCTCMF & $\begin{array}{l}\text { Fraction of forage consumed by milk-producing animals. MACCS variables FRCTCM and } \\
\text { FRCTCB for consumption of forage by milk- and meat-producing animals defined by } \\
\text { FRCTCMF and 1-FRCTCMF, respectively. Range: } 0.104-0.163 \text { (i.e., } 0.13 \times 1.25 \text { ). } \\
\text { Additional information: Sec. } 4.3 .7 \text {, Ref. 32; Sec. } 3.2 .4 \text {, Ref.2. }\end{array}$ \\
\hline FRCTCMG & $\begin{array}{l}\text { Fraction of grain consumed by milk-producing animals. MACCS variables FRCTCM and } \\
\text { FRCTCB for consumption of grain by milk- and meat-producing animals defined by } \\
\text { FRCTCMG and 1-FRCTCMG-FRCTCHG, respectively. Range: } 0.032-0.05 \text { (i.e., } 0.04 \\
\times 1.25 \text { ). Additional information: Same as FRCTCMF. }\end{array}$ \\
\hline FRCTCML & $\begin{array}{l}\text { Same as FRCTCMG but for legumes, with FRCTCHL used in the definition of MACCS } \\
\text { variaable FRCTCB for consumption of legumes by meat-producing animals. Range: } 0.0368 \\
-0.0575(\text { i.e., } 0.046 \times 1.25) \text {. }\end{array}$ \\
\hline FRCTCMP & Same as FRCTCMF but for pasture. Range: $0.08-0.125$ (i.e., $0.01 \times 1.25$ ). \\
\hline FRCTCHG & $\begin{array}{l}\text { Fraction of grain consumed by humans. Defines MACCS variable FRCTCH for } \\
\text { consumption of grain by humans. Range: } 0.28-0.438 \text { (i.e., } 0.35 \times 1.25 \text { ). Additional } \\
\text { information: Same as FRCTCMF. }\end{array}$ \\
\hline FRCTCHL & Same as FRCTCHG but for legumes. Range: $0.192-0.3$ (i.e., $0.24 \times 1.25$ ). \\
\hline GCMSR89 & $\begin{array}{l}\text { Maximum allowable } S r 89 \text { ground concentration }\left(\mathrm{Bq} / \mathrm{m}^{2}\right) \text { for production of crops that assures } \\
\text { the lifetime dose criteria will be met (i.e., the Federal Department of Agriculture protective } \\
\text { action guide that the long-term doses to the thyroid and the whole body should be less than } \\
\left.0.015 \mathrm{~Sv} \text { and } 0.005 \mathrm{~Sv} \text {, respectively } \mathrm{y}^{44}\right) \text {. Defines MACCS variable GCMAXR for Sr90. } \\
\left.\text { Range: } 1.79 \times 10^{7}-1.79 \times 10^{9} \mathrm{~Bq} / \mathrm{m}^{2} \text { (i.e., } 1.79 \times 10^{8} \mathrm{~Bq} / \mathrm{m}^{2} \times 10\right) \text {. Correlation: } 0.75 \\
\text { rank correlation with GCMSR90; }-0.5 \text { rank correlation with TCPSR89, TCPSR90, } \\
\text { TCFSR89, TCFSR90, TCGSR89, TCGSR90, TCLSR89, TCLSR90, TCVSR89, } \\
\text { TCVSR90, TCRSR89, TCRSR90, TCOSR89, TCOSR90. Additional information: Sec. } \\
\text { 4.4, Ref. 32; Appendix C, Ref. } 2 \text {. }\end{array}$ \\
\hline GCMSR90 & $\begin{array}{l}\text { Same as GCMSR89 but for Sr90. Range: } 3.67 \times 10^{3}-3.67 \times 10^{5} \mathrm{~Bq} / \mathrm{m}^{2}(\text { i.e., } 3.67 \times \\
\left.10^{4} \mathrm{~Bq} / \mathrm{m}^{2} \times 10\right) \text {. Correlation: } 0.75 \text { rank correlation with GCMSR } 89 ;-0.5 \text { rank correlation } \\
\text { with TCPSR89, TCPSR90, TCFSR89, TCFSR90,TCGSR89, TCGSR90, TCLSR89, } \\
\text { TCLSR90, TCVSR89, TCVSR90, TCRSR89, TCRSR90, TCOSR89, TCOSR90. }\end{array}$ \\
\hline GCMCS134 & $\begin{array}{l}\text { Same as GCMSR89 but for Cs134. Range: } 4.07 \times 10^{5}-4.07 \times 10^{7} \mathrm{~Bq} / \mathrm{m}^{2} \text { (i.e., } 4.07 \times \\
\left.10^{6} \mathrm{~Bq} / \mathrm{m}^{2} \times 10\right) \text {. Correlation: } 0.75 \text { rank correlation with GCMCS137; }-0.5 \text { rank } \\
\text { correlation with TCPCS134, TCPCS137, TCFCS134, TCFCS137, TCGCS134, } \\
\text { TCGCS137, TCLCS134, TCLCS137, TCVCS134, TCVCS137, TCRCS134, TCRCS137, } \\
\text { TCOC134, TCOCS137. }\end{array}$ \\
\hline
\end{tabular}


Problem for Analysis

Table 9 (continued)

\begin{tabular}{|c|c|}
\hline Variable & Description \\
\hline GCMCS137 & $\begin{array}{l}\text { Same as GCMSR89 but for Cs137. Range: } 1.76 \times 10^{5}-1.76 \times 10^{7} \mathrm{~Bq} / \mathrm{m}^{2} \text { (i.e., } 1.76 \times \\
10^{6} \mathrm{~Bq} / \mathrm{m}^{2} \times 10 \text { ). Correlation: } 0.75 \text { rank correlation with GCMCS134; }-0.5 \text { rank } \\
\text { correlation with TCPCS134, TCPCS137, TCFCS134, TCFCS137, TCGS134, TCGCS137, } \\
\text { TCLCS134, TCLCS137, TCVCS134, TCVCS137, TCRCS134, TCRCS137, TCOC134, } \\
\text { TCOCS137. }\end{array}$ \\
\hline GDELAY & $\begin{array}{l}\text { Time (days) from harvest of grain to consumption. Used in definition of MACCS variables } \\
\text { DCYPCB, DCYPCM, DCYPCH for reduction of radioactivity in grain between harvest and } \\
\text { consumption. Range: } 148-231 \text { days (i.e., } 182 \text { days } \times 1.25 \text { ). Additional information: } \\
\text { Same as FDELAY. }\end{array}$ \\
\hline IF1 & $\begin{array}{l}\text { Fraction of initial radionuclide deposition onto pasture that is retained on plant surfaces. } \\
\text { MACCS variables CTCOEF } 1 \text { and CTCOEF2 for fraction of radionuclide deposition onto } \\
\text { pasture that is retained on plant surfaces and undergoes rapid and slow weathering, } \\
\text { respectively, are defined by AF•IF1 and ( } 1-\text { AF) IF1. Range: } 0.304-0.475 \text { (i.e., } 0.38 \times \\
\text { 1.25). Additional information: Same as AF. }\end{array}$ \\
\hline IF2 & Same as IF1 but for forage. Range: $0.2-0.313$ (i.e., $0.25 \times 1.25$ ). \\
\hline IF5 & Same as IF1 but for green leafy vegetables. Range: $0.24-0.375$ (i.e., $0.3 \times 1.25$ ). \\
\hline IF7 & Same as IF1 but for "other" foods. Range: $0.2-0.313$ (i.e., $0.25 \times 1.25$ ). \\
\hline LDELAY & Same as GDELAY but for legumes. Range: $148-231$ days (i.e., 182 days $\times 1.25$ ). \\
\hline ODELAY & Same as GDELAY but for "other" foods. Range: $137-214$ days (i.e., 171 days $\times 1.25$ ). \\
\hline MDELAY & $\begin{array}{l}\text { Time (days) from production of milk to consumption. Used in definition of MACCS } \\
\text { variable DCYPMH. Range: } 16.8-26.2 \text { days (i.e., } 21 \text { days } \times 1.25 \text { ). Additional } \\
\text { information: Sec. } 4.3 .5 \text {, Ref. 32; Sec. } 3.2 .4 \text {, Ref. } 2 \text {. }\end{array}$ \\
\hline PSMCS134 & 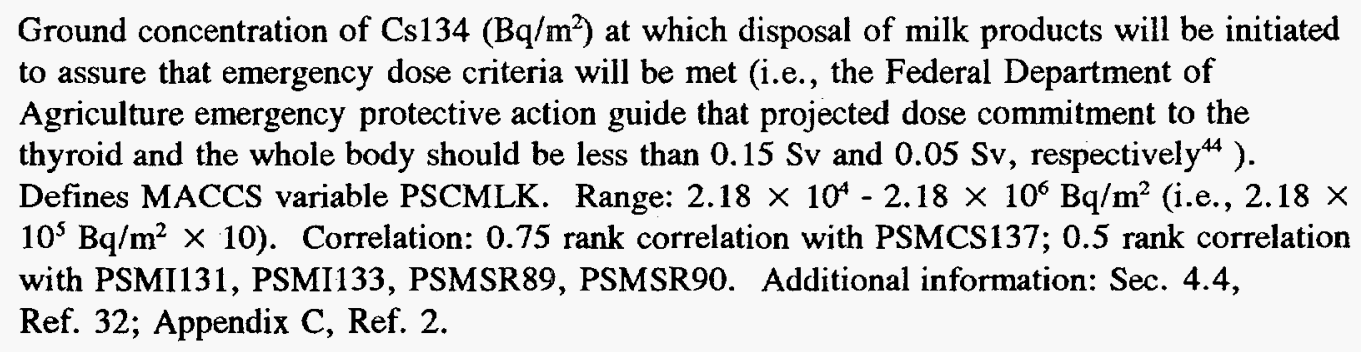 \\
\hline PSMCS137 & $\begin{array}{l}\text { Same as PSMCS134 but for Cs137. Range: } 2.66 \times 10^{4}-2.66 \times 10^{6} \mathrm{~Bq} / \mathrm{m}^{2} \text { (i.e., } 2.66 \times \\
\left.10^{5} \mathrm{~Bq} / \mathrm{m}^{2} \times 10\right) \text {. Correlation: } 0.75 \text { rank correlation with PSMCS134; } 0.5 \text { rank correlation } \\
\text { with PSMI131, PSMI133, PSMSR89, PSMSR90. }\end{array}$ \\
\hline PSMI131 & $\begin{array}{l}\text { Same as PSMCS134 but for I131. Range: } 1.34 \times 10^{5}-1.34 \times 10^{7} \mathrm{~Bq} / \mathrm{m}^{2} \text { (i.e., } 1.34 \times \\
10^{6} \mathrm{~Bq} / \mathrm{m}^{2} \times 10 \text { ). Correlation: } 0.75 \text { rank correlation with PSMI133; } 0.5 \text { rank correlation } \\
\text { with PSMCS134, PSMCS137, PSMSR89, PSMSR90. }\end{array}$ \\
\hline
\end{tabular}


Table 9 (continued)

\begin{tabular}{|c|c|}
\hline Variable & Description \\
\hline PSMI133 & $\begin{array}{l}\text { Same as PSMCS134 but for } 1133 \text {. Range: } 1.05 \times 10^{9}-1.05 \times 10^{11} \mathrm{~Bq} / \mathrm{m}^{2} \text { (i.e., } 1.05 \times \\
10^{10} \mathrm{~Bq} / \mathrm{m}^{2} \times 10 \text { ). Correlation: } 0.75 \text { rank correlation with PSMI131;0.5 rank correlation } \\
\text { with PSMCS134, PSMCS137, PSMSR89, PSMSR90. }\end{array}$ \\
\hline PSMSR89 & $\begin{array}{l}\text { Same as PSMCS134 but for Sr89. Range: } 2.16 \times 10^{6}-2.16 \times 10^{8} \mathrm{~Bq} / \mathrm{m}^{2} \text { (i.e., } 2.16 \times \\
10^{7} \mathrm{~Bq} / \mathrm{m}^{2} \times 10 \text { ). Correlation: } 0.75 \text { rank correlation with PSMSR90; } 0.5 \text { rank correlation } \\
\text { with PSMCS134, PSMCS137, PSMI131, PSMI133. }\end{array}$ \\
\hline PSMSR90 & $\begin{array}{l}\text { Same as PSMCS134 but for Sr90. Range: } 2.41 \times 10^{4}-2.41 \times 10^{6} \mathrm{~Bq} / \mathrm{m}^{2} \text { (i.e., } 2.41 \times \\
10^{5} \mathrm{~Bq} / \mathrm{m}^{2} \times 10 \text { ). Correlation: } 0.75 \text { rank correlation with PSMSR } 89 ; 0.5 \text { rank correlation } \\
\text { wit PSMCS134, PSMCS137, PSMI131, PSMI133. }\end{array}$ \\
\hline PSOCS134 & $\begin{array}{l}\text { Ground concentration of Cs134 }\left(\mathrm{Bq} / \mathrm{m}^{2}\right) \text { at which disposal of crops will be initiated to assure } \\
\text { that emergency dose criteria are met (see PSMCS134). Defines MACCS variable } \\
\left.\text { PSCOTH. Range: } 2.16 \times 10^{6}-2.16 \times 10^{8} \mathrm{~Bq} / \mathrm{m}^{2} \text { (i.e., } 2.16 \times 10^{7} \mathrm{~Bq} / \mathrm{m}^{2} \times 10\right) \text {. } \\
\text { Correlation: } 0.75 \text { rank correlation with PSOCS137; 0.5 rank correlation with PSOI131, } \\
\text { PSOI133, PSOSR89, PSOSR90. Additional information: Same as PSMCS134. }\end{array}$ \\
\hline PSOCS137 & $\begin{array}{l}\text { Same as PSOCS134 but for Cs137. Range: } 2.66 \times 10^{9}-2.66 \times 10^{11} \mathrm{~Bq} / \mathrm{m}^{2} \text { (i.e., } 2.66 \times \\
10^{10} \mathrm{~Bq} / \mathrm{m}^{2} \times 10 \text { ). Correlation: } 0.75 \text { rank correlation with PSOCS134; } 0.5 \text { rank correlation } \\
\text { with PSOI131, PSOI133, PSOSR89, PSOSR90. }\end{array}$ \\
\hline PSOI131 & $\begin{array}{l}\text { Same as PSOCS134 but for I131. Range: } 7.95 \times 10^{5}-7.95 \times 10^{7} \mathrm{~Bq} / \mathrm{m}^{2} \text { (i.e., } 7.95 \times \\
10^{6} \mathrm{~Bq} / \mathrm{m}^{2} \times 10 \text { ). Correlation: } 0.75 \text { rank correlation with PSOI133; } 0.5 \text { rank correlation } \\
\text { with PSOCS134, PSOCS137, PSOSR89, PSOSR90. }\end{array}$ \\
\hline PSOI133 & $\begin{array}{l}\text { Same as PSOCS134 but for I133. Range: } 1.02 \times 10^{10}-1.02 \times 10^{12} \mathrm{~Bq} / \mathrm{m}^{2} \text { (i.e., } 1.02 \times \\
10^{11} \mathrm{~Bq} / \mathrm{m}^{2} \times 10 \text { ). Correlation: } 0.75 \text { rank correlation with PSOI131; } 0.5 \text { rank correlation } \\
\text { with PSOCS134, PSOCS137, PSOSR89, PSOSR90. }\end{array}$ \\
\hline PSOSR89 & $\begin{array}{l}\text { Same as PSOCS134 but for Sr89. Range: } 2.16 \times 10^{6}-2.16 \times 10^{8} \mathrm{~Bq} / \mathrm{m}^{2} \text { (i.e., } 2.16 \times \\
10^{7} \mathrm{~Bq} / \mathrm{m}^{2} \times 10 \text { ). Correlation: } 0.75 \text { rank correlation with PSOSR90; } 0.5 \text { rank correlation } \\
\text { with PSOCS134, PSOCS137, PSOI131, PSOI133. }\end{array}$ \\
\hline PSOSR90 & $\begin{array}{l}\text { Same as PSOCS134 but for Sr90. Range: } 2.41 \times 10^{4}-2.41 \times 10^{6} \mathrm{~Bq} / \mathrm{m}^{2} \text { (i.e., } 2.41 \times \\
10^{5} \mathrm{~Bq} / \mathrm{m}^{2} \times 10 \text { ). Correlation: } 0.75 \text { rank correlation with PSOSR } 89 ; 0.5 \text { rank correlation } \\
\text { with PSOCS134, PSOCS137, PSOI131, PSOI133. }\end{array}$ \\
\hline QRCS134 & $\begin{array}{l}\text { Rate of depletion }\left(\mathrm{yr}^{-1}\right) \text { of Cs134 from the root zone (includes radioactive decay, percolation } \\
\text { into soil below root zone, irreversible binding with soil components). Used in } \\
\text { determination of interdiction period for farmland before crops can be grown without } \\
\text { violating the Federal Department of Agriculture lifetime dose criteria (see GCMSR89). } \\
\text { Defines MACCS variable QROOT. Range: } 0.059-5.9 \mathrm{yr}^{-1} \text { (i.e., } 0.59 \mathrm{yr}^{-1} \times 10 \text { ). } \\
\text { Correlation: } 0.75 \text { rank correlation with QRCS137; -0.5 rank correlation TCFCS134, } \\
\text { TCFCS137, TCGCS134, TCGCS137, TCLCS134,TCLCS137, TCOCS134, TCOCS137, } \\
\text { TCPCS134, TCPCS137, TCRCS134, TCRCS137, TCVCS134, TCVCS137. Additional } \\
\text { information: Sec. } 4.4 .2 \text {, Ref. 32; Sec. 3.2.4, Ref.2. }\end{array}$ \\
\hline
\end{tabular}


Problem for Analysis

Table 9 (continued)

\begin{tabular}{|c|c|}
\hline Variable & Description \\
\hline QRCS137 & $\begin{array}{l}\text { Same as QRCS134 but for Cs137. Range: } 0.028-2.8 \mathrm{yr}^{-1} \text { (i.e., } 0.28 \mathrm{yr}^{-1} \times 10 \text { ). } \\
\text { Correlation: } 0.75 \text { rank correlation with QRCS134; }-0.5 \text { rank correlation with same variables } \\
\text { as QRCS134. }\end{array}$ \\
\hline QRSR90 & $\begin{array}{l}\text { Same as QRCS134 but for Sr90. Range: } 0.0065-0.65 \mathrm{yr}^{-1}\left(\mathrm{i} . \mathrm{e} ., 0.065 \mathrm{yr}^{-1} \times 10\right) \text {. } \\
\text { Correlation: }-0.5 \text { rank correlation with TCFSR89, TCFSR90, TCGSR89, TCGSR90, } \\
\text { TCLSR89, TCLSR90, TCOSR89, TCOSR90, TCPSR89, TCPSR90, TCRSR89, TCRSR90, } \\
\text { TCVSR89, TCVSR90. }\end{array}$ \\
\hline RDELAY & $\begin{array}{l}\text { Same as GDELAY but for roots and tubers. Range: } 146-228 \text { days (i.e., } 182 \text { days } \times \\
1.25 \text { ). }\end{array}$ \\
\hline TCFCS134 & $\begin{array}{l}\text { Ratio Cs134 transferred to forage due to root uptake and resuspension and Cs134 deposition } \\
\text { to soil surface (units: Bq/Bq). Numerator in ratio (i.e., Cs134 transferred to forage) is an } \\
\text { integrated quantity in the sense that it equals the total transfer to forage over all years } \\
\text { subsequent to the deposition and thus incorporates effects due to radioactive decay, } \\
\text { percolation into soil below root zone, irreversible binding with soil, and efficiency of root } \\
\text { uptake. Defines MACCS variable TCROOT. Range: } 7.1 \times 10^{-3}-7.1 \times 10^{-5} \text { (i.e., } 7.1 \times \\
10^{-4} \times 10 \text { ). Correlation: } 0.75 \text { rank correlation with TCFCS137, TCGCS134, TCGCS137, } \\
\text { TCLCS134, TCLCS137, TCOCS134, TCOCS137, TCPCS134, TCPCS137, TCRCS134, } \\
\text { TCRCS137, TCVCS134, TCVCS137; - }-0.5 \text { rank correlation with QRCS134, QRCS137. } \\
\text { Additional information: Sec. } 4.3 .8 \text {, Ref. 32; Sec. 3.2.4, Ref. } 2 \text {. }\end{array}$ \\
\hline TCFCS137 & $\begin{array}{l}\text { Same as TCFCS134 but for Cs137. Range: } 1.5 \times 10^{-4}-1.5 \times 10^{-2} \text { (i.e., } 1.5 \times 10^{-3} \times \\
\text { 10). Correlation: } 0.75 \text { rank correlation with TCFCS134, TCGCS134, TCGCS137, } \\
\text { TCLCS134, TCLCS137, TCOCS134, TCOCS137, TCPCS134, TCPCS137, TCRCS134, } \\
\text { TCRCS137, TCVCS134, TCVCS137; -0.5 rank correlation with QRCS134, QRCS137. }\end{array}$ \\
\hline TCFSR89 & $\begin{array}{l}\text { Same as TCFCS134 but for Sr89. Range: } 1.3 \times 10^{-4}-1.3 \times 10^{-2} \text { (i.e., } 1.3 \times 10^{-3} \times 10 \text { ). } \\
\text { Correlation: } 0.75 \text { rank correlation with TCFSR90; } 0.5 \text { rank correlation with TCGSR89, } \\
\text { TCGSR90, TCLSR89, TCLSR90, TCOSR89, TCOSR90, TCPSR89, TCPSR90, TCRSR89, } \\
\text { TCRS90, TCVSR89, TCVSR90; -0.5 rank correlationwith QRSR90. }\end{array}$ \\
\hline TCFSR90 & $\begin{array}{l}\text { Same as TCFCS134 but for Sr90. Range: } 9 \times 10^{-3}-0.9 \times 10^{-1}\left(\text { i.e., } 9 \times 10^{-2} \times 10\right) \text {. } \\
\text { Correlation: } 0.75 \text { rank correlation with TCFSR } 89 ; 0.5 \text { and }-0.5 \text { rank correlation with same } \\
\text { variables as TCFSR } 89 \text {. }\end{array}$ \\
\hline TCGCS134 & $\begin{array}{l}\text { Same as TCFCS134 but for grain. Range: } 3.5 \times 10^{-6}-3.5 \times 10^{-4} \text { (i.e., } 3.5 \times 10^{-5} \times 10 \text { ), } \\
\text { Correlation: } 0.75 \text { rank correlation with TCFCS134, TCFCS137, TCGCS137, TCLCS134, } \\
\text { TCLCS137, TCOCS134, TCOCS137, TCPCS134, TCPCS137, TCRCS134, TCRCS137, } \\
\text { TCVCS134, TCVCS137; -0.5 rank correlation with QRCS134, QRCS137. }\end{array}$ \\
\hline TCGCS137 & $\begin{array}{l}\text { Same as TCFCS134 but for Cs137 and grain. Range: } 7.6 \times 10^{-6}-7.6 \times 10^{-4}(\text { i.e., } 7.6 \times \\
\left.10^{-5} \times 10\right) \text {. Correlation: } 0.75 \text { rank correlation with TCFCS134, TCFCS137, TCGCS134, } \\
\text { TCLCS134, TCLCS137, TCOCS134, TCOCS137, TCPCS134, TCPCS137, TCRCS134, } \\
\text { TCRCS137, TCVCS134, TCVCS137; -0.5 rank correlation with QRCS134, QRCS137. }\end{array}$ \\
\hline
\end{tabular}


Table 9 (continued)

\begin{tabular}{|c|c|}
\hline Variable & Description \\
\hline TCGSR89 & $\begin{array}{l}\text { Same as TCFCS134 but for Sr89 and grain. Range: } 4.3 \times 10^{-6}-4.3 \times 10^{-4} \text { (i.e., } 4.3 \times \\
10^{-5} \times 10 \text { ). Correlation: } 0.75 \text { rank correlation with TCGSR90; } 0.5 \text { rank correlation with } \\
\text { TCFSR89, TCFSR90, TCLSR89, TCLSR90, TCOSR89, TCOSR90, TCPSR89, TCPSR90, } \\
\text { TCRSR89, TCRSR90, TCVSR89, TCVSR90; }-0.5 \text { rank correlation with QRSR90. }\end{array}$ \\
\hline TCGSR90 & $\begin{array}{l}\text { Same as TCFCS } 134 \text { but for Sr90 and grain. Range: } 3.3 \times 10^{-4}-3.3 \times 10^{-2} \text { (i.e., } 3.3 \times \\
10^{-3} \times 10 \text { ). Correlation: } 0.75 \text { rank correlation with TCGSR89; } 0.5 \text { and }-0.5 \text { rank } \\
\text { correlation with same variables as TCGSR89. }\end{array}$ \\
\hline TCLCS134 & $\begin{array}{l}\text { Same as TCFCS134 but for legumes. Range: } 9.3 \times 10^{-4}-9.3 \times 10^{-6}\left(\text { i.e., } 9.3 \times 10^{-5} \times\right. \\
\text { 10). Correlation: } 0.75 \text { rank correlation with TCFCS134, TCFCS137, TCGCS134, } \\
\text { TCGCS137, TCLCS137, TCOCS134, TCOCS137, TCPCS134, TCPCS137, TCRCS134, } \\
\text { TCRCS137, TCVCS134, TCVCS137; -0.5 rank correlation with QRCS134, QRCS137. }\end{array}$ \\
\hline TCLCS137 & $\begin{array}{l}\text { Same as TCFCS134 but for Cs137 and legumes. Range: } 2 \times 10^{-5}-2 \times 10^{-3} \text { (i.e., } 2 \times \\
\left.10^{-4} \times 10\right) \text {. Correlation: } 0.75 \text { rank correlation with TCFCS134, TCFCS137, TCGCS134, } \\
\text { TCGCS137, TCLCS134, TCOCS134, TCOCS137, TCPCS134, TCPCS137, TCRCS134, } \\
\text { TCRCS137, TCVCS134, TCVCS137; }-0.5 \text { rank correlation with QRCS134, QRCS137. }\end{array}$ \\
\hline TCLSR89 & $\begin{array}{l}\text { Same as TCFCS134 but for Sr89 and legumes. Range: } 3.7 \times 10^{-5}-3.7 \times 10^{-3} \text { (i.e., } 3.7 \\
\times 10^{-4} \times 10 \text { ). Correlation: } 0.75 \text { rank correlation with TCLSR90; } 0.5 \text { rank correlation with } \\
\text { TCFSR89, TCFSR90, TCGSR89, TCGSR90, TCOSR89, TCOSR90, TCPSR89, TCPSR90, } \\
\text { TCRSR89, TCRSR90, TCVSR89, TCVSR90; -0.5 rank correlation with QRSR90. }\end{array}$ \\
\hline TCLSR90 & $\begin{array}{l}\text { Same as TCFCS134 but for Sr90 and legumes. Range: } 2.8 \times 10^{-3}-2.8 \times 10^{-1} \text { (i.e., } 2.8 \\
\times 10^{-2} \times 10 \text { ). Correlation: } 0.75 \text { rank correlation with TCLSR89;0.5 and }-0.5 \text { rank } \\
\text { correlation with same variables as TCLSR89. }\end{array}$ \\
\hline TCOCS134 & $\begin{array}{l}\text { Same as TCFCS134 but for "other" foods. Range: } 1.1 \times 10^{-5}-1.1 \times 10^{-3} \text { (i.e., } 1.1 \times \\
\left.10^{-4} \times 10\right) \text {. Correlation: } 0.75 \text { rank correlation with TCFCS134, TCFCS137, TCGCS134, } \\
\text { TCGCS137, TCLCS134, TCLCS137, TCOCS137, TCPCS134, TCPCS137, TCRCS134, } \\
\text { TCRCS137, TCVCS134, TCVCS137; -0.5 rank correlation with QRCS134, QRCS137. }\end{array}$ \\
\hline TCOCs 137 & $\begin{array}{l}\text { Same as TCFCS134 but for Cs137 and "other" foods. Range: } 2.3 \times 10^{-5}-2.3 \times 10^{-3} \\
\text { (i.e., } 2.3 \times 10^{-4} \times 10 \text { ). Correlation: } 0.75 \text { rank correlation with TCFCS134, TCFCS137, } \\
\text { TCGCS134, TCGCS137, TCLCS134, TCLCS137, TCOCS134, TCPCS134, TCPCS137, } \\
\text { TCRCS134, TCRCS137, TCVCS134, TCVCS137; -0.5 rank correlation with QRCS134, } \\
\text { QRCS137. }\end{array}$ \\
\hline TCOSR89 & $\begin{array}{l}\text { Same as TCFCS134 but for Sr89 and "other" foods. Range: } 8 \times 10^{-7}-8 \times 10^{-5}(\text { i.e., } 8 \times \\
10^{-6} \times 10 \text {. Correlation: } 0.75 \text { rank correlation with TCOSR90; } 0.5 \text { rank correlation with } \\
\text { TCFSR89, TCFSR90, TCGSR89, TCGSR90, TCLSR89, TCLSR90, TCPSR89, TCPSR90, } \\
\text { TCRSR89, TCRSR90, TCVSR89, TCVSR90; }-0.5 \text { rank correlation with QRSR90. }\end{array}$ \\
\hline TCOSR90 & $\begin{array}{l}\text { Same as TCFCS134 but for Sr } 90 \text { and "other" foods. Range: } 6.6 \times 10^{-3}-6.6 \times 10^{-5} \text { (i.e., } \\
6.6 \times 10^{-4} \times 10 \text { ). Correlation: } 0.75 \text { rank correlation with TCOSR89; } 0.5 \text { and }-0.5 \text { rank } \\
\text { correlation with same variables as TCOSR89. }\end{array}$ \\
\hline
\end{tabular}


Problem for Analysis

Table 9 (continued)

\begin{tabular}{|c|c|}
\hline Variable & Description \\
\hline TCPCS134 & $\begin{array}{l}\text { Same as TCFCS134 but for pasture. Range: } 1.3 \times 10^{-4}-1.3 \times 10^{-2} \text { (i.e., } 1.3 \times 10^{-3} \times \\
\text { 10). Correlation: } 0.75 \text { rank correlation with TCFCS134, TCFCS137, TCGCS134, } \\
\text { TCGCS137, TCLCS134, TCLCS137, TCOCS134, TCOCS137, TCPCS137, TCRCS134, } \\
\text { TCRCS137, TCVCS134, TCVCS137; -0.5 rank correlation with QRCS134, QRCS137. }\end{array}$ \\
\hline TCPCS137 & $\begin{array}{l}\text { Same as TCFCS134 but for Cs137 and pasture. Range: } 6.9 \times 10^{-4}-6.9 \times 10^{-2} \text { (i.e., } 6.9 \\
\times 10^{-3} \times 10 \text { ). Correlation: } 0.75 \text { rank correlation with TCFCS134, TCFCS137, } \\
\text { TCGCS134, TCGCS137, TCLCS134, TCLCS137, TCOCS134, TCOCS137, TCPCS134, } \\
\text { TCRCS134, TCRCS137, TCVCS134, TCVCS137; -0.5 rank correlation with QRCS134, } \\
\text { QRCS137. }\end{array}$ \\
\hline TCPSR89 & $\begin{array}{l}\text { Same as TCFCS134 but for Sr89 and pasture. Range: } 4.1 \times 10^{-5}-4.1 \times 10^{-3} \text { (i.e., } 4.1 \times \\
10^{-4} \times 10 \text { ). Correlation: } 0.75 \text { rank correlation with TCPSR90; } 0.5 \text { rank correlation with } \\
\text { TCFSR89, TCFSR90, TCGSR89, TCGSR90, TCLSR89, TCLSR90, TCOSR89, } \\
\text { TCOSR90, TCRSR89, TCRSR90, TCVSR89, TCVSR90; -0.5 rank correlation with } \\
\text { QRSR90. }\end{array}$ \\
\hline TCPSR90 & $\begin{array}{l}\text { Same as TCFCS134 but for Sr90 and pasture. Range: } 2.6 \times 10^{-3}-2.6 \times 10^{-1} \text { (i.e., } 2.6 \times \\
10^{-2} \times 10 \text { ). Correlation: } 0.75 \text { rank correlation with TCPSR89; } 0.5 \text { and }-0.5 \text { rank } \\
\text { correlation with same variables as TCPSR89. }\end{array}$ \\
\hline TCRCS134 & $\begin{array}{l}\text { Same as TCFCS134 but for roots and tubers. Range: } 5.6 \times 10^{-6}-5.6 \times 10^{-4} \text { (i.e., } 5.6 \times \\
\left.10^{-5} \times 10\right) \text {. Correlation: } 0.75 \text { rank correlation with TCFCS134, TCFCS137, TCGCS134, } \\
\text { TCGCS137, TCLCS134, TCLCS137, TCOCS134, TCOCS137, TCPCS134, TCPCS137, } \\
\text { TCRCS137, TCVCS134, TCVCS137; -0.5 rank correlation with QRCS134, QRCS137. }\end{array}$ \\
\hline TCRCS137 & $\begin{array}{l}\text { Same as TCFCS134 but for Cs137 and roots and tubers. Range: } 1.2 \times 10^{-5}-1.2 \times 10^{-3} \\
\text { (i.e., } 1.2 \times 10^{-4} \times 10 \text { ). Correlation: } 0.75 \text { rank correlation with TCFCS134, TCFCS137, } \\
\text { TCGCS134, TCGCS137, TCLCS134, TCLCS137, TCOCS134, TCOCS137, TTCPCS134, } \\
\text { TCPCS137, TCRCS134, TCVCS134, TCVCS137; -05 rank correlation with QRCS134, } \\
\text { QRCS137. }\end{array}$ \\
\hline TCRSR89 & $\begin{array}{l}\text { Same as TCFCS134 but for Sr89 and roots and tubers. Range: } 1.1 \times 10^{-5}-1.1 \times 10^{-3} \\
\text { (i.e., } 1.1 \times 10^{-4} \times 10 \text { ). Correlation: } 0.75 \text { rank correlation with TCRSR90; } 0.5 \text { rank } \\
\text { correlation with TCFSR89, TCFSR90, TCGSR89, TCGSR90, TCLSR89, TCLSR90, } \\
\text { TCOSR89, TCOSR90, TCPSR89, TCPSR90, TCVSR89, TCVSR90; -0.5 rank correlation } \\
\text { with QRSR90. }\end{array}$ \\
\hline TCRSR90 & $\begin{array}{l}\text { Same as TCFCS } 134 \text { but for } \mathrm{Sr} 90 \text { and roots and tubers. Range: } 8.4 \times 10^{-4}-8.2 \times 10^{-2} \\
\text { (i.e., } 8.2 \times 10^{-3} \times 10 \text { ). Correlation: } 0.75 \text { correlation with TCRSR89; } 0.5 \text { and }-0.5 \text { rank } \\
\text { correlation with same variables as TCRSR89. }\end{array}$ \\
\hline TCVCS134 & $\begin{array}{l}\text { Same as TCFCS134 but for green leafy vegetables. Range: } 1.4 \times 10^{-6}-1.4 \times 10^{-4} \text { (i.e., } \\
1.4 \times 10^{-5} \times 10 \text { ). Correlation: } 0.75 \text { rank correlation with TCFCS134, TCFSC137, } \\
\text { TCGCS134, TCGCS137, TCLCS134, TCLCS137, TCOCS134, TCOCS137, TCPCS134, } \\
\text { TCPCS137, TCRCS134, TCRCS137, TCVCS137; -0.5 rank correlation with QRCS134, } \\
\text { QRCS137. }\end{array}$ \\
\hline
\end{tabular}




\begin{tabular}{|c|c|}
\hline Variable & Description \\
\hline TCVCS137 & $\begin{array}{l}\text { Same as TCFCS134 but for Cs137 and green leafy vegetables. Range: } 3 \times 10^{6}-3 \times 10^{-4} \\
\text { (i.e., } 3 \times 10^{-5} \times 5 \text { ). Correlation: } 0.75 \text { rank correlation with TCFCS134, TCFCS137, } \\
\text { TCGCS134, TCGCS137, TCLCS134, TCLCS137, TCOCS134, TCOCS137, TCPCS134, } \\
\text { TCPCS137, TCRCS134, TCRCS137, TCVCS134; }-0.5 \text { rank correlation with QRCS134, } \\
\text { QRCS137. }\end{array}$ \\
\hline TCVSR89 & $\begin{array}{l}\text { Same as TCFCS134 but for Sr89 and green leafy vegetables. Range: } 1.7 \times 10^{-5}-1.7 \times \\
\left.10^{-3} \text { (i.e., } 1.7 \times 10^{-4} \times 10\right) \text {. Correlation: } 0.75 \text { rank correlation with TCVSR90; } 0.5 \text { rank } \\
\text { correlation TCFSR89, TCFSR90, TCGSR89, TCGSR90, TCLSR89, TCLSR90, TCOSR89, } \\
\text { TCOSR90, TCPSR89, TCPSR90, TCRSR89, TCRSR90; -0.5 rank correlation with } \\
\text { QRSR90. }\end{array}$ \\
\hline TCVSR90 & $\begin{array}{l}\text { Same as TCFCS134 but for Sr90 and green leafy vegetables. Range: } 1.3 \times 10^{-3}-1.3 \times \\
10^{-1} \text { (i.e., } 1.3 \times 10^{-2} \times 10 \text { ). Correlation: } 0.75 \text { rank correlation with TCVSR } 89 ; 0.5 \text { and - } \\
0.5 \text { rank correlation with same variables as TCVSR } 89 \text {. }\end{array}$ \\
\hline TFBCS & $\begin{array}{l}\text { Ratio of amount of cesium in edible meat at time of slaughter to amount of cesium } \\
\text { consumed by meat producing animals. Defines MACCS variable TFBF for Cs134 and } \\
\text { Cs137. Range: } 4.8 \times 10^{-3}-1.2 \times 10^{-1} \text { (i.e., } 2.4 \times 10^{-2} \times 5 \text { ). Additional information: } \\
\text { Sec. } 4.3 .9 \text {, Ref. } 32 \text {; Sec. } 3.2 .4 \text {, Ref. } 2 \text {. }\end{array}$ \\
\hline TFBI131 & $\begin{array}{l}\text { Same as TFBCS but for I131. Defines MACCS variable TFBF for I131. Range: } 4.8 \times \\
10^{-4}-1.2 \times 10^{-2} \text { (i.e., } 2.4 \times 10^{-3} \times 5 \text { ). Correlation: } 0.75 \text { rank correlation with TFBI133. }\end{array}$ \\
\hline TFBI133 & $\begin{array}{l}\text { Same as TFBCS for I133. Defines MACCS variable TFBF for I133. Range: } 2.2 \times 10^{-4}- \\
5.5 \times 10^{-3}\left(\text { i.e., } 1.1 \times 10^{-3} \times 5\right) \text {. Correlation: } 0.75 \text { rank correlation with TFBI131. }\end{array}$ \\
\hline TFBSR & $\begin{array}{l}\text { Same as TFBCS but for strontium. Defines MACCS variable TFBF for Sr } 89 \text { and Sr90. } \\
\text { Range: } 4.4 \times 10^{-5}-1.1 \times 10^{-3} \text { (i.e., } 2.2 \times 10^{-4} \times 5 \text { ). }\end{array}$ \\
\hline TFMCS & $\begin{array}{l}\text { Ratio of amount of cesium in milk to amount of cesium consumed by milk-producing } \\
\text { animals. Defines MACCS variable TFMLK for Cs134 and Cs137. Range: } 0.022-0.55 \\
(\text { i.e., } 0.11 \times 5 \text { ). Additional information: Sec. } 4.3 .10 \text {, Ref. 32; Sec. 3.2.4, Ref. } 2 \text {. }\end{array}$ \\
\hline TFMI131 & $\begin{array}{l}\text { Same as TFMCS but for I131. Defines MACCS variable TFMLK for I131. Range: } \\
0.026-0.65 \text { (i.e., } 0.13 \times 5 \text { ). Correlation: } 0.75 \text { rank correlation with TFMI133. }\end{array}$ \\
\hline TFMI133 & $\begin{array}{l}\text { Same as TFMCS but for I133. Defines MACCS variable TFMLK for I133. Range: } 0.0124 \\
-0.31 \text { (i.e., } 0.062 \times 5 \text { ). Correlation: } 0.75 \text { rank correlation with TFMI131. }\end{array}$ \\
\hline TFMSR & $\begin{array}{l}\text { Same as TFMCS but for strontium. Defines MACCS variable TFMLK for Sr89 and Sr90. } \\
\text { Range: } 0.0044-0.11 \text { (i.e., } 0.022 \times 5 \text { ). }\end{array}$ \\
\hline VDELAY & $\begin{array}{l}\text { Same as GDELAY but for green leafy vegetables. Range: } 20.8-32.5 \text { days (i.e., } 26 \text { days } \\
\times 1.25 \text { ). }\end{array}$ \\
\hline
\end{tabular}


Table 10. Predicted Variables Associated with the Food Pathways Model in MACCS Selected for Analysis

Population Dose

Crop Growing Season Dose--total population dose (Sv) resulting from consumption of nondairy food products contaminated as a result of deposition onto crops during the growing season.

Crop Long-Term Dose--total population dose (Sv) resulting from consumption of non-dairy food products contaminated by long-term uptake in the period following the accident.

Milk Growing Season Dose--total population dose (Sv) resulting from consumption of dairy products contaminated as a result of deposition onto crops during the growing season.

Total Food Pathways Dose--total population dose (Sv) from the consumption of contaminated dairy and nondairy products (excludes dose due to consumption of contaminated water).

Total Ingestion Pathways Dose--total population dose (Sv) from the consumption of contaminated dairy products, nondairy products, and water.

Total Long-Term Pathways Dose--total population dose (Sv) from groundshine, resuspension, consumption of contaminated food, ingestion of contaminated surface water, and decontamination work.

\section{Economic Costs}

Area-Dependent Cost--sum of area-dependent decontamination, interdiction, condemnation, milk disposal, and crop disposal costs (\$).

Crop Disposal Cost--compensation (\$) for lost crops.

Milk Disposal Cost--compensation (\$) for lost dairy product sales.

Impacted Area

Condemnation Area--area $(\mathrm{Ha})$ within which farmland condemnation is required.

Crop Disposal Area--affected area (Ha) requiring the loss of nondairy food product sales for one year.

Milk Disposal Area--area $(\mathrm{Ha})$ requiring the loss of dairy product sales for three months. 


\section{DETERMINATION OF DOMINANT VARIABLES}

The purpose of the analyses presented in this section is to determine the effects of uncertainty in the MACCS input variables listed in Table 9 on the food pathway results indicated in Table 10. To accomplish this, the LHS program ${ }^{45}$ was used to generate a Latin hypercube sample ${ }^{18}$ of size 120 from the 87 variables in Table 9, with the Iman/Conover restricted pairing technique ${ }^{42}$ being used to induce the indicated rank correlations. This produced a sample of the form shown in Eq. (5) with $n V=87$ and $n L H S=120$, which was then propagated through MACCS to produce the results shown in Eq. (6). As a reminder, the vector $c S_{i}\left(x_{k}\right)$ in Eq. (6) contains the values for the food pathway results in Table 10 obtained for scenario $S_{i}$, where $S_{i}$ is the set of similar weather conditions defined in Eq. (13) of Ref. 5. The analyses for the individual food pathway results follow.

\subsection{Population Dose}

As described in Table 10, six predicted variables related to long-term population dose (Sv) are considered in this study: total long-term pathways dose, total ingestion pathways dose, milk growing season dose, crop growing season dose, crop long-term dose, and total food pathways dose. Mean and percentile curves for these variables are shown in Figure 1. As a reminder, each set of summary curves in Figure 1 is constructed from MACCS calculations performed for a Latin hypercube sample of size 120 from the 87 variables described in Table 9. Thus, each individual frame in Figure 1 summarizes a distribution of 120 CCDFs. For example, the mean and percentile curves for milk growing season dose are based on the distribution of CCDFs in Figure 2. 
Di:armination of Dominant Variables
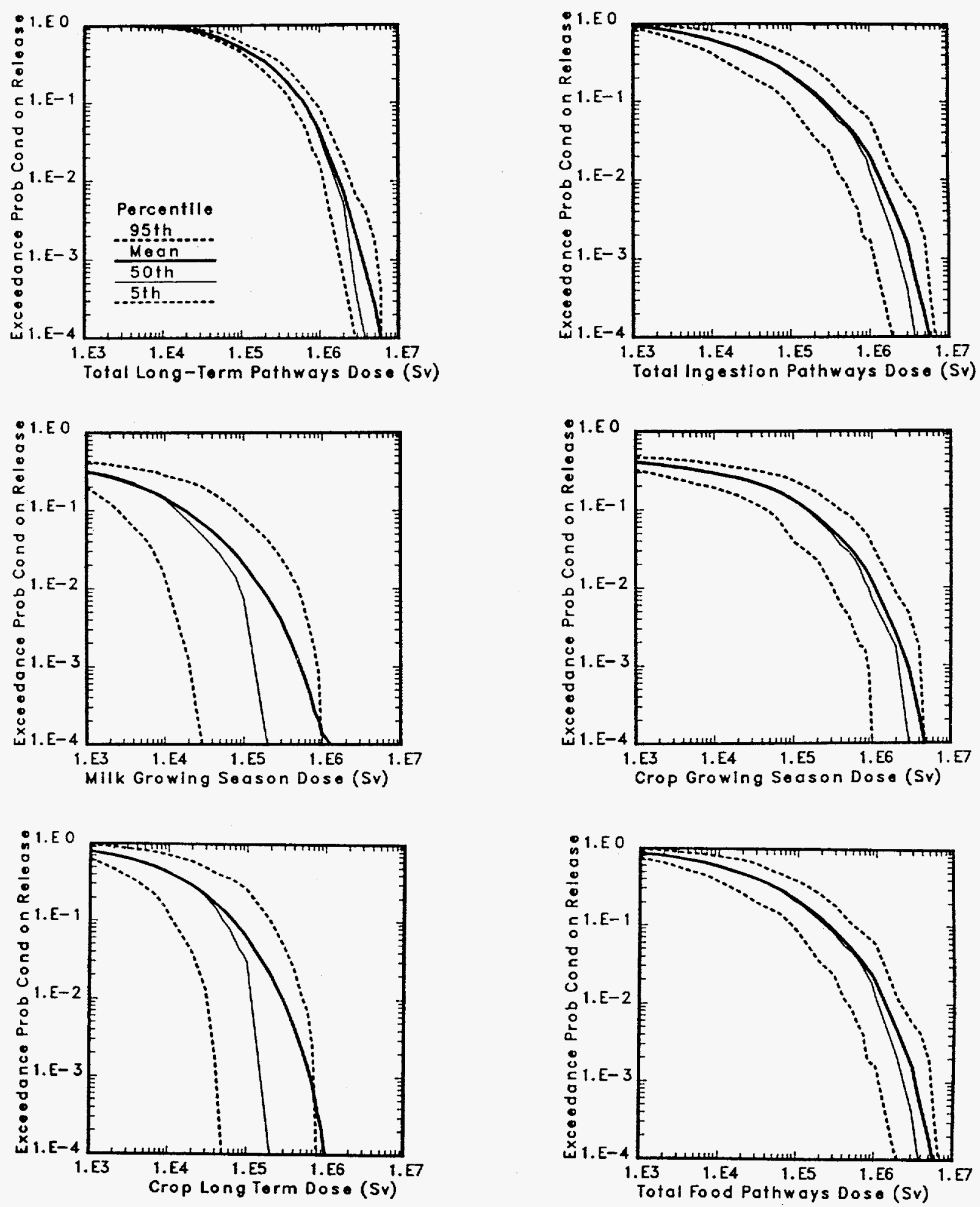

Figure 1 Mean and Percentile Curves for Population Dose. 


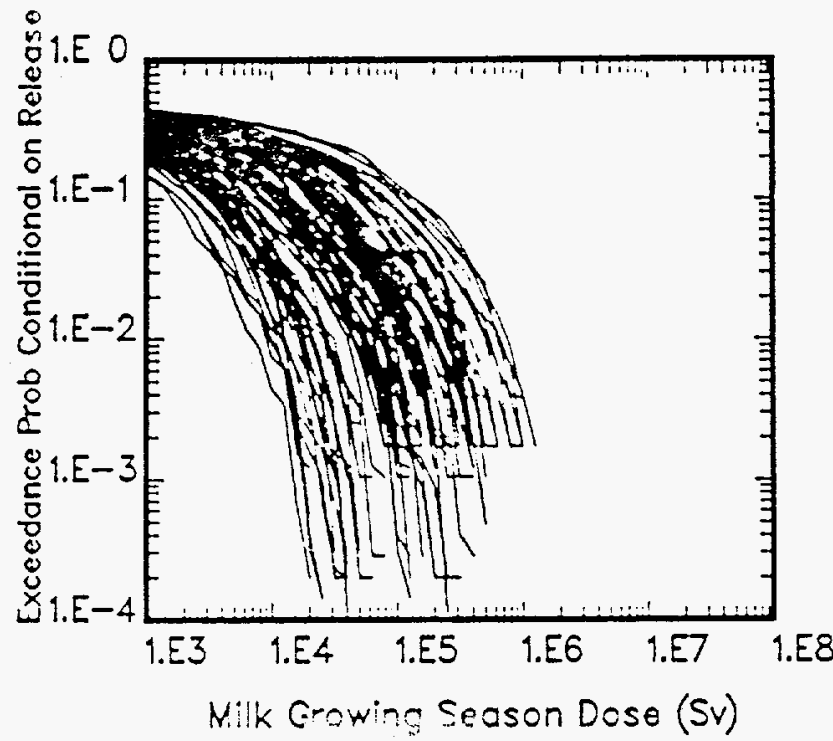

Figure 2. Distribution of $\mathrm{CC}$, $F$, for Milk Growing Season Dose.

Only food pathways variables are treated as being uncertain in this study. In particular, although the total long-term pathways dose and total ingestion pathways dose contain exposures in addition to those incurred through the food pathways, the uncertainty associated with these two doses in Figure 1 originates entirely from uncertainty in variables associated with the food pathways. The total ingestion pathways dose differs from the total food pathways dose in the inclusion of the dose that results from water ingestion. As comparison of the summary curves in Figure 1 for these two doses shows, exposure due to water ingestion is considerably smaller than the exposure due to the food pathways (i.e., the summary curves total ingestion pathways dose and total food pathways dose are essentially the same).

The total long-term pathways dose includes the doses from the ingestion pathways plus doses resulting from groundshine, inhalation of resuspended radionuclides and decontamination work. As comparison of the summary curves in Figure 1 for total long-term pathways dose and total food pathways dose shows, inclusion of the groundshine, resuspension and decontamination doses can cause an upward shift in total dose from the dose that results from ingestion (i.e., $5^{\text {th }}$ percentile curve for total long-term pathways dose is considerably higher than the $5^{\text {th }}$ percentile curve for total food pathways dose). However, the $95^{\text {th }}$ percentile curves for total long-term pathways dose and total food pathways dose are similar. Thus, in this analysis in which only the uncertainty in the food pathways is under consideration, the more extreme values of the food pathways parameters produce doses that exceed those from groundshine, resuspension and decontamination work.

Summaries of the CCDFs for milk growing season dose, crop growing season dose and crop long-term dose are also presented in Figure 1. As examination of these summaries shows, crop long-term dose is the largest contributor to the probability of the total food pathways dose exceeding small doses and crop growing season dose is the largest contributor to the probability of the total food pathways dose exceeding large doses. 
The primary purpose of the analyses presented in this report is to determine the importance of the individual variables in Table 9 in influencing results associated with the food pathways model in MACCS. One way to make such a determination is by using partial correlation analysis to determine the influence of the individual variables in Table 9 on the exceedance probabilities associated with the CCDFs summarized in Figure 1. For a distribution of CCDFs of the form shown in Figure 2, there are 120 exceedance probabilities (i.e., one for each sample element) for each dose on the abscissa. Partial correlation coefficients can be calculated between these probabilities and the variables in Table 9 and then plotted above the corresponding dose values on the abscissa. When the partial correlation values for individual variables from Table 9 are connected, plots of the form shown in Figure 3 are obtained. Due to the absence of any variables in the analysis that affect doses due to groundshine, resuspension, decontamination work and water ingestion, the partial correlation analyses for total long-term pathways dose and total ingestion pathways dose are the same as the analyses for total food pathways dose and thus are not presented in Figure 3.

To reduce the effects of nonlinear relationships, the analyses presented in Figure 3 and other similar figures in this report use partial rank correlation coefficients (PRCCs), which are correlation coefficients calculated with rank-transformed data. Further, to reduce clutter, the individual plot frames in Figure 3 only show PRCC plots for the four variables that have the largest PRCCs that exceed 0.6 in absolute value. The remaining variables that have PRCCs that exceed 0.6 in absolute value are listed in order of the absolute value of their PRCCs. Further, these variables are followed by a " + " or "-" to indicate whether the PRCC is positive $(+)$ or negative $(-)$ when it exceeds 0.6 in absolute value. The PRCCs in Figure 3 and other similar figures were calculated with the PCCSRC program. ${ }^{46}$

The individual analyses presented in Figure 3 are now discussed briefly. The probability of exceeding individual values for the milk growing season dose is dominated by TFMCS (ratio of amount of cesium in milk to amount of cesium consumed by milk-producing animals), with the probability of exceeding a given dose value tending to increase as TFMCS increases. This effect results because increasing TFMCS increases the amount of cesium consumed by milk-producing animals that is transferred to milk. Also included in the top four variables are TFMSR (ratio of amount of strontium in milk to amount of strontium consumed by milk-producing animals), PSMI131 (ground concentration of I-131 at which disposal of milk will be initiated) and TFMI131 (ratio of amount of I-131 in milk to amount of I-131 consumed by milk-producing animals), with the probability of exceeding a given dose value tending to increase as each of these variables increases. As for TFMCS, the positive effects for TFMSR and TFMI131 result from increasing radionuclide transfer from animal feed to milk. The positive effect for PSMI131 results from reducing the amount of milk production that will be interdicted. In addition to TFMCS, TFMSR, PSMI131 and TFMI131, positive effects are also indicated for PSMCS134 (ground concentration of Cs-134 at which disposal of milk will be initiated), PSMCS137 (ground concentration of Cs-137 at which disposal of milk will be initiated), PSMSR90 (ground concentration of $\mathrm{Sr}-90$ at which disposal of milk will be initiated) and IF1 (fraction of initial radionuclide deposition onto pasture that is retained on plant surfaces), and a negative effect is indicated for AF (fraction of intercepted radionuclides undergoing rapid weathering from crop surfaces for pasture, forage, green leafy vegetables and "other" food). The results of this analysis are dominated by two groups of 
Determination of Dominant Variables

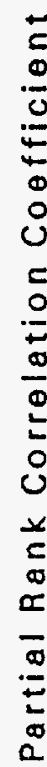

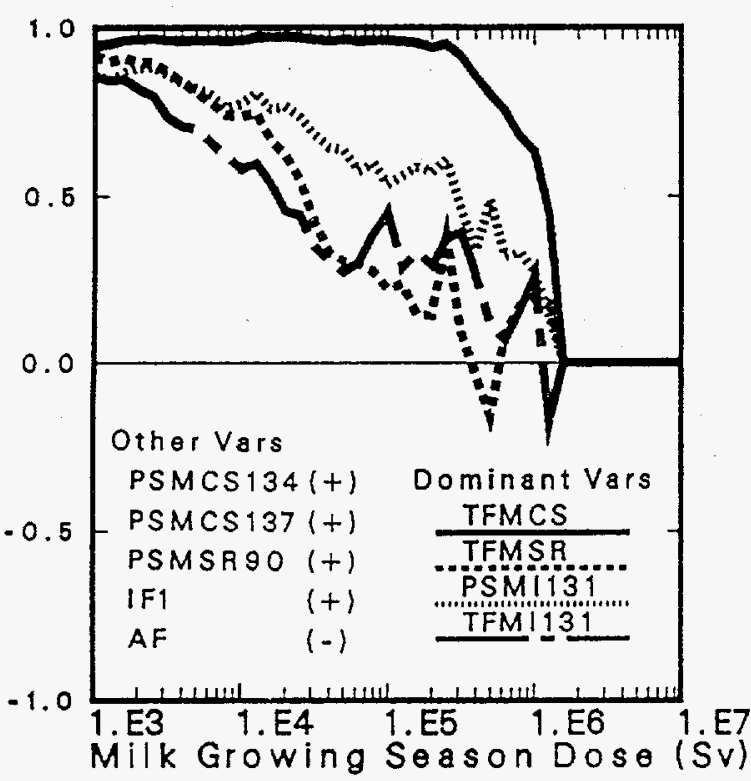

5
0
0
0
0
0
0
0
0
0
0
0
0
0
0
0
0
0
0
0

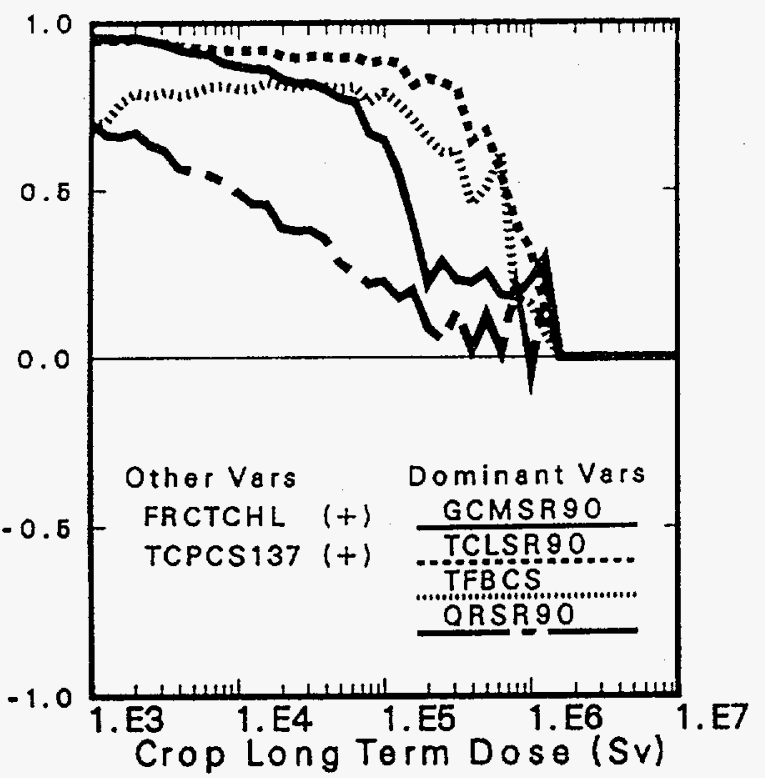

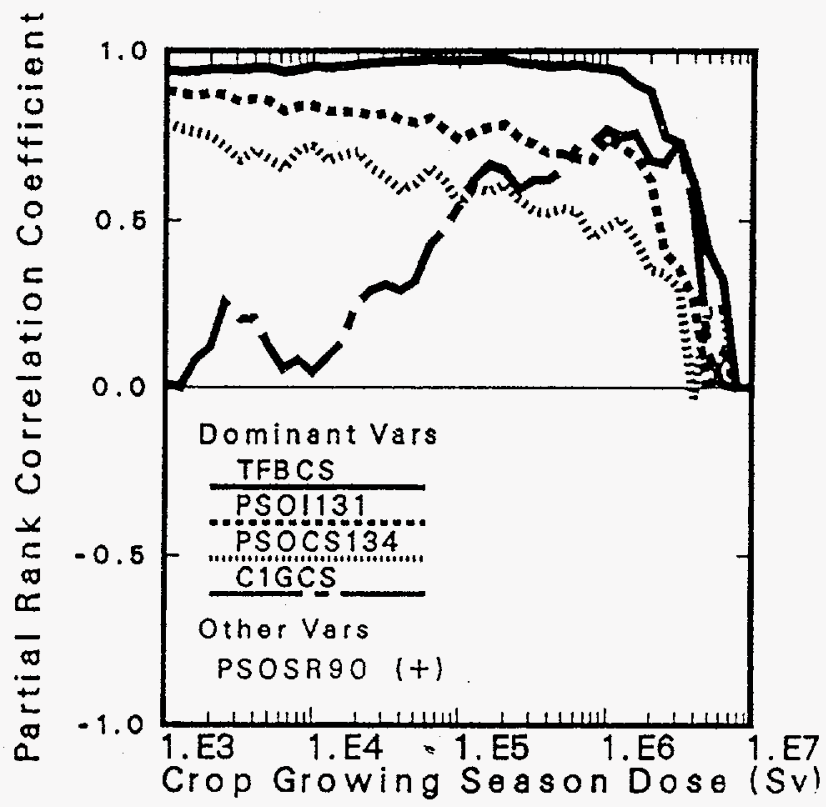

Figure 3 Partial Rank Correlation Coefficients for Exceedance Probabilities Associated with Individual Dose Values. 


\section{Determination of Dominant Variables}

variables: variables that determine transfer of radionuclides from animal feed to milk (TFMCS, TFMSR, TFMI131) and variables that affect interdiction of milk production (PSMI131, PSMCS134, PSMCS137, PSMSR90). A third, but less important, group of variables affects the retention of radionuclides on crop surfaces (IF1, AF).

The probability of exceeding individual values for the crop growing season dose is dominated by TFBCS (ratio of amount of cesium in edible meat at time of slaughter to amount of cesium consumed by meat-producing animals), with the probability of exceeding a given dose value tending to increase as TFBCS increases. The positive effect for TFBCS results because increasing TFBCS increases the amount of cesium consumed by meat-producing animals that is transferred to edible meat. Additional positive effects are indicated for PSOI131 (ground concentration of I-131 at which disposal of crops will be initiated), PSOCS134 (ground concentration of Cs-134 at which disposal of crops will be initiated), C1GCS (fraction of cesium deposition onto grain fields that is retained on plant surfaces and transferred directly to grain) and PSOSR90 (ground concentration of Sr-90 at which disposal of crops will be initiated). The positive effects for PSOI131, PSOCS134 and PSOSR90 result from decreasing the amount of land that undergoes crop interdiction, while the positive effect for C1GCS results from increasing the amount of cesium in grain used as animal feed.

The probability of exceeding individual values for the crop long-term dose is dominated by GCMSR90 (maximum allowable Sr-90 ground concentration for production of crops), TCLSR90 (ratio of amount of Sr-90 transferred to legumes due to root uptake and resuspension and amount of Sr-90 deposited on soil surfaces) and TFBCS (ratio of amount of cesium in edible meat at time of slaughter to amount of cesium consumed by meat-producing animals), with the probability of exceeding a given dose value tending to increases as each of these variables increases. These effects result because increasing GCMSR90 decreases the amount of farmland subject to interdiction, increasing TCLSR90 increases the amount of Sr-90 that will be transferred to legumes, and increasing TFBCS increases the amount of cesium that will be transferred from animal feed to edible meat. After GCMSR90, TCLSR90 and TFBCS, additional positive effects are indicated for QRSR90 (rate of depletion of Sr-90 from the root zone), FRCTCHL (fraction of legumes consumed by humans) and TCPCS137 (ratio of amount of Cs-137 transferred to pasture due to root uptake and resuspension and amount of Cs-137 deposition to soil surface), with the probability of exceeding individual dose values tending to increase as each of these variables increases. The positive effect for QRSR90 probably results from decreasing the time period over which farmland will be interdicted and also decreasing the amount of farmland that will undergo condemnation, which is assumed to remove it permanently from agricultural production. However, QRSR90 has no effect on the probability of exceeding the larger doses observed in this analysis. The positive effects indicated for FRCTCHL and TCPCS137 result because increasing FRCTCHL increases the amount of crop category (i.e., legumes) that will be consumed directly by humans and increasing TCPCS137 increases the amount of deposited cesium that will be transferred from soil to animal feed (i.e., pasture). The variables identified in this analysis can be divided into groups that determine interdiction (GCMSR90, QRSR90), root uptake (TCLSR90, TCPCS137) and transfer in the food chain to man after crop production (TFBCS, FRCTCHL).

The probability of exceeding individual values for total food-pathways dose is dominated by GCMSR90 (maximum allowable Sr-90 ground concentration for production of crops) and TCLSR90 (ratio of amount of $\mathrm{Sr}-90$ transferred to legumes due to root uptake and resuspension and amount of $\mathrm{Sr}-90$ deposited on soil surfaces) for doses less than approximately $5 \times 10^{4} \mathrm{~Sv}$ and by TFBCS (ratio of amount 
of cesium consumed by meat-producing animals) for doses greater than $5 \times 10^{4} \mathrm{~Sv}$, with the probability of exceeding a given dose value tending to increase as each of GCMSR90, TCLSR90 and TFBCS increases. As examination of Figure 3 shows, GCMSR90 and TCLSR90 are the dominant variables in the analysis for crop long-term dose, while TFBCS is the dominant variable in the analysis for crop growing season dose. After these three variables, additional positive effects are indicated for C1GCS (fraction of cesium deposition onto grain fields that is retained on plant surfaces and transferred directly to grain), PSOI131 (ground concentration of I-131 at which disposal of crops will be initiated), TFMCS (ratio of amount of cesium in milk to amount of cesium consumed by milk-producing animals), TCPCS137 (ratio of amount of Cs-137 transferred to pasture due to root uptake and resuspension and amount of Cs-137 deposited on soil surfaces), QRSR90 (rate of depletion of Sr-90 from root zone), and FRCTCHL (fraction of legumes consumed by humans). Each of the variables G1GCS, PSOI131, TFMCS, TCPCS137, QRSR90 and FRCTCHL appears in, and has been discussed in conjunction with, one of the other analyses in Figure 3. In particular, C1GCS and PSOI131 appear in the analysis for crop growing season dose, TFMCS is the dominant variable in the analysis for milk growing season dose, and TCPCS137, QRSR90 and FRCTCHL appear in the analysis for crop long-term dose. Thus, as should be the case, the analysis for total food-pathways dose tends to identify the dominant variables that affect the individual doses from which the total food pathways dose is constructed. The variables affecting total food-pathways dose can be divided into two groups: variables that affect radionuclide transfer within the food chain (TFBCS, TCLSR90, C1GCS, TFMCS, TCPCS137, FRCTCHL) and variables that affect interdiction of food production (GCMSR90, PSOI131, QRSR90).

Distributions for mean population dose are shown in Figure 4. As discussed in conjunction with Eqs. (27) and (28) of Ref. 5, the mean doses summarized in Figure 4 are obtained by reducing the CCDFs associated with the risk representation in Eq. (6) to single numbers. For example, a single mean milk growing season dose is obtained from each

of the 120 CCDFs in Figure 2; in turn, these 120 mean doses are summarized in the plot frame labeled "Milk Growing Season Dose" in Figure 4. Thus, the results summarized in Figure 4 are means over stochastic uncertainty; however, the distributions in Figure 4 are characterizing subjective uncertainty.

The uncertainty analysis results for mean population dose in Figure 4 can be investigated with sensitivity analysis techniques based on stepwise regression analysis. Variable importance is then indicated by the order in which variables enter the regression model, the changes in $R^{2}$ values with the entry of successive variables into the regression model, and the standardized regression coefficients in the final regression model constructed in the stepwise process, with all three ranking procedures producing the same ordering of variable importance for uncorrelated variables. When the variables are uncorrelated, the absolute values of the standardized regression coefficients and the differences between successive $R^{2}$ values will decrease monotonically as additional variables are added to the regression model.

The regression analyses contained in this presentation were performed with the STEP program. ${ }^{47}$ Alpha values of 0.01 and 0.02 were required for variables to enter and remain in the regression models, respectively. Further, the PRESS criterion ${ }^{48}$ was used to check for overfitting the data. The analyses were tried with raw (i.e., untransformed) data, rank-transformed data, ${ }^{49}$ and logarithmically transformed data. The analyses with rank-transformed data and logarithmically transformed data produced similar 
Determination of Dominant Variables
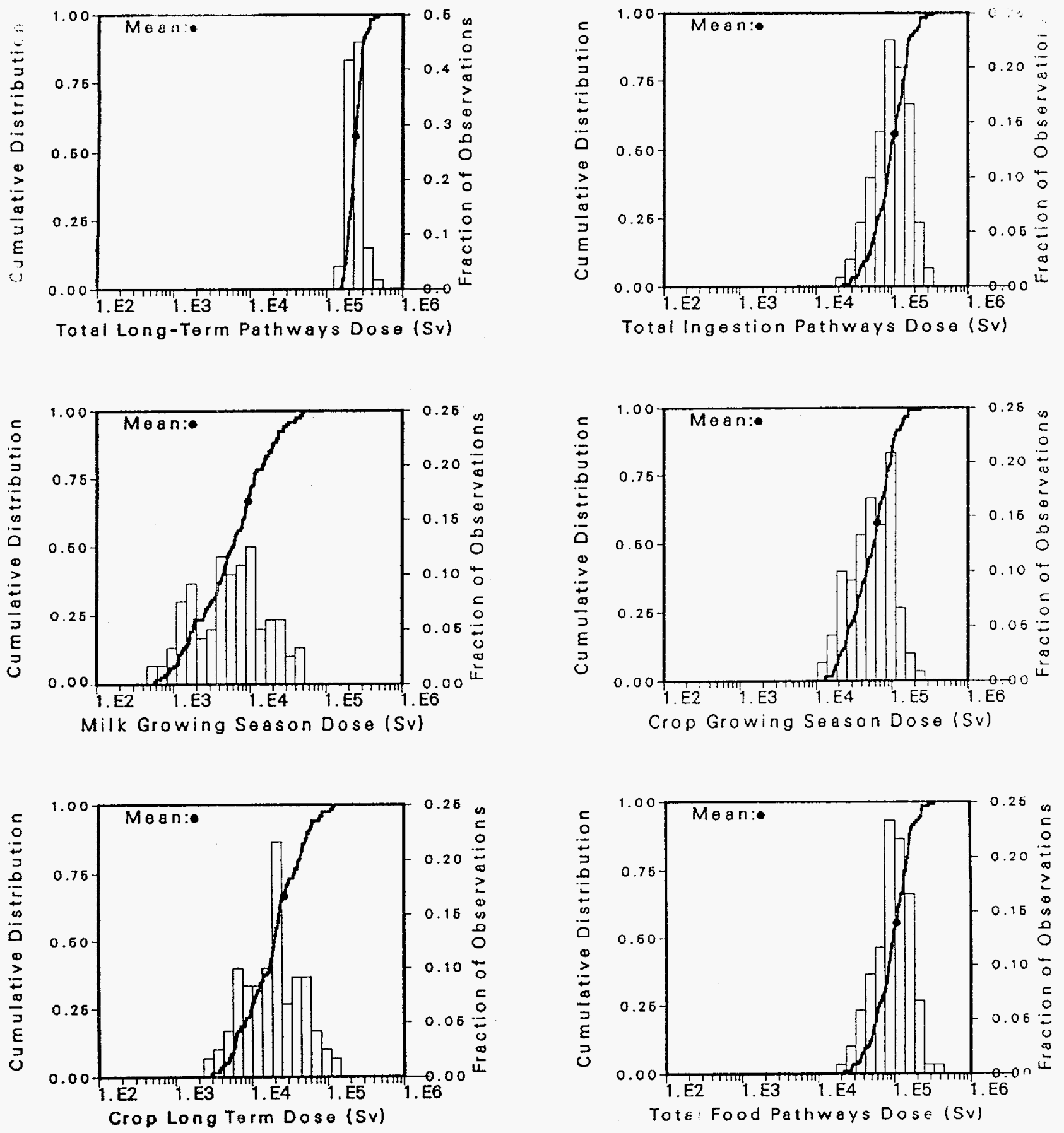

Figure 4. Distributions of Mean Population Dose. 
results and also considerably better results (e.g., higher $\mathrm{R}^{2}$ values) than the analyses with raw data. As the logarithmic transformation has more intuitive appeal than the rank transformation and both transformations produced similar results, this study will use stepwise regression analyses with logarithmically-transformed data. In contrast, the logarithmic transformation is not particularly suitable for analyses of CCDFs of the form presented in Figure 2 due to the large number of zero exceedance probabilities that enter the analysis as the value of the consequence variable increases.

The stepwise regression analyses for milk growing season dose, crop growing season dose, crop long-term dose and total food pathways dose are presented in Table 11. As only variables affecting the food pathways model were sampled in this analysis, the regression analyses for total long-term pathways dose and total ingestion pathways dose are identical to the analysis for total food pathways dose and thus are not presented.

The mean milk-growing season dose is dominated by PSMCS134 (ground concentration of Cs-134 at which disposal of milk products will be initiated), TFMCS (ratio of amount of cesium in milk to amount of cesium consumed by milk-producing animals) and PSMI131 (ground concentration of I-131 at which disposal of milk products will be initiated), with dose tending to increase as each of PSMCS134, TFMCS and PSMI131 increases. Collectively, these three variables can account for $86 \%$ of the observed uncertainty in mean milk-growing season dose. After PSMCS134, TFMCS and PSMI131, the regression analysis identifies a number of additional variables that have small effects. In particular, small positive effects are indicated for PSMCS137 (ground concentration of Cs-137 at which the disposal of milk products will be initiated), TFMI131 (ratio of amount of I-131 in milk to amount of I-131 consumed by milk-producing animals), IF1 (fraction of initial radionuclide deposition onto pasture that is retained on plant surfaces), TFMSR (ratio of amount of Sr-90 in milk to amount of SR-90 consumed by milkproducing animals), FRCTCMP (fracture of pasture consumed by milk-producing animals) and PSMSR90 (ground concentration of Sr-90 at which disposal of milk products will be initiated), and a small negative effect is indicated for AF (fraction of intercepted radionuclides undergoing rapid weathering from crop surfaces for pasture, forage, green leafy vegetables and "other" food). The indicated effects are consistent with the use of the corresponding variables in MACCS. The regression model with all 10 variables can account for $94 \%$ of the observed uncertainty. Two dominant groups of variables appear in the analysis: variables that affect interdiction of milk production (PSMCS134, PSMI131, PSMCS137, PSMSR90) and variables that determine the transfer of radionuclides from animal feed to milk (TFMCS, TFMI131, TFMSR). The two remaining variables (IF1, AF) determine the retention of radionuclides on crop surfaces.

The mean crop growing season dose is dominated by TFBCS (ratio of amount of cesium in edible meat at time of slaughter to amount of cesium consumed by meat producing animals), PSOI131 (ground concentration of I-131 at which disposal of crops will be initiated) and PSOCS134 (ground concentration of Cs-134 at which disposal of crops will be initiated), with dose tending to increase as each of TFBCS, PSOI131 and PSOCS134 increases. Together, these three variables can account for $86 \%$ of the observed uncertainty in crop growing season dose, with TFBCS accounting for $51 \%$ of the uncertainty. In addition, small positive effects are identified for C1GCS (fraction of cesium deposition onto grain fields that is retained on plant surfaces and transferred directly to grain), IF1 (fraction of initial radionuclide 
Determination of Dominant Variables

Table 11. Stepwise Regression Analyses with Logarithmically-Transformed Data for Mean Population Dose

\begin{tabular}{|c|c|c|c|c|c|c|}
\hline & \multicolumn{3}{|c|}{ Milk Growing Season Dose (Sv) } & \multicolumn{3}{|c|}{ Crop Growing Season Dose (Sv) } \\
\hline Step ${ }^{a}$ & Variable $^{b}$ & $\mathrm{SRC}^{\mathrm{c}}$ & $\mathrm{R}^{2 \mathrm{~d}}$ & Variable $^{b}$ & $\mathrm{SRC}^{\mathrm{c}}$ & $R^{2 d}$ \\
\hline 1 & PSMCS134 & 0.27 & 0.38 & TFBCS & 0.74 & 0.51 \\
\hline 2 & TFMCS & 0.62 & 0.78 & PSOI131 & 0.41 & 0.80 \\
\hline 3 & PSMI131 & 0.32 & 0.86 & PSOCS134 & 0.28 & 0.86 \\
\hline 4 & PSMCS137 & 0.19 & 0.89 & CiGCS & 0.20 & 0.90 \\
\hline 5 & TFMI131 & 0.13 & 0.90 & IF1 & 0.13 & 0.91 \\
\hline 6 & IF1 & 0.11 & 0.92 & $\mathrm{AF}$ & -0.09 & 0.92 \\
\hline 7 & $\mathrm{AF}$ & -0.10 & 0.92 & CTHALF1 & 0.08 & 0.93 \\
\hline 8 & TFMSR & 0.09 & 0.93 & & & \\
\hline 9 & FRCTCMP & 0.09 & 0.94 & & & \\
\hline \multirow[t]{2}{*}{10} & PSMSR90 & 0.09 & 0.94 & & & \\
\hline & \multicolumn{3}{|c|}{ Crop Long-Term Dose (Sv) } & \multicolumn{3}{|c|}{ Total Food Pathways Dose (Sv) } \\
\hline Step ${ }^{2}$ & Variable $^{\mathrm{b}}$ & $\mathrm{SRC}^{\mathrm{c}}$ & $\mathrm{R}^{2 \mathrm{~d}}$ & Variable $^{\mathrm{b}}$ & $\mathrm{SRC}^{\mathrm{c}}$ & $R^{2 d}$ \\
\hline 1 & TCLSR90 & 0.86 & 0.40 & TFBCS & 0.65 & 0.39 \\
\hline 2 & GCMSR90 & 0.47 & 0.54 & PSOI131 & 0.35 & 0.61 \\
\hline 3 & TCPCS137 & 0.29 & 0.67 & TCLSR90 & 0.40 & 0.68 \\
\hline 4 & TFBCS & 0.33 & 0.77 & GCMSR90 & 0.27 & 0.74 \\
\hline 5 & FRCTCHL & 0.16 & 0.80 & TCPCS137 & 0.20 & 0.78 \\
\hline 6 & GCMCS137 & 0.18 & 0.81 & PSOCS134 & 0.21 & 0.81 \\
\hline 7 & TCPCS134 & 0.22 & 0.84 & C1GCS & 0.16 & 0.83 \\
\hline 8 & PSOI131 & 0.10 & 0.85 & TFMCS & 0.13 & 0.85 \\
\hline 9 & & & & PSMI131 & 0.13 & 0.87 \\
\hline 10 & & & & FRCTCHL & 0.10 & 0.88 \\
\hline 11 & & & & IF1 & 0.09 & 0.89 \\
\hline
\end{tabular}

"Steps in stepwise regression analysis.

bVariables listed in order of selection in regression analysis.

'Standardized regression coefficients in final regression model.

${ }^{\mathrm{d}}$ Cumulative $\mathrm{R}^{2}$ value with entry of each variable into regression model. 
deposition onto pasture that is retained on plant surfaces) and CTHALF1 (halflife for rapid weathering of deposited radionuclides from plant surfaces), and a small negative effect is indicated for AF (fraction of intercepted radionuclides undergoing rapid weathering from crop surfaces for pasture, forage, green leafy vegetables and "other" food). The indicated effects are consistent with the use of the corresponding variables in MACCS, and the regression model with all seven variables can account for $93 \%$ of the observed uncertainty. The variables identified in this analysis are similar to those identified in the analysis for milk-growing season dose. In particular, the dominant variables define transfer from feed to meat (TFBCS) and interdiction criteria (PSOI131, PSOCS134), while a less important set of variables determines retention on crop surfaces (CIGCS, IF1, AF, CTHALF1).

The mean crop long-term dose is dominated by TCLSR90 (ratio of amount of Sr-90 transferred to legumes due to root uptake and resuspension and amount of $\mathrm{Sr}-90$ deposited on soil surfaces), GCMSR90 (maximum allowable Sr-90 ground concentration for production of crops), TCPCS137 (ratio of amount of Cs-137 transferred to pasture due to root uptake and resuspension and amount of Cs-137 deposited on soil surfaces) and TFBCS (ratio of amount of cesium in edible meat at time of slaughter to amount of cesium consumed by meat producing animals), with dose tending to increase as each of TCLSR90, GCMSR90, TCPCSC137 and TFBCS increases. Together, these four variables can account for $77 \%$ of the observed uncertainty in crop long-term dose. Additional positive effects are indicated for FRCTCHL (fraction of legumes consumed by humans), GCMCS137 (maximum allowable Cs-137 ground concentration for production of crops), TCPCS134 (ratio of amount of Cs-134 transferred to pasture due to root uptake and resuspension and amount of Cs-134 deposited on soil surfaces) and PSOI131 (ground concentration of I-131 at which disposal of crops will be initiated). The positive effects for TCLSR90, GCMSR90, TCPCS137, TFBCS, FRCTHCHL, GCMCS137 and TCPCS134 are consistent with their usage in MACCS. The variable PSOI131 is not used in the determination of long-term doses, and so its appearance at the end of the regression analysis is probably spurious. With PSOI131 excluded, the remaining seven variables identified in the regression analysis can account for $84 \%$ of the observed uncertainty, and can be divided into groups that determine root uptake (TCLSR90, TCPCS137, TCPCS134), interdiction criteria (GCMSR90, GCMCS137), and transfer in the food chain to man after crop production (TFBCS, FRCTCHL).

The mean value for total food pathways dose is dominated by TFBCS (ratio of amount of cesium in edible meat at time of slaughter to amount of cesium consumed by meat producing animals), PSOI133 (ground concentration of I-131 at which disposal of crops will be initiated), TCLSR90 (ratio of amount of Sr-90 transferred to legumes due to root uptake and resuspension and amount of Sr-90 deposited on soil surfaces) and GCMSR90 (maximum allowable Sr-90 ground concentration for production of crops), with dose tending to increase as each of TFBCS, PSOI131, TCLSR90 and GCMSR90 increases. Collectively, these four variables can account for $74 \%$ of the observed uncertainty in total food pathways dose. After these variables, small positive effects are indicated for TCPCS137 (ratio of amount of Cs-137 transferred to pasture due to root uptake and resuspension and amount of Cs-137 deposited on soil surface), PSOCS134 (ground concentration of Cs-134 at which disposal of crops will be initiated), CIGCS (fraction of cesium deposition onto grain fields that is retained on plant surfaces and transferred directly to grain), TFMCS (ratio of amount of cesium in milk to amount of cesium consumed by milk-producing animals), PSMI131 (ground concentration of I-131 at which disposal of milk products will be initiated), FRCTCHL (fraction of legumes consumed by humans) and IF1 (fraction of initial radionuclide deposition 
onto pasture that is retained on plant surfaces). The final regression model contains 11 variables and can account for $89 \%$ of the observed uncertainty in total food pathways dose. These variables can be divided into groups that affect the interdiction of food production (PSOI131, GCMSR90, PSOCS134, PSMI131) and radionuclide transfer within the food chain (TFBCS, TCLSR90, TCPCS137, CIGCS, TFMCS, FRCTCHL, IF1). However, $61 \%$ of the observed uncertainty was accounted for by only two variables: TFBCS (39\%) and PSOI131 (22\%).

\subsection{Economic Cost}

As described in Table 10, three predicted variables related to economic cost $(\$)$ are considered in this study: area-dependent cost, crop disposal cost and milk disposal cost. Mean and percentile curves for these variables are presented in Figure 5. As discussed in conjunction with Figure 1, the mean and percentile curves in Figure 5 summarize the results of 120 MACCS calculations. The summary curves in Figure 5 indicate that area-dependent cost is approximately an order of magnitude above crop disposal cost, which in turn is approximately an order of magnitude above milk disposal cost.

The results of a sensitivity analysis with PRCCs for the CCDFs summarized in Figure 5 are presented in Figure 6. The probability of exceeding a given area-dependent cost is dominated by GCMSR90 (maximum allowable Sr-90 ground concentration for production of crops), QRSR90 (rate of depletion of Sr-90 from root zone) and GCMCS137 (maximum allowable Cs-137 ground concentration for production of crops). The probability of exceeding a given value of area-dependent cost tends to decrease as each of GCMSR90, QRSR90 and GCMCS137 increases due to reductions in the areas and time periods that require interdiction. In particular, increasing each of GCMSR90 and GCMCS137 tends to decrease the amount of farmland that will be interdicted, and increasing QRSR90 tends to decrease the duration of interdiction.

The probability of exceeding a given crop disposal cost is dominated by PSOI131 (ground concentration of $\mathbb{I}-131$ at which disposal of crops will be initiated), PSOSR90 (ground concentration of Sr-90 at which disposal of crops will be initiated) and PSOCS134 (ground concentration of Cs-137 at which disposal of crops will be initiated), with the probability tending to decrease as each of these variables increases. The negative effects for PSOI131, PSOSR90 and PSOCS134 result from reducing the area in which crop disposal is required. A negative effect is also indicated for TCPCS137 (ratio Cs137 transferred to pasture due to root uptake and resuspension and Cs-137 deposition to soil surface). However, TCPCS137 does not effect the crop disposal model in MACCS and so its appearance in this analysis is spurious.

The probability of exceeding a given milk disposal cost is dominated by PSMI131 (ground concentration of I-131 at which disposal of milk products will be initiated), PSMCS134 (ground concentration of Cs-134 at which disposal of milk products will be initiated), PSMSR90 (ground concentration of Sr-90 at which disposal of milk products will be initiated) and PSMCS137 (ground concentration of $\mathrm{Cs}-137$ at which disposal of milk products will be initiated). Thus, as for crop disposal cost, the uncertainty in exceeding individual milk disposal costs is dominated by the radionuclide concentration (i.e., PSMI131, PSMCS134, PSMSR90, PSMCS137) at which disposal will be initiated. 
The distributions for mean economic cost are shown in Figure 7. As with the CCDF summaries in Figure 5, the area dependent cost is about an order of magnitude above the crop disposal cost, which in turn is about an order of magnitude above the milk disposal cost. The regression analyses for the mean costs summarized in Figure 7 are presented in Table 12.

The mean area-dependent cost is dominated by GCMSR90 (maximum allowable Sr-90 ground concentration for production of crops), with this variable accounting for approximately $78 \%$ of the observed uncertainty. Mean area-dependent cost tends to decrease as GCMSR90 increases due to decreased interdiction and condemnation of farmland. After GCMSR90, the regression analysis indicates small negative effects for GCMCS137 (maximum allowable Cs-137 ground concentration for production of crops), QRSR90 (rate of depletion of Sr-90 from the root zone), PSOI131 (ground concentration of I-131 at which disposal of crops will be initiated), FRCTCMG (fraction of grain consumed by milkproducing animals) and QRCS134 (rate of depletion of Cs-137 from the root zone). Collectively, the preceding six variables produce a regression model that can account for approximately $91 \%$ of the observed uncertainty in mean area-dependent dose. The variable FRCTCMG does not enter into the cost calculations performed in MACCS and thus its selection is spurious; however, it accounts for less than $1 \%$ of the observed uncertainty. The remaining five variables can be divided into two groups: variables that set interdiction criteria (GCMSR90, GCMCS137, PSOI131) and variables that determine the rate at which "effective" soil concentration decreases (QRS90, QRCS134).

The mean crop-disposal cost is dominated by variables that define the ground concentration at which crop disposal will be initiated. Specifically, the regression analysis selected PSOI131 (ground concentration of I-131 at which disposal of crops will be initiated), PSOCS134 (ground concentration of Cs-134 at which disposal of crops will be initiated) and PSOSR90 (ground concentration of Sr-90 at which disposal of crops will be initiated), with these three variables producing a regression model that could account for $92 \%$ of the observed uncertainty. The dominant variable was PSOI131, which could account for $71 \%$ of the observed uncertainty.

The mean milk disposal cost is dominated by PSMCS134 (ground concentration of Cs-134 at which disposal of milk products will be initiated) and PSMI131 (ground concentration of I-131 at which disposal of milk products will be initiated), with an additional small contribution from PSMCS137 (ground concentration of Cs-137 at which disposal of milk products will be initiated). Mean milk disposal cost tends to decrease as each of PSMCS134, PSMI131 and PSMCS137 increases. The final regression model accounts for approximately $93 \%$ of the observed uncertainty, with PSMCS134, PSMI131 and PSMCS137 accounting for $72 \%, 17 \%$ and $4 \%$, respectively, of the total uncertainty. 
Determination of Dominant Variables
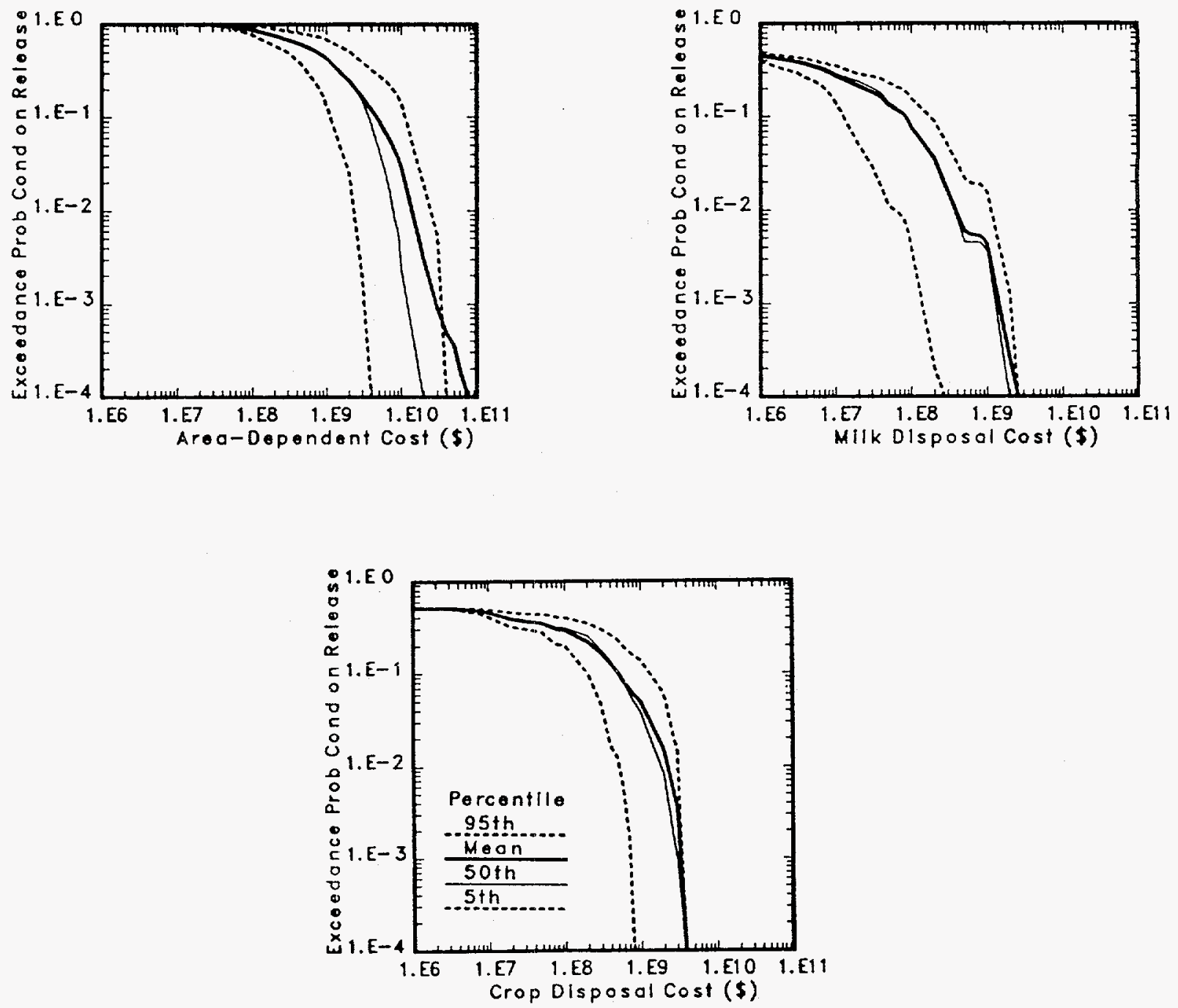

Figure 5 Mean and Percentile Curves for Economic Costs. 
Determination of Dominant Variables

蕰

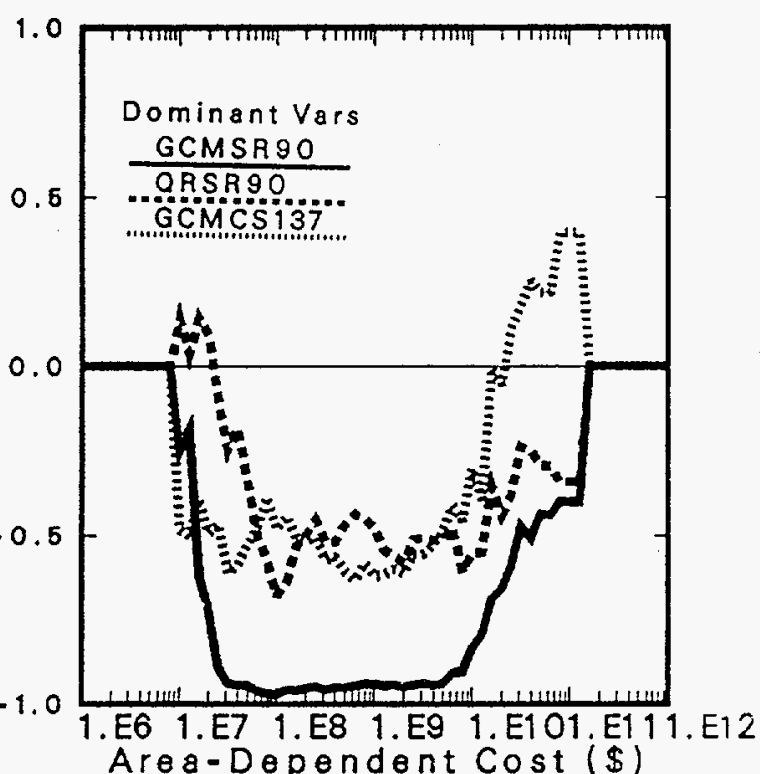

0
0
0
0
0
0
0
0
0
0
0
0
0
0
$\frac{1}{c}$
0
0
$\frac{1}{0}$
$\frac{0}{2}$
0
0
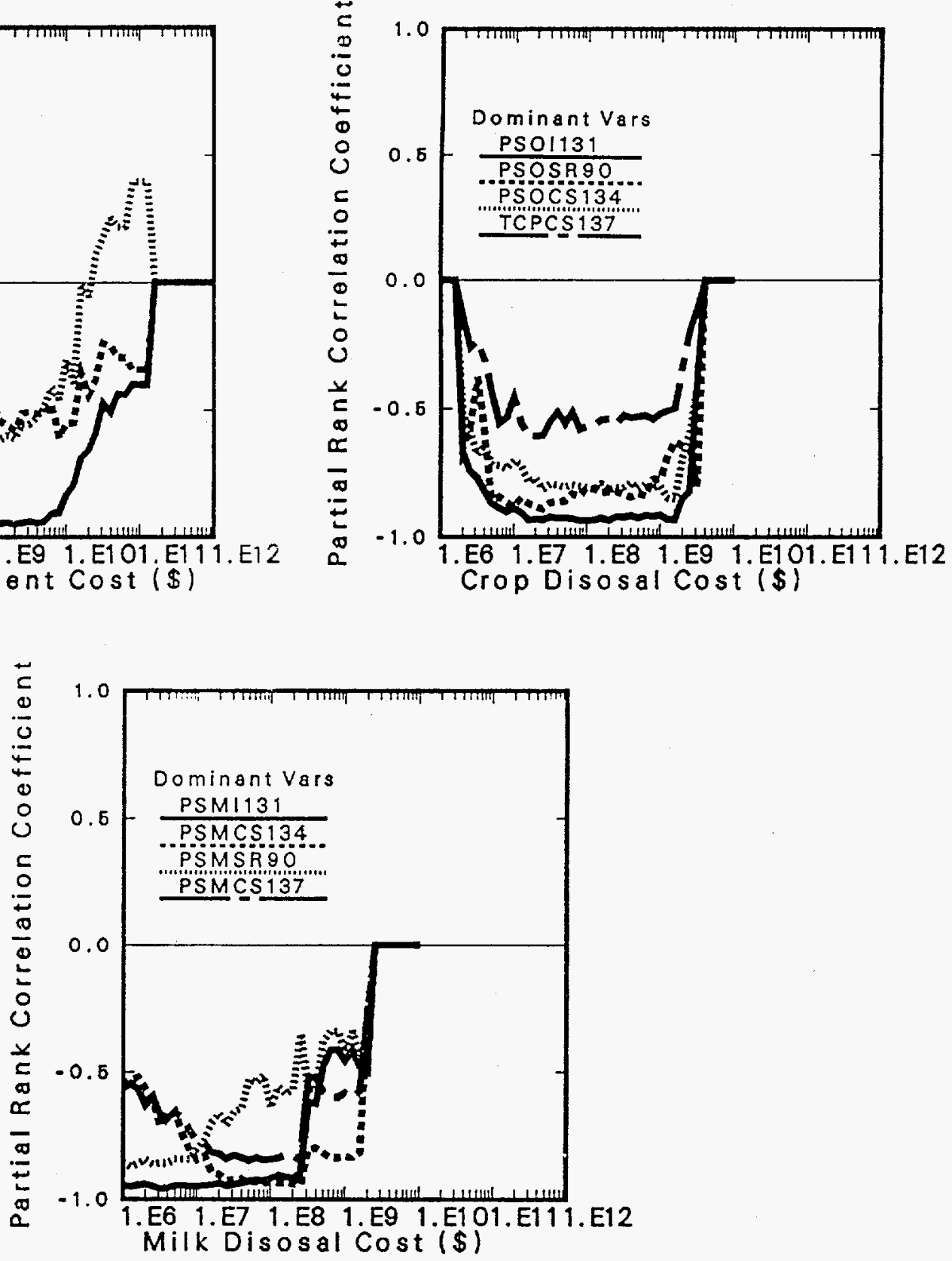

Figure 6 Partial Rank Correlation Coefficients for Exceedance Probabilities Associated with Individual Cost Values. 
Determination of Dominant Variables
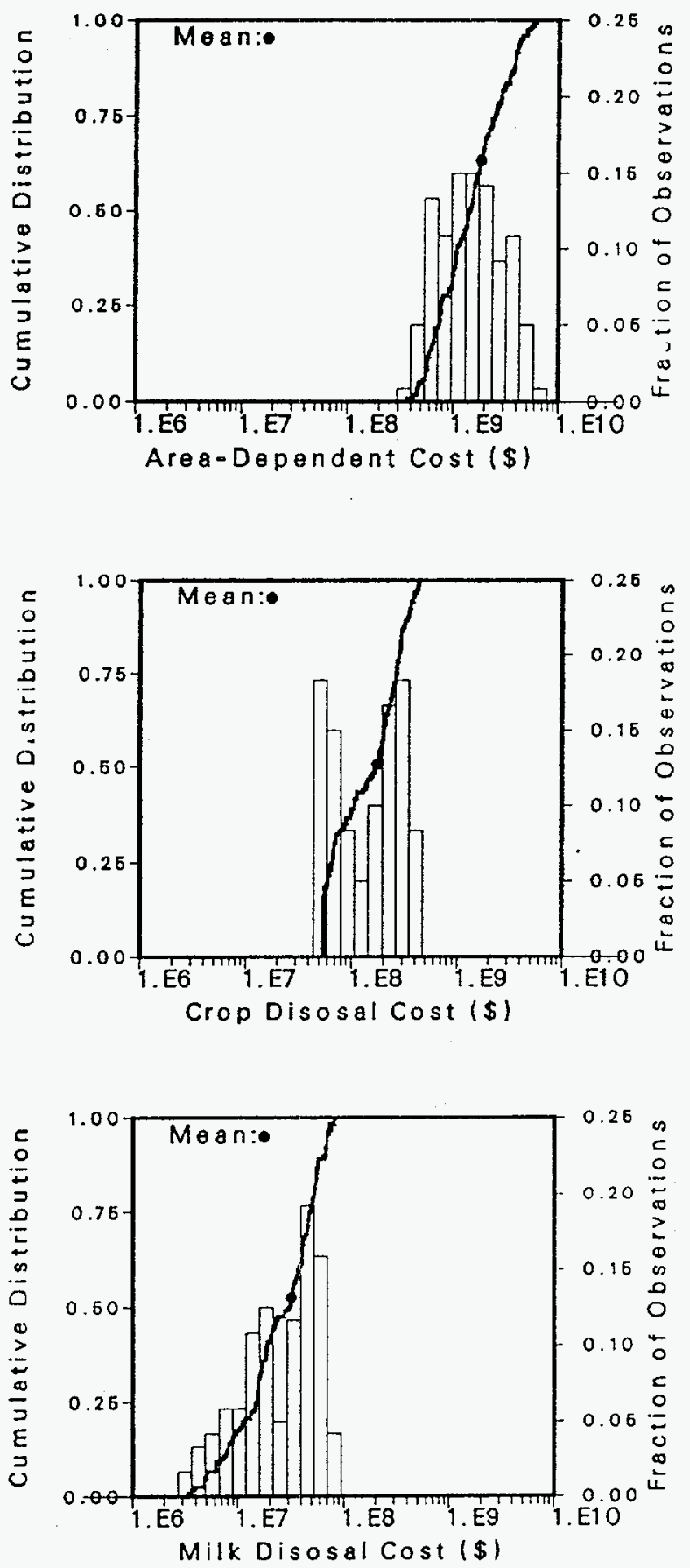

Figure 7 Distributions of Mean Economic Costs. 
Table 12. Stepwise Regression Analyses with Logarithmically-Transformed Data for Mean Economic Cast

\begin{tabular}{|c|c|c|c|c|c|c|c|c|c|}
\hline \multirow[b]{2}{*}{ Step ${ }^{a}$} & \multicolumn{3}{|c|}{ Area-Dependent Cost $(\$)$} & \multicolumn{3}{|c|}{ Crop Disposal Cost } & \multicolumn{3}{|c|}{ Milk Disposal Cost (\$) } \\
\hline & Variable ${ }^{b}$ & SRC $^{\mathrm{e}}$ & $\mathbf{R}^{2 d}$ & Variable $^{b}$ & SRC & $\mathbf{R}^{2} \mathbf{d}$ & Variable ${ }^{b}$ & SRC & $\mathbf{R}^{2 d}$ \\
\hline 1 & GCMSR90 & -0.74 & 0.78 & PSOI131 & -0.53 & 0.71 & PSMCS134 & -0.44 & 0.72 \\
\hline 2 & GCMCS137 & -0.24 & 0.85 & PSOCS134 & -0.35 & 0.86 & PSMI131 & -0.39 & 0.89 \\
\hline 3 & QRSR90 & -0.16 & 0.88 & PSOSR90 & -0.29 & 0.92 & PSMCS137 & -0.26 & 0.93 \\
\hline 4 & PSOI131 & -0.12 & 0.90 & & & & & & \\
\hline 5 & FRCTCMG & -0.09 & 0.90 & & & & & & \\
\hline 6 & QRCS134 & -0.09 & 0.91 & & & & & & \\
\hline
\end{tabular}

2Steps in stepwise regression analysis.

${ }^{b}$ Variables listed in order of selection in regression analysis.

'Standardized regression coefficients in final regression model.

${ }^{\mathrm{d}}$ Cumulative $\mathrm{R}^{2}$ value with entry of each variable into regression model.

\subsection{Impacted Area}

As described in Table 10, three predicted variables related to impacted area (Ha) are considered in this study: condemnation area, crop disposal area and milk disposal area. Mean and percentile curves for these variables are presented in Figure 8, with each plot frame summarizing the results of 120 MACCS calculations. As comparison of the summary curves for the three areas shows, there is considerably more uncertainty associated with the CCDFs for condemnation area than the CCDFs for crop disposal area and milk disposal area.

The results of a sensitivity analysis with PRCCs for the CCDFs summarized in Figure 8 are presented in Figure 9. Two variables are identified as affecting the probability that a given condemnation area will be exceeded: GCMSR90 (maximum allowable $\mathrm{Sr}-90$ ground concentration for production of crops) and QRSR90 (rate of depletion of Sr-90 from root zone). The probability of exceeding a given condemnation area tends to decrease as GCMSR90 and QRSR90 increases. As a reminder, the MACCS food pathways model assumes that condemnation of farmland takes place if the time period over which the land must be removed from farm production exceeds 8 yr or if the cost of farmland decontamination and temporary interdiction exceeds the value of the farmland and associated investments (Section 2.4 of this report; Section 5.3.3.2, Ref. 3). The negative effect for GCMSR90 results from increasing the ground concentration of $\mathrm{Sr}-90$ at which crop production will be interdicted, and the negative effect for QRSR90 results from reducing the time required for land with ground concentrations initially above GCMSR90 to reach concentrations that are below GCMSR90.

The probability that a given crop disposal area will be exceeded is dominated by PSOI131 (ground concentration of I-131 at which disposal of crops will be initiated), PSOSR90 (ground concentration of Sr-90 at which disposal of crops will be initiated) and PSOCS134 (ground concentration of Cs-134 at which disposal of crops will be initiated). As discussed in conjunction with crop disposal 


\section{Determination of Dominant Variables}

cost, the appearance of TCPCS137 (ratio of amount of Cs-137 transferred to pasture due to root uptake and resuspension and amount of Cs-137 deposited on soil surfaces) is spurious. Thus, crop disposal area is dominated by the same three interdiction criteria that dominate crop disposal cost (i.e., PSOI131, PSOSR90, PSOCS134).

The probability of exceeding a given milk disposal area is dominated by PSMI131 (ground concentration of I-131 at which disposal of milk products will be initiated), PSMCS134 (ground concentration of Cs-134 at which disposal of milk products will be initiated), PSMSR90 (ground concentration of Sr-90 at which disposal of milk products will be initiated) and PSMCS137 (ground concentration of CS-137 at which disposal of milk products will be initiated). Thus, as for milk disposal cost, the uncertainty in exceeding individual milk disposal areas is dominated by the radionuclide concentrations at milk which disposal will be initiated (i.e., PSMI131, PSMCS134, PSMSR90, PSMCS137).

The distributions for mean impacted area are shown in Figure 10, with most of these means falling between $1 \times 10^{5}$ and $1 \times 10^{6} \mathrm{Ha}$. Regression analyses for the mean areas summarized in Figure 10 are presented in Table 13.

The mean condemnation area is dominated by GCMSR90 (maximum allowable Sr-90 ground concentration for production of crops) and QRSR90 (rate of depletion of $\mathrm{Sr}-90$ from the root zone). Together, GCMSR90 and QRSR90 can account for $74 \%$ of the observed uncertainty in mean condemnation area, with this area tending to decrease as each of these variables increases. After GCMSR90 and QRSR90, the regression analysis selects the corresponding two variables for Cs-137 (i.e., GCMCS137 and QRCS137). The final regression model with GCMSR90, QRSR90, GCMCS137 and QRCS137 can account for $83 \%$ of the observed uncertainty in mean condemnation area.

The mean crop disposal area is dominated by the same three variables as mean crop disposal cost: PSOI131 (ground concentration of I-131 at which disposal of crops will be initiated), PSOCS134 (ground concentration of Cs-134 at which disposal of crops will be initiated) and PSOSR90 (ground concentration of Sr-90 at which disposal of crops will be initiated). Collectively, these three variables can account for 92\% of the observed uncertainty in mean crop disposal area, with PSOI131, PSOCS134 and PSOSR90 accounting for $71 \%, 15 \%$ and $6 \%$, respectively, of the total uncertainty.

The analysis for mean milk disposal area is essentially the same as the analysis for mean milk disposal cost. In particular, the mean milk disposal area is dominated by PSMCS134, PSMI131, PSMCS137 and PSMSR90, which define the ground concentrations of Cs-134, I-131, Cs-137 and Sr-90, respectively, at which the disposal of milk products will be initiated. All four variables produce a regression model that can account for $94 \%$ of the observed uncertainty in mean milk disposal area. The dominant variable is PSMCS134, which can account for $72 \%$ of the uncertainty. In addition, PSMI131, PSMCS137 and PSMSR90 can account for $17 \%, 4 \%$, and $1 \%$ of the uncertainty. 
Determination of Dominant Variables
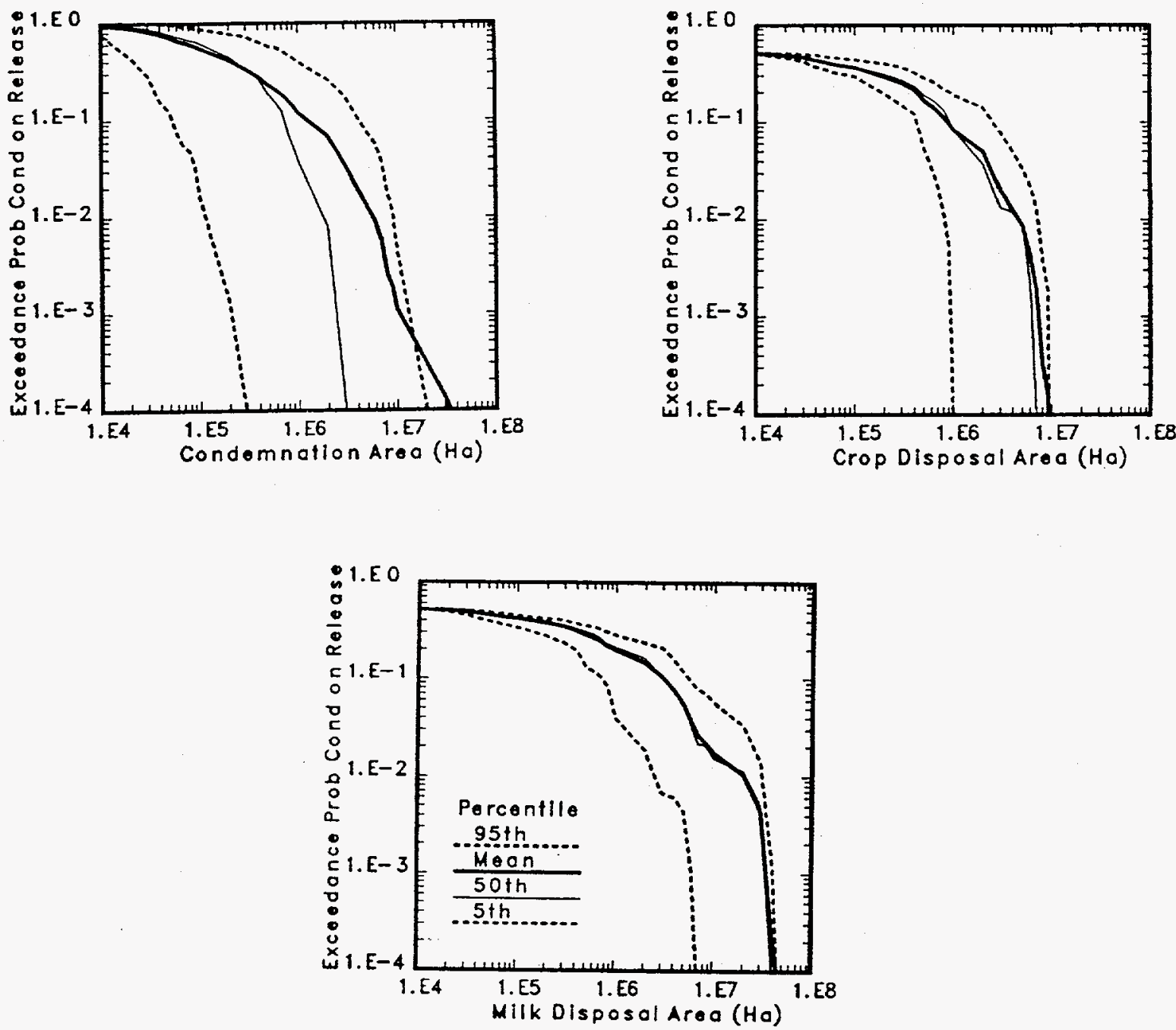

Figure 8 Mean and Percentile Curves for Impacted Area. 
Determination of Dominant Variables
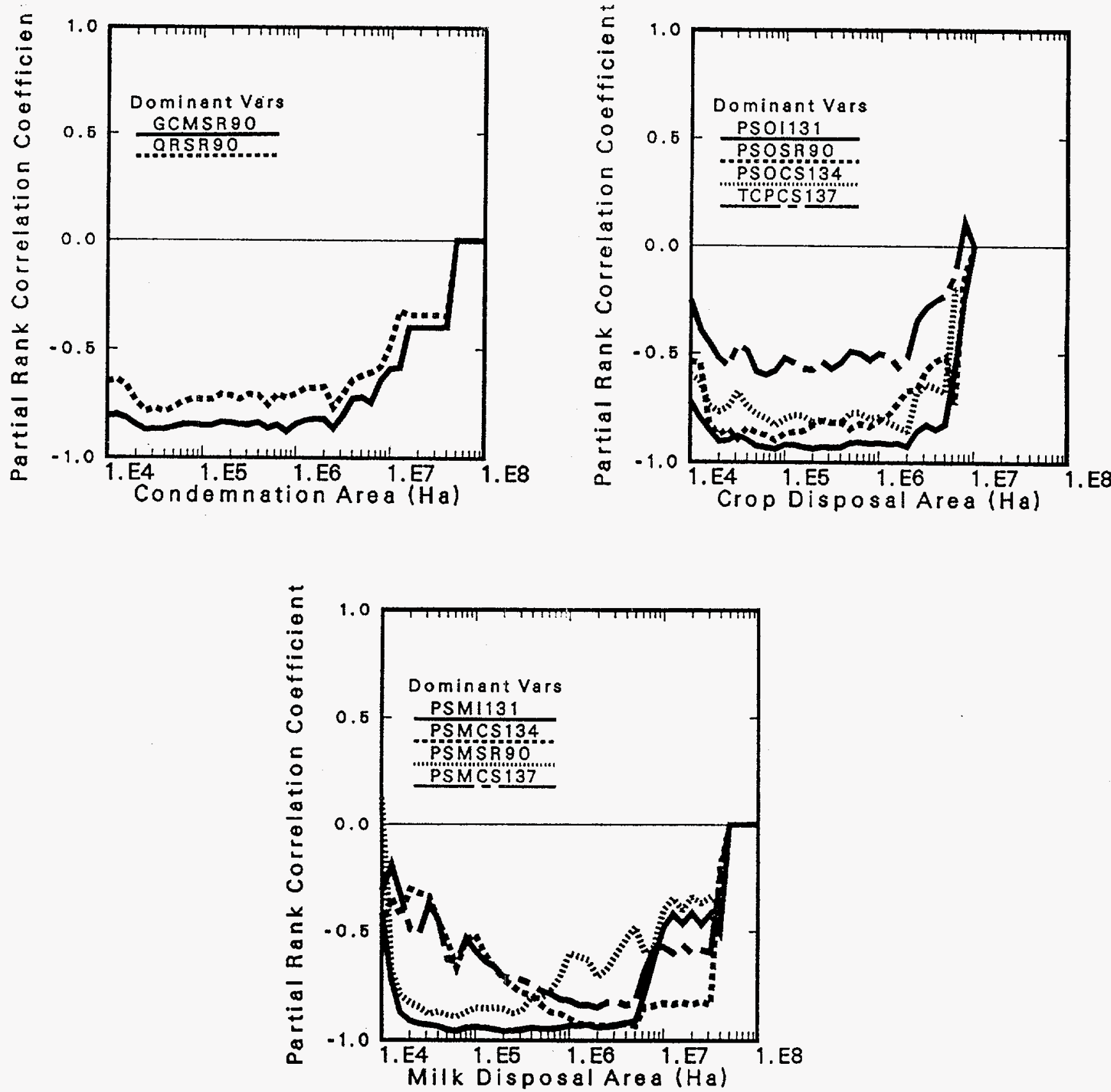

Figure 9 Partial Rank Correlation Coefficients for Excecdance

Probabilitiex Associated with Individual Impacted Areas. 

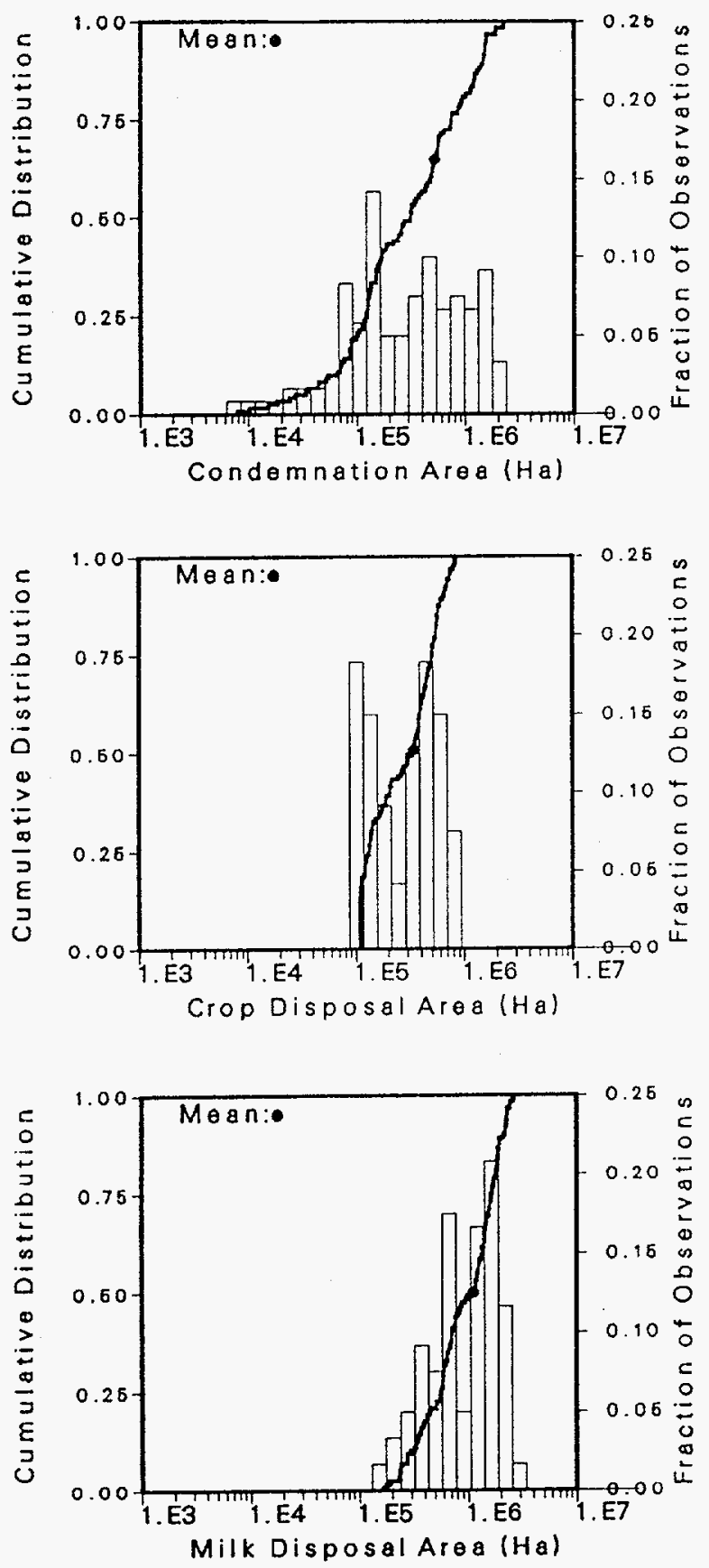

Figure 10 Distributions of Mean Impacted Area. 
Determination of Dominant Variables

Table 13. Stepwise Regression Analyses with Logarithmically-Transformed Data for Mean Impacted Area

\begin{tabular}{||c|l|c|c|c|c|c|c|c|c||}
\cline { 2 - 9 } \multicolumn{1}{c|}{} & \multicolumn{3}{c|}{ Condemnation Area (Ha) } & \multicolumn{3}{c|}{ Crop Disposal Area (Ha) } & \multicolumn{3}{c||}{ Milk Disposal Area (Ha) } \\
\hline Step" & \multicolumn{1}{c|}{ Variable $^{\mathrm{b}}$} & SRC $^{\mathrm{c}}$ & $\mathrm{R}^{2} \mathrm{~d}$ & Variable $^{\mathrm{b}}$ & SRC $^{\mathrm{c}}$ & $\mathrm{R}^{2 \mathrm{~d}}$ & Variable $^{\mathrm{b}}$ & SRC $^{\mathrm{c}}$ & $\mathrm{R}^{2} \mathrm{~d}$ \\
\hline 1 & GCMSR90 & -0.56 & 0.59 & PSOI131 & -0.53 & 0.71 & PSMCS134 & -0.43 & 0.72 \\
2 & QRSR90 & -0.43 & 0.74 & PSOCS134 & -0.36 & 0.86 & PSMI131 & -0.40 & 0.89 \\
3 & GCMCS137 & -0.19 & 0.81 & PSOSR90 & -0.29 & 0.92 & PSMCS137 & -0.26 & 0.93 \\
4 & QRCS137 & -0.17 & 0.83 & & & & PSMSR90 & -0.09 & 0.94 \\
\hline
\end{tabular}

-Steps in stepwise regression analysis.

${ }^{b}$ Variables listed in order of selection in regression analysis.

'Standardized regression coefficients in final regression model.

${ }^{d}$ Cumulative $R^{2}$ value with entry of each variable into regression model. 


\section{EFFECT OF DOMINANT VARIABLES}

The analyses presented in Section 4 identify the dominant MACCS input variables affecting the predicted variables listed in Table 10 conditional on the assumptions used in this analysis. Two questions naturally arise: (1) How much will the observed uncertainty in the variables in Table 10 be reduced if the uncertainty in the dominant variables identified in Section 4 can be reduced? (2) If the uncertainty in the dominant variables identified in Section 4 is reduced, which input variables in Table 9 will then emerge as the new dominant variables? ${ }^{50,51}$

To answer these questions, the dominant variables identified in Section 4 were compiled. For the purposes of this investigation, a variable was included in the set of dominant variables if it was ranked among the top four variables on the basis of either PRCCs or stepwise regression analysis for one of the 12 predicted variables listed in Table 10. This produced the 18 variables listed in Table 14 . As examination of Table 14 shows, selection based on either PRCCs and or stepwise regression analysis would have produced almost identical sets of variables. The MACCS calculations leading to the uncertainty and sensitivity analysis results presented in Section 4 were then repeated with the 18 variables listed in Table 14 set to their best-estimate values indicated in Table 9.

Setting the variables in Table 14 to their best-estimate values produced substantial reductions in the uncertainty in the predicted variables listed in Table 10. As an example, the spread between the percentile curves shown in Figure 11 for crop long-term dose obtained with the variables in Table 14 set to their best-estimate values can be compared with the corresponding spread shown in Figure 1 obtained with the variables in Table 14 allowed to vary. For the other variables in Table 10, the reduction in the spread in the CCDF distribution is greater than that indicated in the preceding comparison for crop longterm dose.

Table 14. Dominant Variables Identified in Uncertainty and Sensitivity Analyses Presented in Section 4

$\begin{array}{lll}\operatorname{C1GCS}\left(+^{*}, t^{\mathrm{b}}\right) & \operatorname{PSMSR90}(+, *) & \operatorname{TCLSR} 90(+,+) \\ \operatorname{GCMCS} 137(+,+) & \operatorname{PSOCS} 134(+,+) & \operatorname{TCPCS} 137(+,+) \\ \operatorname{GCMSR} 90(+,+) & \operatorname{PSOI} 131(+,+) & \operatorname{TFBCS}(+,+) \\ \operatorname{PSMCS} 134(+,+) & \operatorname{PSOSR} 90(+,+) & \operatorname{TFMCS}(+,+) \\ \operatorname{PSMCS} 137(+,+) & \operatorname{QRCS} 137(*,+) & \operatorname{TFM} 131(+, *) \\ \operatorname{PSMI} 131(+,+) & \operatorname{QRSR} 90(+,+) & \operatorname{TFMSR}(+, *)\end{array}$

${ }^{*} /{ }^{*}$ indicates ranked $(+)$ or not ranked $(*)$ in top four variables on basis of PRCCS for at least one of the predicted variables in Table 10.

${ }^{b}+/^{*}$ indicates ranked $(+)$ or not ranked $(*)$ in top four variables on basis of order of selection in a stepwise regression analysis for at least one of the predicted variables in Table 10. 


\section{Effect of Dominant Variables}

The effect of setting the variables in Table 14 to their best-estimate values can also be seen by comparing the means and standard deviations shown in Table 15. The means and standard deviations shown in Table 15 are calculated over the distributions shown in Figures 4, 7 and 10 for the case in which the variables in Table 14 are allowed to vary and over the corresponding distributions that are obtained for the case in which the variables in Table 14 are fixed at their best estimate values. For example, the distribution of mean crop long-term dose obtained with the variables in Table 14 fixed at their best-estimate values is shown in Figure 12; the corresponding mean and standard deviation shown in Table 15 for crop long-term dose are determined from this distribution. As comparison of the standard deviations obtained with and without the variables in Table 14 fixed at their best-estimate values shows, fixing the variables in Table 14 results in substantial reductions in the uncertainty in all the predicted variables under consideration in this study.

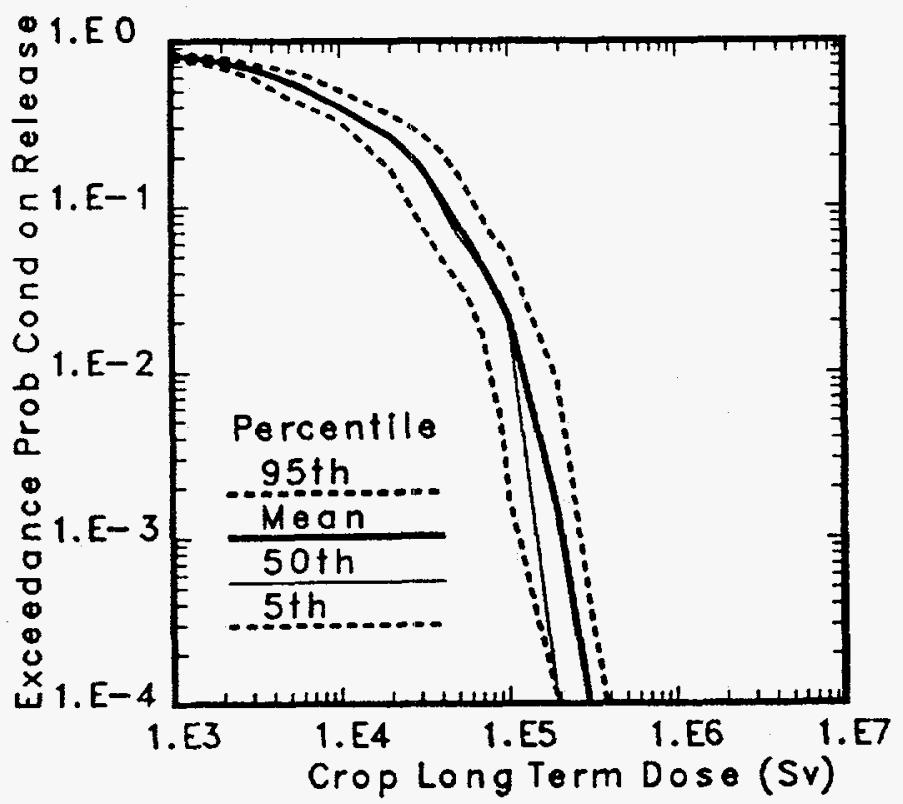

Figure 11 Mean and Percentile Curves for Crop Long-Term Dose with the Variables in Table 14 Set to Their Best-Estimate Values. 
Table 15. Standard Deviations (SDs), Means, Medians and 95th Percentiles for Predicted Variables Obtained With and Without the Variables in Table 14 Set to Their Best-Estimate Values

\begin{tabular}{|c|c|c|c|c|c|c|c|c|}
\hline \multirow[b]{2}{*}{ Predicted Variable } & \multicolumn{4}{|c|}{$\begin{array}{l}\text { All Variables in Table } 9 \\
\text { Allowed to Vary }\end{array}$} & \multicolumn{4}{|c|}{$\begin{array}{l}\text { Variables in Table } 14 \text { Set to } \\
\text { Best-Estimate Values }\end{array}$} \\
\hline & SD & Mean & Median & 95th & SD & Mean & Median & 95th \\
\hline Total Long-Term Pathways Dose (Sv) & $6.1 \times 10^{5}$ & $2.4 \times 10^{5}$ & $2.3 \times 10^{5}$ & $3.6 \times 10^{5}$ & $1.2 \times 10^{5}$ & $2.2 \times 10^{5}$ & $2.2 \times 10^{5}$ & $2.4 \times 10^{5}$ \\
\hline Total Ingestion Pathways Dose (Sv) & $6.1 \times 10^{5}$ & $1.1 \times 10^{\mathrm{s}}$ & $9.7 \times 10^{4}$ & $2.2 \times 10^{5}$ & $1.2 \times 10^{5}$ & $8.9 \times 10^{4}$ & $8.8 \times 10^{4}$ & $1.1 \times 10^{5}$ \\
\hline Milk Growing Season Dose (Sv) & $1.1 \times 10^{5}$ & $9.4 \times 10^{3}$ & $5.8 \times 10^{3}$ & $3.0 \times 10^{4}$ & $1.8 \times 10^{4}$ & $7.5 \times 10^{3}$ & $7.3 \times 10^{3}$ & $9.9 \times 10^{3}$ \\
\hline Crop Growing Season Dose (Sv) & $4.3 \times 10^{3}$ & $6.5 \times 10^{4}$ & $5.8 \times 10^{4}$ & $1.4 \times 10^{\mathrm{s}}$ & $8.2 \times 10^{4}$ & $6.0 \times 10^{4}$ & $6.0 \times 10^{4}$ & $7.3 \times 10^{4}$ \\
\hline Crop Long-Term Dose (Sv) & $2.6 \times 10^{5}$ & $2.6 \times 10^{4}$ & $2.0 \times 10^{4}$ & $7.7 \times 10^{4}$ & $4.8 \times 10^{4}$ & $1.7 \times 10^{5}$ & $1.6 \times 10^{\circ}$ & $2.5 \times 10^{4}$ \\
\hline Total Food Pathways Dose (Sv) & $6.1 \times 10^{3}$ & $1.1 \times 10^{5}$ & $9.5 \times 10^{4}$ & $2.2 \times 10^{\mathrm{s}}$ & $1.2 \times 10^{5}$ & $8.8 \times 10^{4}$ & $8.7 \times 10^{5}$ & $1.1 \times 10^{\mathrm{s}}$ \\
\hline Area Dependent Cost $(\$)$ & $1.4 \times 10^{10}$ & $1.8 \times 10^{9}$ & $1.4 \times 10^{9}$ & $4.3 \times 10^{9}$ & $1.0 \times 10^{9}$ & $1.3 \times 10^{9}$ & $1.2 \times 10^{9}$ & $1.5 \times 10^{9}$ \\
\hline Milk Disposal Cost (\$) & $2.3 \times 10^{8}$ & $3.2 \times 10^{7}$ & $3.0 \times 10^{7}$ & $7.0 \times 10^{7}$ & $3.4 \times 10^{6}$ & $1.8 \times 10^{7}$ & $1.8 \times 10^{7}$ & $1.8 \times 10^{7}$ \\
\hline Crop Disposal Cost (\$) & $1.2 \times 10^{9}$ & $1.8 \times 10^{*}$ & $1.7 \times 10^{\circ}$ & $3.9 \times 10^{4}$ & $1.0 \times 10^{\circ}$ & $1.1 \times 10^{8}$ & $1.0 \times 10^{4}$ & $1.3 \times 10^{8}$ \\
\hline Condemnation Area $(\mathrm{Ha})$ & $5.9 \times 10^{8}$ & $5.2 \times 10^{5}$ & $3.1 \times 10^{5}$ & $1.5 \times 10^{5}$ & $2.2 \times 10^{5}$ & $3.3 \times 10^{5}$ & $3.2 \times 10^{5}$ & $3.7 \times 10^{5}$ \\
\hline Milk Disposal Area (Ha) & $7.4 \times 10^{6}$ & $1.1 \times 10^{6}$ & $1.1 \times 10^{8}$ & $2.3 \times 10^{6}$ & $1.4 \times 10^{5}$ & $6.8 \times 10^{5}$ & $6.7 \times 10^{5}$ & $7.0 \times 10^{3}$ \\
\hline Crop Disposal Area (Ha) & $2.3 \times 10^{6}$ & $3.4 \times 10^{5}$ & $3.3 \times 10^{5}$ & $7.4 \times 10^{5}$ & $1.8 \times 10^{5}$ & $2.0 \times 10^{5}$ & $2.0 \times 10^{5}$ & $2.4 \times 10^{5}$ \\
\hline
\end{tabular}


Effect of Dominant Variables

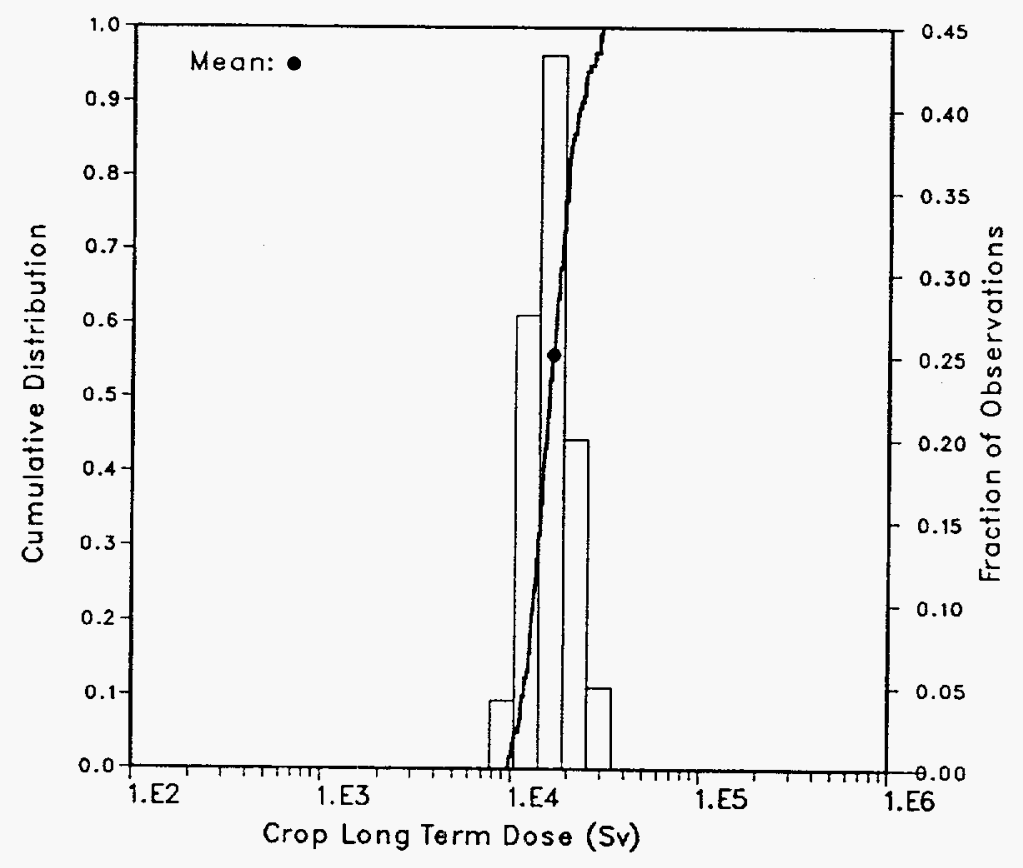

Figure 12 Distribution of Mean Crop Long-Term Dose With the Variables In Table 14 Set to Their Best-Estimate Values. 
Sensitivity analyses of the type previously presented in Section 4 can be used to determine which of the variables in Table 9 emerge as the new dominant variables after the variables in Table 14 have been set to their best-estimate values. The results of an analysis of this type with stepwise regression analysis with logarithmically-transformed data is presented in Table 16 for mean population dose; the corresponding analyses for variation of all variables in Table 9 appear in Table 11. As examination of Table 15 shows, there is little variation in the predicted variables for cost and area after the variables in Table 14 are set to their best-estimate values, and so analyses for these variables are not presented. Results based on stepwise regression rather than PRCCs were selected for presentation because of their compact form; as seen in Section 4, both analysis procedures yield similar sets of important variables.

Table 16. Stepwise Regression Analyses with Logarithmically-Transformed Data for Mean Population Dose With the Variables in Table 14 Set to Their Best-Estimate Values

\begin{tabular}{|c|l|l|l|l||}
\cline { 2 - 5 } \multicolumn{1}{|c||}{} & \multicolumn{2}{c|}{$\begin{array}{c}\text { Milk Growing } \\
\text { Season Dose (Sv) }\end{array}$} & \multicolumn{2}{c|}{$\begin{array}{c}\text { Crop Growing } \\
\text { Season Dose (Sv) }\end{array}$} \\
\hline \hline Step $^{\mathrm{a}}$ & Variable $^{\mathrm{b}}$ & \multicolumn{1}{|c|}{$\mathrm{R}^{2 \mathrm{c}}$} & \multicolumn{1}{|c|}{ Variable $^{\mathrm{b}}$} & \multicolumn{1}{|c|}{$\mathrm{R}^{2 \mathrm{c}}$} \\
\hline 1 & FRCTCMP & $0.31(+)$ & AF & $0.31(-)$ \\
2 & IF1 & $0.59(+)$ & IF1 & $0.53(+)$ \\
3 & AF & $0.86(-)$ & CTHALF1 & $0.63(+)$ \\
5 & CTHALF1 & $0.94(+)$ & C1LCS & $0.72(+)$ \\
6 & CTHALF2 & $0.96(+)$ & FPLSCHG & $0.80(+)$ \\
7 & MDELAY & $0.97(-)$ & FRCTCHG & $0.88(+)$ \\
8 & IF2 & $0.97(+)$ & CTHALF2 & $0.90(+)$ \\
9 & FRCTCMG & $0.98(+)$ & FRCTCHL & $0.92(+)$ \\
10 & FRCTCMF & $0.98(+)$ & FPLSCHL & $0.94(+)$ \\
11 & & & PSOSR89 & $0.95(+)$ \\
12 & & & FPLSCHO & $0.95(+)$ \\
\hline \hline
\end{tabular}


Effect of Dominant Variables

Table 16 (concluded)

\begin{tabular}{|c|c|c|c|c|}
\hline \multirow[b]{2}{*}{ Step ${ }^{2}$} & \multicolumn{2}{|c|}{$\begin{array}{l}\text { Crop Long-Term } \\
\text { Dose (Sv) }\end{array}$} & \multicolumn{2}{|c|}{$\begin{array}{c}\text { Total Food } \\
\text { Pathways Dose (Sv) }\end{array}$} \\
\hline & Variable $^{b}$ & $\mathrm{R}^{2 \mathrm{c}}$ & Variable $^{b}$ & $\mathbf{R}^{2 \mathfrak{c}}$ \\
\hline 1 & TCPCS134 & $0.38(+)$ & $\mathrm{AF}$ & $0.24(-)$ \\
\hline 2 & TCGSR90 & $0.61(+)$ & IF1 & $0.40(+)$ \\
\hline 3 & FPLSCHL & $0.70(+)$ & TCPCS134 & $0.54(+)$ \\
\hline 4 & FRCTCHL & $0.78(+)$ & FPLSCHG & $0.60(+)$ \\
\hline 5 & TCRSR90 & $0.81(+)$ & FRCTCHG & $0.65(+)$ \\
\hline 6 & GCMCS134 & $0.83(+)$ & FRCTCHL & $0.70(+)$ \\
\hline 7 & TCFCS137 & $0.86(+)$ & CTHALF1 & $0.75(+)$ \\
\hline 8 & TCLCS134 & $0.87(+)$ & FPLSCHL & $0.79(+)$ \\
\hline 9 & TCVSR90 & $0.88(+)$ & TCRSR90 & $0.83(+)$ \\
\hline 10 & & & CTHALF2 & $0.86(+)$ \\
\hline 11 & & & CILCS & $0.89(+)$ \\
\hline 12 & & & TCVSR90 & $0.90(t)$ \\
\hline 13 & & & GCMCS134 & $0.91(t)$ \\
\hline 14 & & & FRCTCMP & $0.92(+)$ \\
\hline 15 & & & TCFCS137 & $0.93(+)$ \\
\hline 16 & & & PSOSR89 & $0.94(+)$ \\
\hline
\end{tabular}

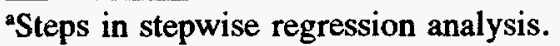

${ }^{b}$ Variables listed in order of selection in regression analysis.

${ }^{\text {CCumulative }} \mathrm{R}^{2}$ value with entry of each variable into regression model, with $"+"$ and $"-"$ indicating positive $(+)$ and negative $(-)$ regression coefficients, respectively. 


\section{DISCUSSION}

The present analysis considered the effect of 87 imprecisly-known variables used in the MACCS food pathways model. Further, three groups of predicted variables were selected for study: population dose (crop growing season dose, crop long-term dose, milk growing season dose, total food pathways dose, total ingestion pathways dose, total long-term pathways dose), economic cost (area dependent cost, crop disposal cost, milk disposal cost), and impacted area (condemnation area, crop disposal area, milk disposal area).

Uncertainty/sensitivity analysis techniques based on Latin hypercube sampling, partial correlation analysis and stepwise regression analysis were used to determine the effect of the imprecisely-known variables on MACCS predictions. In performing this analysis, care was taken to maintain a distinction between stochastic uncertainty, which enters the analysis through the probability for different types of weather at the time of occurrence of a reactor accident, and subjective uncertainty, which enters the analysis due to a lack of knowledge about variables supplied as input to MACCS. In particular, the distributions assigned to the 87 variables under consideration characterize subjective uncertainty.

The uncertainty in milk growing season dose was dominated by the ground concentrations at which interdiction of milk production occurs (PSMCS134, PSMI131, PSMCS137) and by the transfer of cesium from animal feed to milk (TFMCS). Similarly, the crop growing season dose was dominated by the ground concentrations at which interdiction of farm production occurs (PSOI131, PSOCS134) and by the transfer of cesium from animal feed to meat (TFBCS). The crop long-term dose is dominated by the transfer of Sr-90 from soil to legumes (TCLSR90), the ground concentration of Sr-90 at which crop production is prohibited (GCMSR90), and the transfer of cesium within the food chain (TCPCS137, TFBCS). The total food pathways dose is dominated by the crop growing season dose and the crop longterm dose. As a result, the dominant variables for total food pathways dose are the dominant variables for crop growing season dose (i.e., tranfer of cesium from animal feed to meat, ground concentration of I-131 at which interdiction of farm production occurs) and crop long-term dose (i.e., transfer of Sr-90 from soil to legumes, ground concentration of $\mathrm{Sr}-90$ at which crop production is prohibited). The total ingestion pathways dose differs from the total food pathways dose due to the inclusion of radiation exposures incurred through the consumption of water, and the total long-term pathways dose differs from the total food pathways dose due to the inclusion of radiation exposures incurred through groundshine, inhalation of resuspended material, decontamination work and consumption of water. As none of the MACCS inputs used in the calculation of the additional exposure modes associated with the total ingestion pathways and the total long-term pathways were treated as being uncertain in the analysis, the uncertainty in these variables for this analysis is controlled by the same variables as the uncertainty in the total food pathways dose. The effect of uncertainty in variables that affect groundshine, inhalation of resuspended material, decontamination work and water ingestion will be considered in a later study. ${ }^{6}$

The uncertainty in area-dependent cost (i.e., the sum of decontamination, interdiction, condemnation, milk disposal and crop disposal costs) is dominated by the uncertainty in the ground concentrations at which prohibition of crop production will occur (GCMSR90, GCMCS137). Similarly, crop disposal cost is dominated by the ground concentrations at which crop disposal will be initiated (PSOI131, PSOCS134, PSOSR90), and milk disposal cost is dominated by the uncertainty in the ground concentrations at which milk disposal will be initiated (PSMCS134, PSMI131, PSMCS134). The sensitivity analyses for condemnation area, crop disposal area and milk disposal area produce results that 
Discussion

are similar to those obtained for area-dependent cost, crop disposal cost and milk disposal cost, respectively.

After the dominant variables were determined, a second uncertainty/sensitivity analysis was performed to determine if reducing the uncertainty in the dominant variables would also substantially reduce the uncertainty in the predicted variables under consideration. In particular, the dominant variables from the first analysis were set to their best-estimate values, and then the uncertainty/sensitivity analysis was repeated with the remaining variables assigned the same distributions as before. The result was a substantial reduction in the uncertainty in the predicted variables. Further, the associated sensitivity analysis identified a new set of dominant variables conditional on the original set of dominant variables taking on their best-estimate values.

This analysis primarily considered variables that are actualy used as input to MACCS. Many of these variables are not very natural as they are not quantities that are typically measured in studies of radionuclide movement through foodchains. For example, the variable TFMCS defines the ratio of amount of cesium in milk to amount of cesium consumed by milk-producing animals (units: $\mathrm{Bq} / \mathrm{Bq}$ ); a related and more natural variable is the ratio between the concentration of cesium in milk and the daily consumption of cesium by a milk-producing animal (units: $(\mathrm{Bq} / \mathrm{l}) /(\mathrm{Bq} / \mathrm{d})$ ) (Table 5.36, Ref. 52). As another example, QRCS134 is the rate of depletion $\left(\mathrm{yr}^{-1}\right)$ of Cs-134 from the root zone due to radioactive decay, percolation into soil below the root zone and irreversible binding with soil components; a more informative analysis would result if QRCS134 and other similar variables were expressed as functions of variables more closely related to the individual processes that give rise to the overall depletion rate defined by QRCS134. The incorporation of such variables into the analysis requires either a preprocessor that maps from the sampled variables to the actual input variables used by MACCS or a change to MACCS.

The primary purpose of the analyses contained in this report is to identify the most important input variables used in the MACCS food pathways model. These variables can then be examined in more detail in future studies. As discussed in the introduction, these analyses help in the identification of variables for inclusion in a joint CEC/NRC review of the data used in reactor accident consequence calculations. ${ }^{1}$ Further, the dominant variables identified in this analysis and a previous analysis of early health effects ${ }^{5}$ will be used together with additional variables in an uncertainty/sensitivity analysis of the chronic exposure model in MACCS. ${ }^{6}$ 


\section{References}

1. Harper, F. T., et al., Joint USNRC/CEC Consequence Uncertainty Study: Summary of Objectives, Approach, Application, and Results for the Dispersion and Deposition Uncertainty Assessment, Sandia National Laboratories, Albuquerque, NM, NUREG/CR-6244, SAND94-1543, December 1994.

2. Chanin, D. I., et al., MELCOR Accident Consequence Code System (MACCS): User's Guide, Sandia National Laboratories, Albuquerque, NM, NUREG/CR-4691, SAND 86-1562, Volume $1,1990$.

3. Jow, H.-N., et al., MELCOR Accident Consequence Code System (MACCS): Model Description, Sandia National Laboratories, Albuquerque, NM, NUREG/CR-4691, SAND861562, Volume 2, 1990.

4. Rollstin, J. A., et al., MELCOR Accident Consequence Code System (MACCS): Programmer's Reference Manual, Sandia National Laboratories, Albuquerque, NM, NUREG/CR-4691, SAND86-1562, Volume 3, 1990.

5. Helton, J. C., et al., Uncertainty and Sensitivity Analysis of Early Exposure Results with the MACCS Reactor Accident Consequence Model, Sandia National Laboratories, Albuquerque, NM, NUREG/CR-6135, SAND93-2371, 1994.

6. Helton, J. C., et al., Uncertainty and Sensitivity Analysis of Chronic Exposure with the MACCS Reactor Accident Consequence Model, Sandia National Laboratories, Albuquerque, NM, NUREG/CR-6134, SAND93-2370, 1994.

7. U. S. Nuclear Regulatory Commission, Severe Accident Risks: An Assessment For Five U.S. Nuclear Power Plants, NUREG-1150, 1990.

8. Breeding, R. J., et al., Evaluation of Severe Accident Risks: Surry Unit 1, Sandia National Laboratories, Albuquerque, NM, NUREG/CR-4551, SAND86-1309, Volume 3, Rev. 1, 1990.

9. Breeding, R. J., et al., "The NUREG-1150 Probabilistic Risk Assessment for the Surry Nuclear Power Station," Nuclear Engineering and Design, 135:29-59, 1992.

10. Helton, J. C. and Breeding, R. J., "Calculation of Reactor Accident Safety Goals," Reliability Engineering and System Safety, 39:129-158, 1993.

11. Helton, J. C., " Risk, Uncertainty in Risk, and the EPA Release Limits for Radioactive Waste Disposal," Nuclear Technology, 101:18-39, 1993.

12. International Atomic Energy Agency, Evaluating the Reliability of Predictions Made Using Environmental Transfer Models, Vienna, Austria, Safety Series Report No. 100, 1989.

13. Parry, G. W., "On the Meaning of Probability in Probabilistic Safety Assessment," Reliability Engineering and System Safety, 93:319-327, 1986. 
References

14. Paté-Cornell, M. E., "Probability and Uncertainty in Nuclear Safety Decisions," Nuclear Engineering Design, 93:319-327, 1986.

15. Stern, E. and Tadmor, J., "Uncertainty Bands in CCDF Risk Curves; Their Importance in Decision Making Processes," Proceedings of ANS/ENS International Topical Meeting on Probabilistic Safety Methods and Applications, pp. 21.1-22.9, American Nuclear Society, La Grange Park, IL, 1985.

16. Vesely, W. E. and Rasmussen, D. M., "Uncertainties in Nuclear Probabilistic Risk Analyses," Risk Analysis , 4:313-322, 1984.

17. Kaplan, S. and Garrick, B. J., "On the Quantitative Definition of Risk," Risk Analysis, 1:11-27, 1981.

18. McKay, M. D., et al., "A Comparison of Three Methods for Selecting Values of Input Variables in the Analysis of Output From a Computer Code," Technometrics, 21:239-245, 1979.

19. Iman, R. L. and Conover, W. J., "Small Sample Sensitivity Analysis Techniques for Computer Models, with an Application to Risk Assessment," Communications in Statistics, A9:1749-1842, "Rejoinder to Comments," ibid.:1863-1874, 1980.

20. Iman, R. L., et al., "An Approach to Sensitivity Analysis of Computer Models, Part 1. Introduction, Input Variable Selection and Preliminary Variable Assessment," Journal of Quality Technology, 13:174-183, 1981.

21. Iman, R. L., et al., "An Approach to Sensitivity Analysis of Computer Models, Part 2. Ranking of Input Variables, Response Surface Validation, Distribution Effect and Technique Synopsis," Journal of Quality Technology, 13:232-240, 1981.

22. Iman, R. L. and Helton, J. C., "An Investigation of Uncertainty and Sensitivity Analysis Techniques for Computer Models," Risk Analysis, 8:71-90, 1988.

23. Helton, J. C., et al., Sensitivity Analysis Techniques and Results for Performance Assessment at the Waste Isolation Pilot Plant, Sandia National Laboratories, Albuquerque, NM, SAND907103, 1991.

24. Helton, J. C., "Uncertainty and Sensitivity Analysis Techniques for Use in Performance Assessment for Radioactive Waste Disposal," Reliability Engineering and System Safety, 42: 327$367,1993$.

25. U.S. Nuclear Regulatory Commission, "Environmental Transport and Consequence Analysis," PRA Procedures Guide, Vol. II, Chapter 9, Washington, D.C., NUREG/CR-2300, 1983.

26. Hofer, E. and Krzykacz, B., Uncertainty Analysis of the Computational Assessment of the Radiological Consequences of Nuclear Accidents, Part 1, Gesellschaft fuer Reaktorsicherheit, Garching, Federal Republich of Germany, 1984. 
27. Hofer, E. and Krzykacz, B., Uncertainty Analysis of the Computational Assessment of the Radiological Consequences of Nuclear Accidents, Part 2, Gesellschaft fuer Reaktorsicherheit, Garching, Federal Republic of Germany, 1985.

28. Alpert, D. J., et al., A Demonstration Uncertainty/Sensitivity Analysis Using the Health and Economic Consequence Model CRAC2, Sandia National Laboratories, Albuquerque, NM, NUREG/CR-4199, SAND84-1824, 1985.

29. Kocher, D. C., et al., "Sensitivity and Uncertainty Studies of the CRAC2 Computer Code," Risk Analysis, 7:497-507, 1987.

30. Fischer, F., et al., Uncertainty and Sensitivity Analyses of the Complete Program System UFOMOD and of Selected Submodels, Kernforschungszentrum Karlsruhe, Federal Republic of Germany, KfK 4627, 1990.

31. Madni, I. K., et al., "Assessment of Uncertainties in Early Off-Site Consequences From Nuclear Reactor Accidents," Nuclear Technology, 90:63-77, 1990.

32. Sprung, J. L., et al., Evaluation of Severe Accident Risks: Quantification of Major Input Parameters, MACCS inputs, Sandia National Laboratories, Albuquerque, NM, NUREG/CR4551, SAND86-1309, Volume 2, Rev. 1, Part 7, 1990.

33. Breshears, D. D., et al., "Uncertainty in Predictions of Fallout Radionuclides in Foods and Subsequent Ingestion," Health Physics, 57:943-953, 1989.

34. Jones, J. A., et al., "An Uncertainty Analysis Using the NRPB Accident Consequence Code MARC", In Proceedings Seminar on Methods and Codes for Assessing the Off-Site Consequences of Nuclear Accidents, Athens, May 1990, edited by G. N. Kelly and F. Luykx, Commission of the European Communities, pp. 929-948, 1991.

35. Helton, J. C., et al., "An Exploratory Sensitivity Study With the MACCS Reactor Accident Consequence Model," Reliability Engineering and System Safety, 36:137-164, 1992.

36. ICRP, Limits for Intake of Radionuclides by Workers, ICRP Publication 30, Pergamon Press, Oxford, 1979.

37. Runkle, G. E. and Ostmeyer, R. M., An Assessment of Dosimetry Data for Accidental Radionuclide Release from Nuclear Reactors, Sandia National Laboratories, Albuquerque, NM, NUREG/CR-4185, SAND85-0283, 1985.

38. Kocher, D. C., "Dose Rate Conversion Factors for External Exposure to Photons and Electron Radiation from Radionuclides Occurring in Routine Releases from Nuclear Fuel Cycle Facilities," Health Physics, 38: 543-621, 1980.

39. Burke, R. P., et al., Economic Risks of Nuclear Power Reactor Accidents, Sandia National Laboratories, Albuquerque, NM, NUREG/CR-3673, SAND84-0178, 1984. 
References

40. Gale, H. J., et al., "Weathering of Caesium-137 in Soil," Nature, 201: 257-261 1964.

41. Helton, J. C., et al., "Contamination of Surface-Water Bodies After Reactor Accidents by the Erosion of Atmospherically Deposited Radionuclides," Health Physics, 48:757-771, 1985.

42. Iman, R. L. and Conover, W. J., "A Distribution-Free Approach to Inducing Rank Correlation Among Input Variables," Communications in Statistics: Part B--Simulation and Computation, B11:311-334, 1982.

43. Iman, R. L. and Davenport, J. M., "Rank Correlation Plots for Use With Correlated Input Variables," Communications in Statistics: Part B--Simulation and Computation, B11:335-360, 1982.

44. Federal Food and Drug Administration, "Accidental Radioactive Contamination of Human Food and Animal Feeds; Recommendations for State and Local Agencies, Federal Register, 47: 47073$47083,1982$.

45. Iman, R. L. and Shortencarier, M. J., A FORTRAN 77 Program and User's Guide for the Generation of Latin Hypercube and Random Samples For Use With Computer Models, Sandia National Laboratories, Albuquerque, NM, NUREG/CR-3624, SAND83-2365, 1984.

46. Iman, R. L., et al., A FORTRAN 77 Program and User's Guide for the Calculation of Partial Correlation and Standardized Regression Coefficients, Sandia National Laboratories, Albuquerque, NM, NUREG/CR-4122, SAND85-0044, 1985.

47. Iman, R. L., et al., Stepwise Regression With PRESS and Rank Regression (Program User's Guide), Sandia National Laboratories, Albuquerque, NM, SAND79-1472, 1980.

48. Allen, D. M., The Prediction Sum of Squares as a Criterion for Selecting Predictor Variables," Report No. 23, Department of Statistics, University of Kentucky, Lexington, KY, 1971.

49. Iman, R. L. and Conover, W. J., "The Use of the Rank Transform in Regression," Technometrics, $21: 499-509,1979$.

50. McKay, M. D., et. al., "An Alternative View of Sensitivity in the Analysis of Computer Codes," 1992 Proceedings of the Section on Physical and Engineering Sciences of the American Statistical Association, American Statistical Association, Washington, D.C., pp.87-92, 1992.

51. McKay, M. D. and Beckman, R. J., "A Procedure For Assessing Uncertainty in Models," Proceedings of PSAM II. An International Conference Devoted to the Advancement of Systembased Methods for the Design and Operation of Technological Systems and Processes, San Diego, CA, March 20-25, 1994, edited by G.E. Apostolakis and J. S. Wu, Vol 1: pp. 9-13 to 9-18, 1994. 


\section{References}

52. Peterson, H. T., "Terrestrial and Aquatic Food Chain Pathways, " in J. E. Till and H. R. Meyer (eds.), Radiological Assessment, U. S. Nuclear Regulatory Commission, Washington, DC, NUREG/CR-3332, ORNL-5968, pp. 5-1 to 5-156, 1983. 


\section{Distribution}

U.S. Nuclear Regulatory Commission (10)

Attn: C. Lui

Mail Stop NLS-372

U.S. Nuclear Regulatory Commission

Washington, DC 20555

U.S. Nuclear Regulatory Commission Attn: A. Buslik

Mail Stop NLS-377

U.S. Nuclear Regulatory Commission

Washington, DC 20555

B. John Garrick

4590 MacArthur Blvd., \#400

Newport Beach, CA 92660-2027

Clement International Corp.

Attn: Christopher Whipple

160 Spear St.

Suite 1380

San Francisco, CA 94105-1535

Future Resources

Associates, Inc.

Attn: Robert J. Budnitz

2000 Center Street

Suite 418

Berkeley, CA 94704

Battelle Columbus Laboratories (3)

Attn: Paul Baybutt

R. S. Denning

Steve Unwin

505 King Avenue

Columbus, OH 43201

Judy Rollstin

GRAM B-370

8500 Menaul Blvd NE

Albuquerque, NM 87112
Battelle Northwest

Attn: Pamela Doctor

P.O. Box 999

Richland, WA 99352

Los Alamos National Laboratory (2) Analysis and Assessment Division, A-1, MS F600

Attn: M. D. McKay

M. A. Meyer

P.O. Box 1663

Los Alamos, NM 87544

Oak Ridge National Laboratory

Computer Sciences

Attn: Darryl Downing

Building 2029, P.O. Box X

Oak Ridge, TN 37830

Oak Ridge National Laboratory (3)

Engineering Physics and Mathematics Division

Attn: E. M. Oblow

Francois G. Pin

Brian A. Worley

P.O. Box X

Oak Ridge, TN 37820

Oak Ridge National Laboratory (2)

Environmental Sciences Division

Attn: Steve Bartell

R. H. Gardner

P.O. Box X

Oak Ridge, TN 37830

Oak Ridge National Laboratory (2) Health and Safety Research Division

Attn: David G. Kocher

F. O. Hoffman

P.O. Box X

Oak Ridge, TN 37830 
Science Applications International

Corporation (2)

Attn: John Young

Dave Lester

18706 North Creek Parkway

Suite 110

Bothell, WA 98011

Science Applications International

Coporation

Attn: David C. Aldrich

1710 Goodridge Drive

P.O. Box 1303

McLean, VA 22102

Science Applications International Corporation

Attn: Mark D. Otis

P.O. Box 50697

101 S. Park Ave.

Idaho Falls, ID 83405

D. G. Cacuci

Dept. of Nuclear Engineering

University of Illinois

103 South Goodwin Avenue

Urbana, IL 61801-2984

W. J. Conover

College of Business Administration

Texas Tech University

Lubbock, TX 79409

John Evans

Harvard School of Public Health

665 Huntington Avenue

Boston, MA 02115

F. E. Haskin

Dept. of Chemical \& Nuclear Engr.

University of New Mexico

Albuquerque, NM 87131

Max Henrion

Dept. of Engineering and Public

Policy

Carnegie-Mellon University

Pittsburgh, PA 15213
Stan Kaplan

Pickard, Lowe and Garrick, Inc.

2260 University Drive

Newport Beach, CA 92660

Thomas B. Kirchner

Natural Resource Ecology Lab

Colorado State University

Fort Collins, CO 85023

Greg McRae

Dept. Of Chemical Engineering

Carnegie-Mellon University

Pittsburgh, PA 15213

M. Granger Morgan

Dept. of Engineering and Public

Policy

Carnegie-Mellon University

Pittsburgh, PA 15213

H. Rabitz

Department of Chemistry

Princeton University

Princeton, NJ 08544

K. H. Reckhow

School of Forestry and Environmental

Studies

Duke University

Durham, NC 27706

S. K. Seaholm

University of Minnesota

Div. of Health Computer Science

Box 511 UMHC

420 Delaware St., SE

Minneapolis, MN 55455

F. Ward Whicker

Dept. of Radiology and Radiation

Biology

Colorado State University

Fort Collins, Co 80523 
Timothy M. Barry

Office of Policy, Planning, and Evaluation

PM 223X U.S. EPA

Washington, DC 20460

SENES Oak Ridge, Inc. (2)

Attn: Steve M. Bartell

F. O. Hoffman

Center for Risk Analysis

677 Emory Valley Road, Suite C

Oak Ridge, TN 37830

Kenneth T. Bogen

Environmental Sciences Division

Lawrence Livermore National Laboratory

Livermore, CA 94550

David Burmaster, President

Alceon Corporation

P.O. Box 2669

Harvard Square Station

Cambridge, MA 02239

Adam Finkel

Center for Risk Management

Resources for the Future

1616 P Street, NW

Washington, DC 20036

Yacov Y. Haimes

Center for Risk Management of Engineering

Systems

D111 Thornton Hall

University of Virginia

Charlottsville, VA 22901

Nicholas Matalas

Water Resources Division

Geological Survey

U.S. Department of the Interior

Reston, VA 22092

Elisabeth Pate-Cornell

Industrial Engineering \& Engineering Mgmt.

Stanford University

Stanford, CA 94305
Robert L. Sielken

Sielken, Inc.

Suite 410

3833 Texas Avenue

Bryan, TX 77802

Alison Taylor

Dept. of Environmental Health

Harvard School of Public Health

Bldg. 1 Room 1308

664 Huntington Ave.

Boston, MA 02115

University of California (2)

Mechanical, Aerospace, and

Nuclear Engineering Dept.

Attn: W. Kastenberg

G. Apostolakis

5532 Boelter Hall

Los Angeles, CA 90024

University of Hawaii at Hilo

Attn:. S. Hora

Business Administration

Hilo, HI 96720-4091

Gordon S. Linsley

Division of Nuclear Fuel Cycle and

Waste Management

International Atomic Energy Agency

P.O. Box 100

A-1400 Vienna

AUSTRIA

J. Marivoet

Centre d'Etudes de l'Energie

Nucleaire

CEN/SCK

Boeretang 200

B-2400 Mol

BELGIUM

Eduard Hofer

Gesellschaft fur Reaktorsicherheit

(GRS) MBH

Forschungsgelande

D-8046 Garching

GERMANY 
Oak Ridge National Laboratory (2)

Attn: Steve Fisher

Sherrel Greene

MS-8057

P.O. Box 2009

Oak Ridge, TN 37831

Westinghouse Savannah River Company (2)

Attn: Kevin O'Kula

Jackie East

Safety Technology Section

1991 S. Centennial Ave., Bldg. 1

Aiken, SC 29803

Vern Peterson

Building T886B

EG \& G Rocky Flats

P.O. Box 464

Golden, CO 80402

Brookhaven National Laboratory (3)

Attn: Lev Neymotin

Arthur Tingle

Trevor Pratt

Building 130

Upton, NY 11973

EG \& G Idaho, Inc. (2)

Attn: Doug Brownson

Darrel Knudson

MS-2508

P.O. Box 1625

Idaho Falls, ID 83415

EG \& G, Idaho Inc. (2)

Attn: Art Rood

Mike Abbott

MS-2110

P.O. Box 1625

Idaho Falls, ID 83415

Los Alamos National Laboratory (2)

Attn: Desmond Stack

Kent Sasser

N-6, K-557

Los Alamos, NM 87545
Technadyne Engineering Consultants (3)

Attn: David Chanin Jeffery Foster Walt Murfin

Suite A225

8500 Menual Blvd. NE

Albuquerque, NM 87112

David M. Brown

Paul C. Rizzo Associates, Inc.

300 Oxford Drive

Monroeville, PA 15146-2347

Westinghouse Electric Company (2)

Attn: John Iacovino

Burt Morris

Energy Center East, Bldg. 371

P.O. Box 355

Pittsburgh, PA 15230

Marc Rothschild

Halliburton NUS

1303 S. Central Ave.

Suite 202

Kent, WA 98032

Knolls Atomic Power Labortory (2)

Attn: Ken McDonough

Dominic Sciaudone

Box 1072

Schenectady, NY 12301

Mr. Dennis Strenge

Pacific Northwest Laboratory

RTO/ 125

P.O. Box 999

Richland, WA 99352

Mr. Fred Mann

Westinghouse Hanford Co.

W/A-53

P.O. Box 1970

Richland, WA 99352 
Distribution

Lawrence Livermore National Lab. (3)

Attn: George Greenly

Marvin Dickerson

Rolf Lange

Livermore, CA 94550

Mr. Terry Foppe

Safety Analysis Engineering

Rocky Flats Plant

Energy Systems Group

Rockwell International Corp

P.O. Box 464

Golden, CO 80401

U.S. Environmental Protection Agency (2)

Attn: Allen Richardson

Joe Logsdon

Office of Radiation Programs

Environmental Analysis Division

Washington, DC 20460

U.S. Department of Energy (2)

Attn: Ken Murphy (EH351)

Ed Branagan (EH332)

Washington, DC 20545

Mr. Robert Ostmeyer

U.S. Department of Energy

Rocky Flats Area Office

P.O. Box 928

Golden, CO 80402

Mr. Bruce Burnett

CDRH (HFZ-60)

U.S. Department of Health and Human Services

Food and Drug Administration

5600 Fishers Lane

Rockville, MD 20857

Mr. Scott Bigelow

S-CUBED

2501 Yale SE, Suite 300

Albuquerque, NM 87106

David Black

American Electric Power

1 Riverside Plaza

Columbus, $\mathrm{OH} 43215$

Gerald Davidson

Fauske and Associates, Inc.

16 W 070 West 83rd Street

Burr Ridge, IL 60521

Keith Woodard

Pickard, Lowe, and Garrick

Suite 730

1615 M. Street

Washington, DC 20056

Jim Mayberry

Ebasco Services

160 Chubb Ave.

Lyndhurst, NJ 07071

Mr. Mike Cheok

NUS

910 Clopper Road

Gaithersburg, MD 20878

Ken O'Brien

University of Wisconsin

Nuclear Engineering Dept.

153 Engineering Research Blvd.

Madison, WI 53706

Mr. Harold Careway

General Electric Co., M/C 754

175 Curtner Ave.

San Jose, CA 95129

Zen Mendoza

SAIC

5150 El Camino Real

Suite C31

Los Altos, CA 94022

Roger Blond

SAIC

20030 Century Blvd.

Suite 201

Germantown, MD 20874 
John Luke

Florida Power \& Light

P.O. Box 14000

Juno Beach, FL 33408

Duke Power Co. (2)

Attn: Duncan Brewer Steve Deskevich

422 South Church Street

Charlotte, NC 28242

Mr. Griff Holmes

Westinghouse Electric Co.

Energy Center East

Bldg. 371

P.O. Box 355

Pittsburgh, PA 15230

Mr. Edward Warman

Stone \& Webster Engineering Corp.

P.O. Box 2325

Boston, MA 02107

Mr. William Hopkins

Bechtel Power Corporation

15740 Shady Grove Road

Gaithersburg, MD 20877

R. Toossi

Physical Research, Inc.

25500 Hawthorn Blvd.

Torrance, CA 90505

Bill Eakin

Northeast Utilities

Box 270

Hartford, CT 06141

Ian Wall

Electric Power Research Institute

3412 Hillview Avenue

Palo Alto, CA 94304

Jim Meyer

Scientech

11821 Parklawn Dr.

Suite 100

Rockville, MD 20852
Ray Ng

NUMARC

1776 Eye St. NW

Suite 300

Washington, DC 20006-2496

Robert Gobel

Clark University

Center for Technology, Environment and Development

950 Main St.

Worcester, MA 01610-1477

Ken Keith

TVA

W 20 D 201

400 West Summit Hill

Knoxville, TN 37092

Shengdar Lee

Yankee Atmoic Electric Company

580 Main St.

Bolton, MA 01740

Paul Govaerts

Studiecentrum voor Kernenergie

(SCK/CEN)

Boeretang, 200

B-2400 Mol

BELGIUM

S. Daggupaty

Environment Canada

4905 Dufferin Street

Downsview

Ontario, M3H 5T4

CANADA

Soren Thykier-Nielsen

Riso National Laboratory

Postbox 49

DK-4000 Roskile

DENMARK

Jay Johnson

2265 East Fairview Circle

Mesa, AZ 85204 
Seppo Vuori

Technical Research Centre of Finland Nuclear Engineering Laboratory

Lonnrotinkatu 37

P.O. Box 169

Sf-00181 Helsinki 18

FINLAND

Daniel Manesse

IPSN

Voite Postale 6

F-92265 Fontenay-auz-Roses CEDEX FRANCE

John G. Kollas

Institute of Nuclear Technology and

Radiation Protection

N.R.C.P.S. "Domokritos"

P.O. Box 60228

GR-153 10 Aghia Paraskevi

Attiki

GREECE

ENEA/DISP (2)

Attn: Alvaro Valeri

Alfredo Bottino

Via Vitaliano Brancati, 48

00144 Roma EUR

ITALY

Mr. Hideo Matsuzuru

Tokai Research Establishment

Tokai-mur

Maka-gun

Ibaraki-ken, 319-11

JAPAN

Mr. Jan Van de Steen

KEMA Laboratories

Utrechtseweg, 310

Postbus 9035

NL-6800 ET Arnhem

NETHERLANDS
D. Eugenio Gil Lopez

Consejo de Seguridad Nuclear

Calle Justo Dorado, 11

E-28040 Madrid

SPAIN

Lennart Devell

Studsvik Nuclear

Studsvik Energiteknik AB

S-611 82 Nykoping

SWEDEN

Hanspeter Isaak

Abteilung Strahlenschutz

Hauptabteilung fur die Dicherheit

der Kernanlagen (HSK)

CH-5303 Wurenlingen

SWITZERLAND

Ephraim Asculai

Division of Nuclear Safety

Wagramestrasse, 5

P.O. Box 100

A-1400 Wien

AUSTRIA

Ulf Tveten

Enviornmental Physics Section

Institutt for Energiteknikk

Postboks 40

N-2007 Kjeller

NORWAY

M. K. Yeung

University of Hong Kong

Mechanical Engineering Dept.

Polfulam

HONG KONG

Leonel Canelas

New University of Lisbon

Quinta de Torre

2825 Monte de Caparica

PORTUGAL 
Stephen Boult

Electrowatt Engineering Services (UK) Ltd.

Grandford House

16 Carfax, Horsham

West. Sussex RH12 1UP

ENGLAND

Nadia Soido Falcao Martins

Comissao Nacional de Energia Nuclear

R General Severianao 90 S/408-1

Rio de Janeiro

BRAZIL

Eli Stern

Israel AEC Licensing Div.

P.O. Box 7061

Tel-Aviv 61070

ISRAEL

Der-Yu Hsia

Atomic Energy Council

67, Lane 144

Keelung Road, Section 4

Taipei, Taiwan 10772

TAIWAN

Shankaran Nair

Central Electricity Generating Board

Berkeley Nuclear Laboratories

Berkeley

Gloucestershire CL13 9PB

UNITED KINGDOM

Paul Kayser

Division de la Radioprotection

1, Avenue des Archiducs

L-1135 Luxembourg-Belair

Luxembourg

U.S. Nuclear Regulatory Commission

Attn: Richard Codell

Mail Stop 4-H-3

Washington, D.C. 20555
Andrea Saltelli

Commission of the European Communities

Joint Research Centre od Ispra

I-21020 Ispra (Varese)

ITALY

Radiation Protection Program CEC

Attn: G. Neale Kelly

Rue de al Loi, 200

B-1049 Bruxelles

BELGIUM

National Water Research Institute

Attn: E. Halfon

Canada Centre for Inland Waters

Burlington, Ontario

CANADA

BGA/ISH/ZBD

Attn: Anton Bayer

P.O. Box 1108

D-8042 Neuherberg

GERMANY

Gesellschaft fur Reaktorsicherheit

Attn: Bernard Krzykacz

D-8046 Garching

GERMANY

Kernforschungszentrum Karlsruhe/INR (2)

Attn: Joachim Ehrhardt Friedmar Fischer

Postfach 3640

D-7500 Karlsruhe 1

GERMANY

Catholic University Brabant

Attn: J. P. C. Kleijnen

Tilburg

THE NETHERLANDS

Delft University of Technology

Dept. of Mathematics

Attn: Roger Cooke

Julianalaan 132

Delft

THE NETHERLANDS 
Abtielung fur die Sicherheit der

Kernanlagen

Attn: S. Chakraborty

Eidgenossisches Amt fur

Energiewirtschaft

CH-5303

Wurenlingen

SWITZERLAND

The University of Reading

Department of Statistics

Attn: Derek J. Pike

Whiteknights

Reading RG6 2AN

UNITED KINGDOM

National Radiological Protection Board (3)

Attn: M. Crick

Marion Hill

J. A. Jones

Chilton, Didcot

Oxon OX11 ORQ

UNITED KINGDOM

United Kingdom Atomic Energy Authority

Attn: William Nixon

Safety \& Reliability Directorate

Wigshaw Lane

Culcheth

Warrington WA3 4NE

UNITED KINGDOM
INTERNAL

MS0455 A. C. Payne, 4115

MS1337 D. R. Anderson, 6342

MS1337 M. G. Marietta, 6342

MS1337 R. P. Rechard, 6342

MS1337 P. Swift, 6342

MS1337 M. Tierney, 6342

MS1337 J. Garner, 6342

MS1337 J. C. Helton, 6342 (20)

MS1337 A. W. Shiver,6342

MS1337 J. L. Sprung, 6342

MS0405 R. J. Breeding, 6411

MS0747 A. L. Camp, 6412

MS0747 S. E. Dingman, 6412

MS0748 F. T. Harper, 6413

MS6416 D. A. Zimmerman, 6416

MS0737 M. P. Bohn, 6449

MS1175 L. F. Restrepo, 6513

MS0746 J. E. Campbell, 6613

MS0746 R. M. Cranwell, 6613

MS0746 R. M. Iman, 6613

MS0746 C. Leigh, 6613

MS1093 H. N. Jow, 7714

MS9017 R. C. Christman

MS0491 N. Grandjean,12333

MS9018 Central Technical Files (1)

MS0899 Technical Library, 13414 (5)

MS0619 Technical Publications, 13416 (1) 


\begin{tabular}{|c|c|}
\hline $\begin{array}{l}\text { U.S. NUCLEAR REGULATORY COMMISSION } \\
\text { BIBLIOGRAPHIC DATA SHEET } \\
\text { (See instructions on the reverse) }\end{array}$ & \multirow[t]{2}{*}{$\begin{array}{l}\text { 1. REPORT NUMBER } \\
\text { (Asslgned by NRC. Add Vol., Supp., Rev., } \\
\text { ond Addendum Numbers, if any.) } \\
\text { NUREG/CR-6136 } \\
\text { SAND93-2372 }\end{array}$} \\
\hline \multirow{4}{*}{$\begin{array}{l}\text { 2. TITLE AND SUBTITLE } \\
\text { Uncertainty and Sensitivity Analysis of Food Pathway } \\
\text { Results with the MACCS Reactor Accident Consequence Mode1 }\end{array}$} & \\
\hline & 3. DATE REPORT PUBLISHED \\
\hline & \begin{tabular}{c|c} 
MONTH & YEAR \\
January & 1995
\end{tabular} \\
\hline & $\begin{array}{l}\text { 4. FIN OR GRANT NUMBER } \\
\text { L2294 }\end{array}$ \\
\hline $\begin{array}{l}\text { 5. AUTHOR(S) } \\
\text { J. C. Helton, } 1 \text { J. D. Johnson, }{ }^{2} \text { J. A. Rollstin, }\end{array}$ & $\begin{array}{r}\text { 6. TYPE OF REPORT } \\
\text { Technical }\end{array}$ \\
\hline A. W. Shiver, J. L. Sprung & 7. PERIOD COVERED (Inclusive Dates/ \\
\hline $\begin{array}{l}\text { 8. PERFORMING ORGANIZATION - NAME AND ADDRESS (ff NAC, provide Divisian, office or Region, U.S. Nuclear Regulatory Com } \\
\text { name and maifing address.) } \\
\begin{array}{ll}\text { Sandia Nationa1 Laboratories } & 1 \\
\text { Albuquerque, NM } 87185 & 2 \text { Arizona State University, Temp }\end{array}\end{array}$ & $\begin{array}{l}\text { nission, and mailing address; if cantractor, } \\
\text { AZ } 85287 \\
2\end{array}$ \\
\hline
\end{tabular}

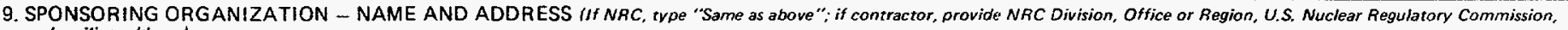
and mailing address.)

Division of Systems Technology

office of Nuclear Regulatory Research

U.S. Nuclear Regulatory Research

Washington, DC 20555-0001

10. SUPPLEMENTARY NOTES

11. ABSTRACT (200 words or less)

Uncertainty and Sensitivity analysis techniques based on Latin hypercube sampling, partial correlation analysis and stepwise regression analysis are used in an investigation with the MACCS model of the food pathways associated with a severe accident at a nuclear power station. The primary purpose of this study is to provide guidance on the variables to be considered in future review work to reduce the uncertainty in the important variables used in the calculation of reactor accident consequences. The effects of 87 imprecisely known input variables on the following reactor accident consequences are studied: crop growing season dose, crop long-term dose, milk growing season dose, total fond pathways dose, total ingestion pathways dose, total long-term pathways dose, area cependent cost, crop disposal cost, milk disposal cost, condemnation area, crop disposal area and milk disposal area.

\begin{tabular}{|c|}
\hline $\begin{array}{l}\text { 13. AVAILABILITY STATEMENT } \\
\text { Un } 1 \text { imited }\end{array}$ \\
\hline 14. SECURITY CLASSIFICATION \\
\hline (This Page) \\
\hline Unclassified \\
\hline (This Report) \\
\hline Unclassified \\
\hline 15. NUMBER OF PAGES \\
\hline 16. PRICE \\
\hline
\end{tabular}

